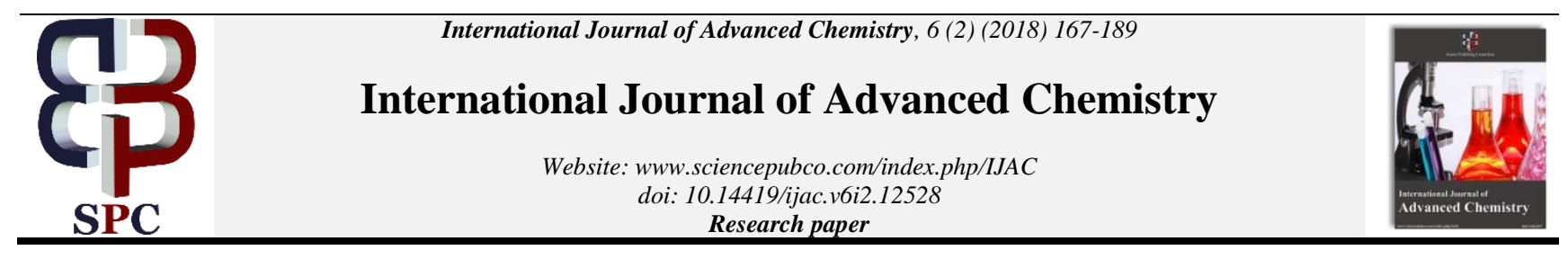

\title{
Vibrational biospectroscopic study and chemical structure analysis of unsaturated polyamides nanoparticles as anti-cancer polymeric nanomedicines using synchrotron radiation
}

\author{
Alireza Heidari * \\ Faculty of Chemistry, California South University, 14731 Comet St. Irvine, CA 92604, USA \\ *Corresponding author E-mail: Scholar.Researcher.Scientist@gmail.com; Alireza.Heidari@calsu.us
}

\begin{abstract}
Firstly, unsaturated polyamides nanoparticles were hardened by continuous synchrotron radiation and then, the induced changes in its chemical structure were studied by Attenuated Total Reflection-Fourier Transform Infrared (ATR-FTIR) spectroscopy. It was shown that applying synchrotron radiation for hardening not only leads to reduction of hardening time but also creates cross link in polymer by breaking Carbon-Carbon double bond, without any considerable change in its chemical structure. In addition, an unsaturated polyamide nanoparticle as anti-cancer polymeric nanomedicines is hardened by synchrotron radiation. Its chemical structure before and after hardening is studied using Raman and Attenuated Total Reflection-Fourier Transform Infrared (ATR-FTIR) spectroscopy. The results show that Raman spectroscopy is considerably better than Attenuated Total Reflection-Fourier Transform Infrared (ATR-FTIR) spectroscopy in detecting the changes happened in chemical structure.
\end{abstract}

Keywords: Unsaturated Polyamides Nanoparticles; Attenuated Total Reflection-Fourier Transform Infrared (ATR-FTIR) Spectroscopy; CarbonCarbon Double Bond; Hardening-Cross Link; Cross Link; Raman Spectroscopy; Anti-Cancer Polymeric Nanomedicines; Synchrotron Radiation.

\section{Introduction}

Polyamides nanoparticles as anti-cancer polymeric nanomedicines are one the most applicable polymers in the industry. Its hardening usually performs by adding a nanomaterial as hardener and heating them (Heidari and Brown 2018; Heidari 2016). In the current paper, Carbon-Carbon double bond presented in the structure is broken using continuous synchrotron radiation, without any damage to other presented bonds and unsaturated polyamides nanoparticles as anti-cancer polymeric nanomedicines is hardened by creating cross link (along with phase change from liquid to solid). In this regard, Attenuated Total Reflection-Fourier Transform Infrared (ATR-FTIR) spectroscopy was used to demonstrate breaking the bonds and no change in the structure of other bonds It is worthwhile to note that in addition to above mentioned advantages, hardening with synchrotron radiation shortens the hardening time down to lower than 10 minutes. However, in traditional methods, which are mainly thermal methods, about 30 minutes is required for hardening and chemical structure changes during hardening process. The hardening process is molding not selective with small cross section. Unsaturated polyamides nanoparticles as anti-cancer polymeric nanomedicines is one of the most applicable known polymers which uses in liquid and hardened form for connections, molding, etc.

There are various spectroscopy methods to investigate chemical bonds of polyamides nanoparticles including Raman and Attenuated Total Reflection-Fourier Transform Infrared (ATR-FTIR) spectroscopy methods, which have their specific characteristics.
Researches have been shown that some molecular symmetry cannot be detected by Attenuated Total Reflection-Fourier Transform Infrared (ATR-FTIR) spectroscopy while these can be detected by Raman spectroscopy. Polymers become harden due to creation of cross link in linear structure of polymer; these bonds are $\mathrm{C}-\mathrm{C}$ type and cannot be detected by Attenuated Total Reflection-Fourier Transform Infrared (ATR-FTIR) spectroscopy while Raman spectroscopy is able to clearly detect these bonds. In the considered unsaturated polyamides nanoparticles structure, $\mathrm{C}=\mathrm{C}$ bonds cannot be detected by Attenuated Total Reflection-Fourier Transform Infrared (ATR-FTIR) spectroscopy since this bond is symmetrical in linear structure of polymer. According to the reasons that are expressed in the following sections, the emerging region of this bond $\left(1600-1700 \mathrm{~cm}^{-1}\right)$ is very important. Therefore, it is expected that these changes can be more clearly detected by Raman method. The aim of the current study is showing the efficiency of Raman method by comparing these two spectroscopy methods.

\section{Chemical structure}

In traditional methods, a hardener is always used for polymer hardening (its ratio for this polymer is 3 to 1 ) and it heats in $70^{\circ} \mathrm{C}$ for 30 minutes to harden the polymer. Hardening process is so that polymer changes to free radical by absorbing the required energy for breaking Carbon-Carbon double bond and then, make a bond with hardener (here, it is divinylbenzene) (Heidari 2016). The hardener can makes bond with two polymeric chains and it leads to creation of a cross link with the aid of hardener. Creation of cross link leads to change of polymer structure from linear to lat- 
tice structure and hence, it hardens the polymer. Chemical structure for unsaturated polyamides nanoparticles is shown in Figure (1). Moreover, its hardened form using (+)-Benzo(a)pyrene-7,8dihydrodiol-9,10-epoxide is shown in Figure (2).

In the current paper, this double bond is broken by synchrotron radiation, without adding hardener, and cross link is created between linear chains of polymer. The utilized synchrotron radiation is continuous synchrocyclotron radiation with 20 (W) powers (Heidari 2016, 2017; Heidari and Brown 2017; Bastogne 2017; Vanić et al. 2013; Islan et al. 2017; Bawarski et al. 2008; Eaton et al. 2011; Hadinoto et al. 2014; Svenson et al. 2011; Sosnik et al 2013; Filipović-Grčić et al. 2013; Yu et al. 2015; Moghimi et al 2013; Eliasof et al. 2010; Domingo et al. 2012; Samadder et al. 2016; Yen et al. 2010; Azmi et al. 2016; L et al. 2015; Liu et al. 2012; Gabellieri et al. 2011; Frederickson 2016 et al; Namdari et al. 2017; Kiew et al. 2015; Moghimi et al. 2012; Gil et al. 2010; Rzigalinski et al. 2009; Fako et al. 2009; Sainz et al. 2015; Duncan et al. 2010; Zhou et al. 2014; Wibroe et al. 2016; Nguyen et al. 2016; Beija et al. 2012; Vaishali et al. 2017; Bawa 2009; Marianecci et al. 2016; Patil et al. 2017; Fonseca et al. 2014; Bedi et al. 2011; Canal et al. 2011; Hügel et al. 2014; Donaldson 2012; Bose et al. 2016; Hall et al. 2017; Storm 2012; du Toit et al. 2010; Kumar et al. 2016; Rajabi et al. 2016; Andersen et al. 2012; Kabanov et al. 2011; Nagy et al. 2015; Nickols-Richardson et al. 2007; Gaspar et al. 2009; Bourlinos et al. 2012; Svenson et al. 2012; Sitterberg et al. 2010; Telford 2005). Synchrotron radiation properties are listed in Table (1) (Heidari 2016, 2017; Heidari and Brown 2017; Bastogne 2017; Vanić et al. 2013; Islan et al. 2017; Bawarski et al. 2008; Eaton et al. 2011; Hadinoto et al. 2014 Svenson et al. 2011; Sosnik et al. 2013; Filipović-Grčić et al. 2013; Yu et al. 2015; Moghimi et al. 2013; Eliasof et al. 2010; Domingo et al. 2012; Samadder et al. 2016; Yen et al. 2010; Azmi et al. 2016; L et al. 2015; Liu et al. 2012; Gabellieri et al. 2011; Frederickson 2016 et al; Namdari et al. 2017; Kiew et al. 2015; Moghimi et al. 2012; Gil et al. 2010; Rzigalinski et al. 2009; Fako et al. 2009; Sainz et al. 2015; Duncan et al. 2010; Zhou et al. 2014; Wibroe et al. 2016; Nguyen et al. 2016; Beija et al. 2012; Vaishali et al. 2017; Bawa 2009; Marianecci et al. 2016; Patil et al. 2017; Fonseca et al. 2014; Bedi et al. 2011; Canal et al. 2011; Hügel et al. 2014; Donaldson 2012; Bose et al. 2016; Hall et al. 2017; Storm 2012; du Toit et al. 2010; Kumar et al. 2016; Rajabi et al. 2016; Andersen et al. 2012; Kabanov et al. 2011; Nagy et al 2015; Nickols-Richardson et al. 2007; Gaspar et al. 2009; Bourlinos et al. 2012; Svenson et al. 2012; Sitterberg et al. 2010; Telford 2005).

As mentioned before, the polymer used in the current study is unsaturated polyamides nanoparticles with chemical structure shown in Figure (1). These polyamides nanoparticles can be hardened by synchrotron radiation for 3 to 6 minutes (Alibolandi et al. 2015; Bridoux et al. 2009; Stuurman et al. 2010; Kondo 2010; Jindal et al. 2017; Rapoport 2007; Fernández 2011; Pippa et al. 2013; Verreault et al. 2012; Hassanzadeh et al. 2017; Sivanesan et al. 2017; Phillips et al. 2010; Varan et al. 2017; Moghimi et al. 2014; Soria et al. 2010; McMurray et al. 2010; Sans-Serramitjana et al. 2016; Rigo et al. 2017; Alibolandi et al. 2017; Bridoux et al. 2010; Tutaj et al. 2016; Kuppusamy et al. 2013; Tomalia 2006; Menjoge et al. 2010; Vega-Villa et al. 2008; Gaur et al. 2014; Tietze et al. 2015; Schwengber et al. 2015; Adhikari et al. 2017; Szebeni et al. 2015; Chen et al. 2011; Requejo-Aguilar et al. 2017; Golyshkin et al. 2016; Szulc et al. 2016; Haddad et al. 2008; Mignani et al. 2013; Eaton et al. 2015; Lollo et al. 2015; Thompson et al. 2012; Muntimadugu et al. 2017; Foldvari et al. 2008; Riley et al. 2012; Fernandes et al. 2015; Mehra et al. 2016; Mignani et al. 2016; Naderkhani et al. 2014; Newton 2013; Aoki et al. 2015; Ita 2014; Liu et al. 2008; Mallapragada et al. 2015; Peres et al. 2017; Ferreira et al. 2013; Salerno et al. 2015; Tyler et al. 2016; Iannazzo et al. 2015; Jemec et al. 2012; Chen et al. 2012; Lütscher et al. 2012; Park et al. 2013; Huang et al. 2011; Depan et al. 2011; Guo et al. 2014; Duncan 2011; Sidik et al. 2016; Yuan et al. 2010; He et al. 2014; An et al. 2013; Meenach et al. 2013; England et al. 2012; Pippa et al. 2013; Boisseau et al. 2011; Petrichenko et al.
2015; Rodríguez-Gascón et al. 2015; Frima et al. 2012; Yallapu et al. 2015; Duan et al. 2012; Perez et al. 2015; Costantino et al. 2012; Wei et al. 2006; Murday et al. 2009; Dixit et al. 2015; Nair et al. 2010; Bawa et al. 2005; Farkhani et al. 2014; Lal et al. 2010; Hacklin et al. 2009; Gabizon et al. 2016; Zhang et al. 2013; Vanić et al. 2014; Ellis-Behnke 2007; Srivalli et al. 2016; Collnot et al. 2012; Rychak et al. 2006; Watala et al. 2016; Palombo et al. 2009; Kuzmov et al. 2015; Diebold et al. 2010; Bal et al. 2011; Bharali et al. 2010; Ray et al. 2010; Mishra et al. 2010; Torchilin 2009; Cupaioli et al. 2014; Sosnik et al. 2014; Guan et al. 2013; Toit et al. 2013; Zhang et al. 2012; Muthaiyan et al. 2011; Duncan 2009; Palao-Suay et al. 2016; Morrow et al. 2007; Punetha et al. 2017; Manickam 2017; Osorio et al. 2015; Karami et al. 2016; Park et al. 2013; Heidari 2017, 2018; Gobato et al. 2018; Gobato, Heidari 2018; Heidari, Gobato 2018). As we know, polyamides nanoparticles are hardened due to creation of $\mathrm{C}-\mathrm{C}$ cross links in the structure of polyamides nanoparticles. These bonds are resulted from breaking Carbon double bond $(\mathrm{C}=\mathrm{C})$ and can connect two linear structure of polyamides nanoparticles to each other (Alibolandi et al. 2015; Bridoux et al. 2009; Stuurman et al. 2010; Kondo 2010; Jindal et al. 2017; Rapoport 2007; Fernández 2011; Pippa et al. 2013; Verreault et al. 2012; Hassanzadeh et al. 2017; Sivanesan et al. 2017; Phillips et al. 2010; Varan et al. 2017; Moghimi et al. 2014; Soria et al. 2010; McMurray et al. 2010; Sans-Serramitjana et al. 2016; Rigo et al. 2017; Alibolandi et al. 2017; Bridoux et al. 2010; Tutaj et al. 2016; Kuppusamy et al. 2013; Tomalia 2006; Menjoge et al. 2010; Vega-Villa et al. 2008; Gaur et al. 2014; Tietze et al. 2015; Schwengber et al. 2015; Adhikari et al. 2017; Szebeni et al. 2015; Chen et al. 2011; Requejo-Aguilar et al. 2017; Golyshkin et al. 2016; Szulc et al. 2016; Haddad et al. 2008; Mignani et al. 2013; Eaton et al. 2015; Lollo et al. 2015; Thompson et al. 2012; Muntimadugu et al. 2017; Foldvari et al. 2008; Riley et al. 2012; Fernandes et al. 2015; Mehra et al. 2016; Mignani et al. 2016; Naderkhani et al. 2014; Newton 2013; Aoki et al. 2015; Ita 2014; Liu et al. 2008; Mallapragada et al. 2015; Peres et al. 2017; Ferreira et al. 2013; Salerno et al. 2015; Tyler et al. 2016; Iannazzo et al. 2015; Jemec et al. 2012; Chen et al. 2012; Lütscher et al. 2012; Park et al. 2013; Huang et al. 2011; Depan et al. 2011; Guo et al. 2014; Duncan 2011; Sidik et al. 2016; Yuan et al. 2010; He et al. 2014; An et al. 2013; Meenach et al. 2013; England et al. 2012; Pippa et al. 2013; Boisseau et al. 2011; Petrichenko et al. 2015; Rodríguez-Gascón et al. 2015; Frima et al. 2012; Yallapu et al. 2015; Duan et al. 2012; Perez et al. 2015; Costantino et al. 2012; Wei et al. 2006; Murday et al. 2009; Dixit et al. 2015; Nair et al. 2010; Bawa et al. 2005; Farkhani et al. 2014; Lal et al. 2010; Hacklin et al. 2009; Gabizon et al. 2016; Zhang et al. 2013; Vanić et al. 2014; Ellis-Behnke 2007; Srivalli et al. 2016; Collnot et al. 2012; Rychak et al. 2006; Watala et al. 2016; Palombo et al. 2009; Kuzmov et al. 2015; Diebold et al. 2010; Bal et al. 2011; Bharali et al. 2010; Ray et al. 2010; Mishra et al. 2010; Torchilin 2009; Cupaioli et al. 2014; Sosnik et al. 2014; Guan et al. 2013; Toit et al. 2013; Zhang et al. 2012; Muthaiyan et al. 2011; Duncan 2009; Palao-Suay et al. 2016; Morrow et al. 2007; Punetha et al. 2017; Manickam 2017; Osorio et al. 2015; Karami et al. 2016; Park et al. 2013; Heidari 2017, 2018; Gobato et al. 2018; Gobato, Heidari 2018; Heidari, Gobato 2018). In chemical methods, titration method is used to demonstrate such bond and hardening so that both hardening and breaking of $\mathrm{C}=\mathrm{C}$ bond can be determined. The aim of the current study is observing and calculating the breaking and creation of cross link in a hardened polyamides nanoparticles (Figure (3)) using synchrotron radiation and comparing it with the results obtained from Attenuated Total Reflection-Fourier Transform Infrared (ATR-FTIR) spectroscopy.

\section{Experimental work}

To do this work, the considered polyamides nanoparticles as anticancer polymeric nanomedicines was subjected to synchrotron radiation for 3 and 6 minutes so that it was completely hardened (Alibolandi et al. 2015; Bridoux et al. 2009; Stuurman et al. 2010; 
Kondo 2010; Jindal et al. 2017; Rapoport 2007; Fernández 2011; Pippa et al. 2013; Verreault et al. 2012; Hassanzadeh et al. 2017; Sivanesan et al. 2017; Phillips et al. 2010; Varan et al. 2017; Moghimi et al. 2014; Soria et al. 2010; McMurray et al. 2010; Sans-Serramitjana et al. 2016; Rigo et al. 2017; Alibolandi et al 2017; Bridoux et al. 2010; Tutaj et al. 2016; Kuppusamy et al. 2013; Tomalia 2006; Menjoge et al. 2010; Vega-Villa et al. 2008; Gaur et al. 2014; Tietze et al. 2015; Schwengber et al. 2015; Adhikari et al. 2017; Szebeni et al. 2015; Chen et al. 2011; RequejoAguilar et al. 2017; Golyshkin et al. 2016; Szulc et al. 2016; Haddad et al. 2008; Mignani et al. 2013; Eaton et al. 2015; Lollo et al 2015; Thompson et al. 2012; Muntimadugu et al. 2017; Foldvari et al. 2008; Riley et al. 2012; Fernandes et al. 2015; Mehra et al. 2016; Mignani et al. 2016; Naderkhani et al. 2014; Newton 2013; Aoki et al. 2015; Ita 2014; Liu et al. 2008; Mallapragada et al. 2015; Peres et al. 2017; Ferreira et al. 2013; Salerno et al. 2015; Tyler et al. 2016; Iannazzo et al. 2015; Jemec et al. 2012; Chen et al. 2012; Lütscher et al. 2012; Park et al. 2013; Huang et al. 2011; Depan et al. 2011; Guo et al. 2014; Duncan 2011; Sidik et al. 2016; Yuan et al. 2010; He et al. 2014; An et al. 2013; Meenach et al. 2013; England et al. 2012; Pippa et al. 2013; Boisseau et al. 2011; Petrichenko et al. 2015; Rodríguez-Gascón et al. 2015; Frima et al. 2012; Yallapu et al. 2015; Duan et al. 2012; Perez et al 2015; Costantino et al. 2012; Wei et al. 2006; Murday et al. 2009; Dixit et al. 2015; Nair et al. 2010; Bawa et al. 2005; Farkhani et al. 2014; Lal et al. 2010; Hacklin et al. 2009; Gabizon et al. 2016; Zhang et al. 2013; Vanić et al. 2014; Ellis-Behnke 2007; Srivalli et al. 2016; Collnot et al. 2012; Rychak et al. 2006; Watala et al. 2016; Palombo et al. 2009; Kuzmov et al. 2015; Diebold et al 2010; Bal et al. 2011; Bharali et al. 2010; Ray et al. 2010; Mishra et al. 2010; Torchilin 2009; Cupaioli et al. 2014; Sosnik et al 2014; Guan et al. 2013; Toit et al. 2013; Zhang et al. 2012; Muthaiyan et al. 2011; Duncan 2009; Palao-Suay et al. 2016; Morrow et al. 2007; Punetha et al. 2017; Manickam 2017; Osorio et al. 2015; Karami et al. 2016; Park et al. 2013; Heidari 2017, 2018; Gobato et al. 2018; Gobato, Heidari 2018; Heidari, Gobato 2018).

Now, Attenuated Total Reflection-Fourier Transform Infrared (ATR-FTIR) spectroscopy was used to investigate the changes happened in the chemical structure of polyamides nanoparticles. To qualitatively investigate the changes happened during radiation, a specific amount of polymer was placed on $\mathrm{KBr}$ pill and its spectrum was recorded. Then, pill was subjected to synchrotron radiation for 3 minutes and then, spectrum was again recorded and this process was repeated for another 3 minutes. Therefore, three graphs were available which have similar mass ratio, as shown in Figure (4). In this figure, Carbon-Carbon double bond $(C=C)$ at the range of $1600-1700\left(\mathrm{~cm}^{-1}\right)$ is shown as two peaks. The peak at $1630\left(\mathrm{~cm}^{-1}\right)$ is related to double bond $\mathrm{C}=\mathrm{C}$ bond and the peak at $1644\left(\mathrm{~cm}^{-1}\right)$ is related to conjugated $\mathrm{C}=\mathrm{C}$ bond. It is expected that double bond bond eliminates during radiation. In addition, the peak at $1725.5\left(\mathrm{~cm}^{-1}\right)$ which is related to Carbon-Oxygen double bond $(\mathrm{C}=\mathrm{O})$ is expected to emerge at $1715\left(\mathrm{~cm}^{-1}\right)$. However, due to the presence of resonance, which is happened because of adjoining a Carbonyl group $(\mathrm{C}=\mathrm{C})$ with an Ester group $(\mathrm{C}=\mathrm{O})$ ( similar to Figure (5)), it emerges in this region. It is expected that the shift induced by resonance reduces and the peak related to $\mathrm{C}=\mathrm{O}$ bond shifts back to its original position as $\mathrm{C}=\mathrm{C}$ bond eliminates (Table (2)) (Alibolandi et al. 2015; Bridoux et al. 2009; Stuurman et al. 2010; Kondo 2010; Jindal et al. 2017; Rapoport 2007; Fernández 2011; Pippa et al. 2013; Verreault et al. 2012; Hassanzadeh et al. 2017; Sivanesan et al. 2017; Phillips et al. 2010; Varan et al. 2017; Moghimi et al. 2014; Soria et al. 2010; McMurray et al. 2010; Sans-Serramitjana et al. 2016; Rigo et al. 2017; Alibolandi et al. 2017; Bridoux et al. 2010; Tutaj et al. 2016; Kuppusamy et al. 2013; Tomalia 2006; Menjoge et al. 2010; VegaVilla et al. 2008; Gaur et al. 2014; Tietze et al. 2015; Schwengber et al. 2015; Adhikari et al. 2017; Szebeni et al. 2015; Chen et al 2011; Requejo-Aguilar et al. 2017; Golyshkin et al. 2016; Szulc et al. 2016; Haddad et al. 2008; Mignani et al. 2013; Eaton et al. 2015; Lollo et al. 2015; Thompson et al. 2012; Muntimadugu et al. 2017; Foldvari et al. 2008; Riley et al. 2012; Fernandes et al. 2015; Mehra et al. 2016; Mignani et al. 2016; Naderkhani et al. 2014; Newton 2013; Aoki et al. 2015; Ita 2014; Liu et al. 2008; Mallapragada et al. 2015; Peres et al. 2017; Ferreira et al. 2013; Salerno et al. 2015; Tyler et al. 2016; Iannazzo et al. 2015; Jemec et al. 2012; Chen et al. 2012; Lütscher et al. 2012; Park et al. 2013; Huang et al. 2011; Depan et al. 2011; Guo et al. 2014; Duncan 2011; Sidik et al. 2016; Yuan et al. 2010; He et al. 2014; An et al. 2013; Meenach et al. 2013; England et al. 2012; Pippa et al. 2013; Boisseau et al. 2011; Petrichenko et al. 2015; RodríguezGascón et al. 2015; Frima et al. 2012; Yallapu et al. 2015; Duan et al. 2012; Perez et al. 2015; Costantino et al. 2012; Wei et al. 2006; Murday et al. 2009; Dixit et al. 2015; Nair et al. 2010; Bawa et al. 2005; Farkhani et al. 2014; Lal et al. 2010; Hacklin et al. 2009; Gabizon et al. 2016; Zhang et al. 2013; Vanić et al. 2014; EllisBehnke 2007; Srivalli et al. 2016; Collnot et al. 2012; Rychak et al. 2006; Watala et al. 2016; Palombo et al. 2009; Kuzmov et al. 2015; Diebold et al. 2010; Bal et al. 2011; Bharali et al. 2010; Ray et al. 2010; Mishra et al. 2010; Torchilin 2009; Cupaioli et al. 2014; Sosnik et al. 2014; Guan et al. 2013; Toit et al. 2013; Zhang et al. 2012; Muthaiyan et al. 2011; Duncan 2009; Palao-Suay et al. 2016; Morrow et al. 2007; Punetha et al. 2017; Manickam 2017; Osorio et al. 2015; Karami et al. 2016; Park et al. 2013; Heidari 2017, 2018; Gobato et al. 2018; Gobato, Heidari 2018; Heidari, Gobato 2018)

In Figure (6), energy range of $1540-1680\left(\mathrm{~cm}^{-1}\right)$ is magnified so that the changes can be more clearly seen (Figure (8)).

As it is expected, double bond is eliminated and conjugated bond is considerably reduced. To calculate the remained amount of double bond, a reference peak (a bond that is not changed) is used that is related to Carbon-Oxygen double bond (Ester function $\mathrm{C}=\mathrm{O})$ and is shown as a large peak at $1725\left(\mathrm{~cm}^{-1}\right)$. In this regard, the area below the curves of $\mathrm{C}=\mathrm{O}$ and $\mathrm{C}=\mathrm{C}$ are calculated in each step, by Origin latest version 2018 software, and the obtained results are compared with each other.

If the obtained ratio from the curve of liquid (black curve) is considered as reference value, it can be said that after 3 and 6 minutes of radiation, about $49 \%$ and $35 \%$, respectively, of double bonds are remained. Therefore, it seems that double bond is broken and cross link is created. Changes in color and not solving in initial solvent (acetone) can be considered as the signs of this issue. To show that the considered method is applicable for all unsaturated polyamides nanoparticles as anti-cancer polymeric nanomedicines, this process was repeated for general polyamides nanoparticles as anti-cancer polymeric nanomedicines and again, it was radiated for 6 minutes with similar mass ratio.

Again, $\mathrm{C}=\mathrm{O}$ bond was considered as reference and previous works were repeated to obtain the remained amount of $\mathrm{C}=\mathrm{C}$ bonds. In this nanomaterial, the remained amount of $\mathrm{C}=\mathrm{C}$ bond after 6 minutes of radiation is about $48 \%$.

For quantitative evaluation of the changes happened in the presented peaks in Raman and Attenuated Total Reflection-Fourier Transform Infrared (ATR-FTIR) spectra, it is enough to harden a small amount of nanomaterial and obtain its spectrum before and after hardening.

For Raman spectroscopy, a given amount of the nanomaterial is selected and its spectrum is obtained. Then, an equal mass of nanomaterial is hardened and its spectrum is obtained again (Figure 9). For Attenuated Total Reflection-Fourier Transform Infrared (ATR-FTIR) spectrum, a given amount of nanomaterial is placed over $\mathrm{KBr}$ pill and then, its spectrum is obtained. Then, the pill is subjected to synchrotron radiation for 6 minutes and then its spectrum is obtained to create Figure (10) (Alibolandi et al. 2015; Bridoux et al. 2009; Stuurman et al. 2010; Kondo 2010; Jindal et al. 2017; Rapoport 2007; Fernández 2011; Pippa et al. 2013; Verreault et al. 2012; Hassanzadeh et al. 2017; Sivanesan et al. 2017; Phillips et al. 2010; Varan et al. 2017; Moghimi et al. 2014; Soria et al. 2010; McMurray et al. 2010; Sans-Serramitjana et al. 2016; Rigo et al. 2017; Alibolandi et al. 2017; Bridoux et al. 2010; Tutaj et al. 2016; Kuppusamy et al. 2013; Tomalia 2006; Menjoge et al. 2010; Vega-Villa et al. 2008; Gaur et al. 2014; Tietze et al. 
2015; Schwengber et al. 2015; Adhikari et al. 2017; Szebeni et al 2015; Chen et al. 2011; Requejo-Aguilar et al. 2017; Golyshkin et al. 2016; Szulc et al. 2016; Haddad et al. 2008; Mignani et al. 2013; Eaton et al. 2015; Lollo et al. 2015; Thompson et al. 2012; Muntimadugu et al. 2017; Foldvari et al. 2008; Riley et al. 2012; Fernandes et al. 2015; Mehra et al. 2016; Mignani et al. 2016; Naderkhani et al. 2014; Newton 2013; Aoki et al. 2015; Ita 2014; Liu et al. 2008; Mallapragada et al. 2015; Peres et al. 2017; Ferreira et al. 2013; Salerno et al. 2015; Tyler et al. 2016; Iannazzo et al. 2015; Jemec et al. 2012; Chen et al. 2012; Lütscher et al. 2012; Park et al. 2013; Huang et al. 2011; Depan et al. 2011; Guo et al. 2014; Duncan 2011; Sidik et al. 2016; Yuan et al. 2010; He et al. 2014; An et al. 2013; Meenach et al. 2013; England et al. 2012; Pippa et al. 2013; Boisseau et al. 2011; Petrichenko et al. 2015; Rodríguez-Gascón et al. 2015; Frima et al. 2012; Yallapu et al. 2015; Duan et al. 2012; Perez et al. 2015; Costantino et al. 2012; Wei et al. 2006; Murday et al. 2009; Dixit et al. 2015; Nair et al. 2010; Bawa et al. 2005; Farkhani et al. 2014; Lal et al. 2010; Hacklin et al. 2009; Gabizon et al. 2016; Zhang et al. 2013; Vanić et al. 2014; Ellis-Behnke 2007; Srivalli et al. 2016; Collnot et al. 2012; Rychak et al. 2006; Watala et al. 2016; Palombo et al. 2009; Kuzmov et al. 2015; Diebold et al. 2010; Bal et al. 2011; Bharali et al. 2010; Ray et al. 2010; Mishra et al. 2010; Torchilin 2009; Cupaioli et al. 2014; Sosnik et al. 2014; Guan et al. 2013; Toit et al. 2013; Zhang et al. 2012; Muthaiyan et al. 2011; Duncan 2009; Palao-Suay et al. 2016; Morrow et al. 2007; Punetha et al. 2017; Manickam 2017; Osorio et al. 2015; Karami et al. 2016; Park et al. 2013; Heidari 2017, 2018; Gobato et al. 2018; Gobato, Heidari 2018; Heidari, Gobato 2018).

To investigate the hardening process, the region in which $\mathrm{C}=\mathrm{O}$, $\mathrm{C}-\mathrm{O}$ and $\mathrm{C}=\mathrm{C}$ bonds can be observed is considered $(900-1800$ $\mathrm{cm}^{-1}$ ). Using Origin software and experimental data, this range can be depicted as shown in Figures (10) and (11).

As is expected, $\mathrm{C}=\mathrm{C}$ bond is considerably synchrotron radiation than $\mathrm{C}=\mathrm{O}$ bond in Raman spectrum. Further, $\mathrm{C}-\mathrm{C}$ bond that is not shown in Attenuated Total Reflection-Fourier Transform Infrared (ATR-FTIR) spectrum can be clearly observed in this spectrum in the range of 900-1300 $\left(\mathrm{cm}^{-1}\right)$ (Figure (7)). As the main reason for creation of cross link is elimination of this bond and its converting to $\mathrm{C}-\mathrm{C}$ cross link, variations at this peak $\left(1624 \mathrm{~cm}^{-1}\right)$ and creation of new bonds in the range related to $\mathrm{C}-\mathrm{C}$ bonds is very important. Firstly, the changes observed between liquid and hardened polymer in Attenuated Total Reflection-Fourier Transform Infrared (ATR-FTIR) spectrum are considered. As can be seen in Figure (10), $\mathrm{C}=\mathrm{C}$ bond emerges at $1644\left(\mathrm{~cm}^{-1}\right)$. After hardening, the heights of peaks are considerably reduced (due to clouding of nanomaterial). As the height of peak is strongly depend on the concentration of nanomaterial, it cannot be the only criterion for breaking the bonds. To demonstrate the reduction in number of bonds, the ratio of area below the related curve to $\mathrm{C}=\mathrm{C}$ bond and the related curve to a bond that is not changed during hardening before and after hardening process are calculated (Alibolandi et al. 2015; Bridoux et al. 2009; Stuurman et al. 2010; Kondo 2010; Jindal et al. 2017; Rapoport 2007; Fernández 2011; Pippa et al. 2013; Verreault et al. 2012; Hassanzadeh et al. 2017; Sivanesan et al. 2017; Phillips et al. 2010; Varan et al. 2017; Moghimi et al. 2014; Soria et al. 2010; McMurray et al. 2010; Sans-Serramitjana et al. 2016; Rigo et al. 2017; Alibolandi et al. 2017; Bridoux et al 2010; Tutaj et al. 2016; Kuppusamy et al. 2013; Tomalia 2006; Menjoge et al. 2010; Vega-Villa et al. 2008; Gaur et al. 2014; Tietze et al. 2015; Schwengber et al. 2015; Adhikari et al. 2017; Szebeni et al. 2015; Chen et al. 2011; Requejo-Aguilar et al. 2017; Golyshkin et al. 2016; Szulc et al. 2016; Haddad et al. 2008; Mignani et al. 2013; Eaton et al. 2015; Lollo et al. 2015; Thompson et al. 2012; Muntimadugu et al. 2017; Foldvari et al. 2008; Riley et al. 2012; Fernandes et al. 2015; Mehra et al. 2016; Mignani et al. 2016; Naderkhani et al. 2014; Newton 2013; Aoki et al. 2015; Ita 2014; Liu et al. 2008; Mallapragada et al. 2015; Peres et al. 2017; Ferreira et al. 2013; Salerno et al. 2015; Tyler et al. 2016; Iannazzo et al. 2015; Jemec et al. 2012; Chen et al. 2012; Lütscher et al. 2012; Park et al. 2013; Huang et al. 2011; Depan et al. 2011;
Guo et al. 2014; Duncan 2011; Sidik et al. 2016; Yuan et al. 2010; He et al. 2014; An et al. 2013; Meenach et al. 2013; England et al. 2012; Pippa et al. 2013; Boisseau et al. 2011; Petrichenko et al. 2015; Rodríguez-Gascón et al. 2015; Frima et al. 2012; Yallapu et al. 2015; Duan et al. 2012; Perez et al. 2015; Costantino et al. 2012; Wei et al. 2006; Murday et al. 2009; Dixit et al. 2015; Nair et al. 2010; Bawa et al. 2005; Farkhani et al. 2014; Lal et al. 2010; Hacklin et al. 2009; Gabizon et al. 2016; Zhang et al. 2013; Vanić et al. 2014; Ellis-Behnke 2007; Srivalli et al. 2016; Collnot et al. 2012; Rychak et al. 2006; Watala et al. 2016; Palombo et al. 2009; Kuzmov et al. 2015; Diebold et al. 2010; Bal et al. 2011; Bharali et al. 2010; Ray et al. 2010; Mishra et al. 2010; Torchilin 2009; Cupaioli et al. 2014; Sosnik et al. 2014; Guan et al. 2013; Toit et al. 2013; Zhang et al. 2012; Muthaiyan et al. 2011; Duncan 2009; Palao-Suay et al. 2016; Morrow et al. 2007; Punetha et al. 2017; Manickam 2017; Osorio et al. 2015; Karami et al. 2016; Park et al. 2013; Heidari 2017, 2018; Gobato et al. 2018; Gobato, Heidari 2018; Heidari, Gobato 2018).

As can be observed, decrease in this ratio shows that Carbon double bond $(\mathrm{C}=\mathrm{C})$ is broken. In fact, the remaining amount of Carbon double bond is $33.3 \%$ after 6 minutes of synchrotron radiation. In this curve, it is not possible to directly observe creation of cross links and it is only possible to indirectly guess the creation of some bonds in $\mathrm{C}-\mathrm{O}$ structure. Further, low height of peak related to $\mathrm{C}=\mathrm{C}$ makes it impossible to clearly observe the changes induced by breaking the bond. However, the shift in peaks towards longer wavelengths is another reason for breaking Carbon double bonds and creation of cross links (in fact, the existence of resonance in chemical structure that is made from adjoining $\mathrm{C}=\mathrm{O}$ and $\mathrm{C}=\mathrm{C}$ bonds leads to shifting the peak of $\mathrm{C}=\mathrm{O}$ from $1715\left(\mathrm{~cm}^{-1}\right)$ to $1725\left(\mathrm{~cm}^{-1}\right)$. Therefore, by elimination of double bond it is expected that this bond shifts back to its original position) (Figure (11) and Table (2)). However, there are various interesting points in Raman spectrum. The ratios of peak reduction are:

The remaining $\mathrm{C}=\mathrm{C}$ bond derived from these ratios is $12.5 \%$. Such large difference between the obtained ratios from Attenuated Total Reflection-Fourier Transform Infrared (ATR-FTIR) spectrum $(33.3 \%)$ and Raman spectrum $(12.5 \%)$ indicates that the changes happened in this bond is considerably better observed in Raman spectrum than Attenuated Total Reflection-Fourier Transform Infrared (ATR-FTIR) one. To better understand the potentials of Raman, see Figure (10). As can be seen, in the range of 1000$1300\left(\mathrm{~cm}^{-1}\right)$ related to $\mathrm{C}-\mathrm{C}$ bond, it is possible to clearly observe cross links with increase in the number of peaks that are overlapped. In addition, converting the peak at $1471\left(\mathrm{~cm}^{-1}\right)$ that is related to $\mathrm{CH}_{2}$ and $\mathrm{CH}_{3}$ structures to two peaks and addition of peak at $1423.43\left(\mathrm{~cm}^{-1}\right)$ (related to $\mathrm{CH}_{3}$ structure) because of the presence of $\mathrm{CH}_{3}$ at the end of the chain, indicate the shortening of polymeric chain. Decreasing the peak at $99.4\left(\mathrm{~cm}^{-1}\right)(\mathrm{C}-\mathrm{O}-\mathrm{C}$ structure) confirms that linear structure of polymer is broken in a specific position and this is the reason for shortening the chain length and amorphous chemical structure.

Regarding the fact that this hardening method reduces the hardening time down to 7 minutes and considering this point that the chemical structure of polyamides nanoparticles are not mainly changed, against traditional methods (which use hardener nanomaterial), except that in the region of creation of cross links, it is proposed that this method can be used for capsulation and lithography. In addition, the following points can be derived from the differences between Attenuated Total Reflection-Fourier Transform Infrared (ATR-FTIR) and Raman spectra.

(I) Raman spectroscopy is the best method for detecting the bonds in non-polarized nanomolecules, especially the nanomolecules that are not detectable in traditional methods due to the symmetry of chemical structure. Opposite to Attenuated Total ReflectionFourier Transform Infrared (ATR-FTIR) spectroscopy which shows rotational and vibration modes of polarized bonds such as $\mathrm{C}-\mathrm{H}$ and $\mathrm{C}-\mathrm{O}$, Raman spectrum is able to show non-polarized structures such as $\mathrm{C}-\mathrm{C}$ and $\mathrm{C}-\mathrm{O}-\mathrm{C}$.

(II) It is better that both Raman and Attenuated Total ReflectionFourier Transform Infrared (ATR-FTIR) spectra obtain from the 
sample. If both Raman and Attenuated Total Reflection-Fourier Transform Infrared (ATR-FTIR) spectra obtain, it can be seen that these two spectra are supplement of each other. Finally, it can be said that Raman spectroscopy is better than Attenuated Total Reflection-Fourier Transform Infrared (ATR-FTIR) spectroscopy since $\mathrm{C}=\mathrm{C}$ and $\mathrm{C}-\mathrm{C}$ bonds cannot be clearly observed in Attenuated Total Reflection-Fourier Transform Infrared (ATR-FTIR) spectroscopy. However, the synchrotron radiation amount in Raman spectroscopy should not be so high that leads to change in chemical structure.

\section{Conclusion}

As can be seen in Figure (1), except that $\mathrm{C}=\mathrm{C}$ bonds at 1630 and $1644\left(\mathrm{~cm}^{-1}\right)$, remained bonds have not change and it can be clearly seen from constant area ratio related to reference peak $(C=O)$, before and after radiation. Except that bonds which are indirectly related to $\mathrm{C}=\mathrm{C}$ bond, such as vinyl Hydrogen, that its considerable reduction is the sign of major changes in $\mathrm{C}=\mathrm{C}$, cross-links are not observed in spectroscopy. However, the changes happened in $\mathrm{C}-\mathrm{O}$ bonds in the range of $1000-1300\left(\mathrm{~cm}^{-1}\right)$ show some changes in linear structure of polyamides nanoparticles. It is expected that the mentioned bonds $(\mathrm{C}=\mathrm{C}$ and $\mathrm{C}-\mathrm{C})$ will be more clearly emerged in Raman spectroscopy since the symmetry in these structures (Figure (2)) leads to inefficiency of Attenuated Total ReflectionFourier Transform Infrared (ATR-FTIR) spectroscopy. Meanwhile, decreasing the peak height in each step is due to clouding of polymer and increasing the reflection from polymer surface. The bond energy of $\mathrm{C}=\mathrm{C}$ bond is about $611(\mathrm{~kJ})$. As $20 \%$ of synchrotron radiation wavelength $(10.6 \mu \mathrm{m})$ is absorbed by nanomaterial and synchrotron radiation is radiated with enough time, the energy required for breaking the bond is provided for the nanomaterial. Creation of free radicals and high energy of bond for recombination of $\mathrm{C}=\mathrm{C}$ bond lead to bonds with lower energy and as free radicals are happened over Carbon double bond, this bond is $\mathrm{C}-\mathrm{C}$ cross-link.

\section{References}

[1] Heidari, A., Brown, C. (2015). Study of Composition and Morphology of Cadmium Oxide (CdO) Nanoparticles for Eliminating Cancer Cells, Journal of Nanomedicine Research, Volume 2, Issue 5, 20 Pages

[2] Heidari, A., Brown, C. (2015). Study of Surface Morphological, Phytochemical and Structural Characteristics of Rhodium (III) Oxide $\left(\mathrm{Rh}_{2} \mathrm{O}_{3}\right)$ Nanoparticles, International Journal of Pharmacology, Phytochemistry and Ethnomedicine, Volume 1, Pages 15-19. https://doi.org/10.18052/www.scipress.com/IJPPE.1.15.

[3] Heidari, A. (2016). An Experimental Biospectroscopic Study on Seminal Plasma in Determination of Semen Quality for Evaluation of Male Infertility, Int $\mathbf{J}$ Adv Technol 7: e007. https://doi.org/10.4172/0976-4860.1000e007.

[4] Heidari, A. (2016). Extraction and Preconcentration of N-TolylSulfonyl-Phosphoramid-Saeure-Dichlorid as an Anti-Cancer Drug from Plants: A Pharmacognosy Study, J Pharmacogn Nat Prod 2: e103. https://doi.org/10.4172/2472-0992.1000e103.

[5] Heidari, A. (2016). A Thermodynamic Study on Hydration and Dehydration of DNA and RNA-Amphiphile Complexes, J Bioeng Biomed Sci S: 006

[6] Heidari, A. (2016). Computational Studies on Molecular Structures and Carbonyl and Ketene Groups' Effects of Singlet and Triplet Energies of Azidoketene $\mathrm{O}=\mathrm{C}=\mathrm{CH}-\mathrm{NNN}$ and Isocyanatoketene $\mathrm{O}=\mathrm{C}=\mathrm{CH}-\mathrm{N}=\mathrm{C}=\mathrm{O}, \mathrm{J}$ Appl Computat Math 5: e142.

[7] Heidari, A. (2016). Study of Irradiations to Enhance the Induces the Dissociation of Hydrogen Bonds between Peptide Chains and Transition from Helix Structure to Random Coil Structure Using ATRFTIR, Raman and ${ }^{1}$ HNMR Spectroscopies, J Biomol Res Ther 5: e146. https://doi.org/10.4172/2167-7956.1000e146.

[8] Heidari, A. (2016). Future Prospects of Point Fluorescence Spectroscopy, Fluorescence Imaging and Fluorescence Endoscopy in Photodynamic Therapy (PDT) for Cancer Cells, J Bioanal Biomed 8: e135. https://doi.org/10.4172/1948-593X.1000e135.

[9] Heidari, A. (2016). A Bio-Spectroscopic Study of DNA Density and Color Role as Determining Factor for Absorbed Irradiation in
Cancer Cells, Adv Cancer Prev 1: e102. https://doi.org/10.4172/2472-0429.1000e102.

[10] Heidari, A. (2016). Manufacturing Process of Solar Cells Using Cadmium Oxide (CdO) and Rhodium (III) Oxide $\left(\mathrm{Rh}_{2} \mathrm{O}_{3}\right)$ Nanoparticles, J Biotechnol Biomater 6: e125. https://doi.org/10.4172/2155952X.1000e 125.

[11] Heidari, A. (2016). a Novel Experimental and Computational Approach to Photobiosimulation of Telomeric DNA/RNA: A Biospectroscopic and Photobiological Study, J Res Development 4: 144.

[12] Heidari, A. (2016). Biochemical and Pharmacodynamical Study of Microporous Molecularly Imprinted Polymer Selective for Vancomycin, Teicoplanin, Oritavancin, Telavancin and Dalbavancin Binding, Biochem Physiol 5: e146. https://doi.org/10.4172/2168$9652.1000 \mathrm{e} 146$.

[13] Heidari, A. (2016). Anti-Cancer Effect of UV Irradiation at Presence of Cadmium Oxide (CdO) Nanoparticles on DNA of Cancer Cells: A Photodynamic Therapy Study, Arch Cancer Res. 4: 1. https://doi.org/10.21767/2254-6081.100061.

[14] Heidari, A. (2016). Biospectroscopic Study on Multi-Component Reactions (MCRs) in Two A-Type and B-Type Conformations of Nucleic Acids to Determine Ligand Binding Modes, Binding Constant and Stability of Nucleic Acids in Cadmium Oxide (CdO) Nanoparticles-Nucleic Acids Complexes as Anti-Cancer Drugs, Arch Cancer Res. 4: 2. https://doi.org/10.21767/2254-6081.100065.

[15] Heidari, A. (2016). Simulation of Temperature Distribution of DNA/RNA of Human Cancer Cells Using Time-Dependent BioHeat Equation and Nd: YAG Lasers, Arch Cancer Res. 4: 2 https://doi.org/10.21767/2254-6081.100069.

[16] Heidari, A. (2016). Quantitative Structure-Activity Relationship (QSAR) Approximation for Cadmium Oxide $(\mathrm{CdO})$ and Rhodium (III) Oxide $\left(\mathrm{Rh}_{2} \mathrm{O}_{3}\right)$ Nanoparticles as Anti-Cancer Drugs for the Catalytic Formation of Proviral DNA from Viral RNA Using Multiple Linear and Non-Linear Correlation Approach, Ann Clin Lab Res. 4: 1. https://doi.org/10.21767/2386-5180.100076.

[17] Heidari, A. (2016). Biomedical Study of Cancer Cells DNA Therapy Using Laser Irradiations at Presence of Intelligent Nanoparticles, J Biomedical Sci. 5: 2. https://doi.org/10.4172/2254-609X.100023.

[18] Heidari, A. (2016). Measurement the Amount of Vitamin D2 (Ergocalciferol), Vitamin D3 (Cholecalciferol) and Absorbable Calcium $\left(\mathrm{Ca}^{2+}\right)$, Iron (II) $\left(\mathrm{Fe}^{2+}\right)$, Magnesium $\left(\mathrm{Mg}^{2+}\right)$, Phosphate $\left(\mathrm{PO}^{4-}\right)$ and Zinc $\left(\mathrm{Zn}^{2+}\right)$ in Apricot Using High-Performance Liquid Chromatography (HPLC) and Spectroscopic Techniques, J Biom Biostat 7: 292. https://doi.org/10.4172/2155-6180.1000292.

[19] Heidari, A. Spectroscopy and Quantum Mechanics of the Helium Dimer $\left(\mathrm{He}^{2+}\right)$, Neon Dimer $\left(\mathrm{Ne}^{2+}\right)$, Argon Dimer $\left(\mathrm{Ar}^{2+}\right)$, Krypton Dimer $\left(\mathrm{Kr}^{2+}\right)$, Xenon Dimer $\left(\mathrm{Xe}^{2+}\right)$, Radon Dimer $\left(\mathrm{Rn}^{2+}\right)$ and Ununoctium Dimer $\left(\mathrm{Uuo}^{2+}\right)$ Molecular Cations, Chem Sci J 7: e112, 2016. https://doi.org/10.4172/2150-3494.1000e112.

[20] Heidari, A. (2016). Human Toxicity Photodynamic Therapy Studies on DNA/RNA Complexes as a Promising New Sensitizer for the Treatment of Malignant Tumors Using Bio-Spectroscopic Tech$\begin{array}{lllll}\text { niques, J Drug Metab Toxicol 7: } 129 . & \text {. }\end{array}$ https://doi.org/10.4172/2157-7609.1000e129.

[21] Heidari, A. (2016). Novel and Stable Modifications of Intelligent Cadmium Oxide (CdO) Nanoparticles as Anti-Cancer Drug in Formation of Nucleic Acids Complexes for Human Cancer Cells' Treatment, Biochem Pharmacol (Los Angel) 5: 207. https://doi.org/10.4172/2167-0501.1000207.

[22] Heidari, A. (2016). A Combined Computational and QM/MM Molecular Dynamics Study on Boron Nitride Nanotubes (BNNTs), Amorphous Boron Nitride Nanotubes (a-BNNTs) and Hexagonal Boron Nitride Nanotubes (h-BNNTs) as Hydrogen Storage, Struct Chem Crystallogr Commun 2: 1 .

[23] Heidari, A. (2016). Pharmaceutical and Analytical Chemistry Study of Cadmium Oxide $(\mathrm{CdO})$ Nanoparticles Synthesis Methods and Properties as Anti-Cancer Drug and its Effect on Human Cancer Cells, Pharm Anal Chem Open Access 2: 113.

[24] Heidari, A. (2016). A Chemotherapeutic and Biospectroscopic Investigation of the Interaction of Double-Standard DNA/RNABinding Molecules with Cadmium Oxide (CdO) and Rhodium (III) Oxide $\left(\mathrm{Rh}_{2} \mathrm{O}_{3}\right)$ Nanoparticles as Anti-Cancer Drugs for Cancer Cells' Treatment, Chemo Open Access 5: e129.

[25] Heidari, A. (2016). Pharmacokinetics and Experimental Therapeutic Study of DNA and Other Biomolecules Using Lasers: Advantages and Applications, J Pharmacokinet Exp Ther 1: e005.

[26] Heidari, A. (2016). Determination of Ratio and Stability Constant of DNA/RNA in Human Cancer Cells and Cadmium Oxide $(\mathrm{CdO})$ Nanoparticles Complexes Using Analytical Electrochemical and Spectroscopic Techniques, Insights Anal Electrochem 2: 1. 
[27] Heidari, A. (2016). Discriminate between Antibacterial and NonAntibacterial Drugs Artificial Neutral Networks of a Multilayer Perceptron (MLP) Type Using a Set of Topological Descriptors, J Heavy Met Toxicity Dis. 1: 2. https://doi.org/10.21767/24736457.100009 .

[28] Heidari, A. (2016). Combined Theoretical and Computational Study of the Belousov-Zhabotinsky Chaotic Reaction and Curtius Rearrangement for Synthesis of Mechlorethamine, Cisplatin, Streptozotocin, Cyclophosphamide, Melphalan, Busulphan and BCNU as Anti-Cancer Drugs, Insights Med Phys. 1: 2.

[29] Heidari, A. (2016). a Translational Biomedical Approach to Structural Arrangement of Amino Acids' Complexes: A Combined Theoretical and Computational Study, Transl Biomed. 7: 2. https://doi.org/10.21767/2172-0479.100072.

[30] Heidari, A. (2016). Ab Initio and Density Functional Theory (DFT) Studies of Dynamic NMR Shielding Tensors and Vibrational Frequencies of DNA/RNA and Cadmium Oxide (CdO) Nanoparticles Complexes in Human Cancer Cells, J Nanomedine Biotherapeutic Discov 6: e144.

[31] Heidari, A. (2016). Molecular Dynamics and Monte-Carlo Simulations for Replacement Sugars in Insulin Resistance, Obesity, LDL Cholesterol, Triglycerides, Metabolic Syndrome, Type 2 Diabetes and Cardiovascular Disease: A Glycobiological Study, J Glycobiol 5: e111. https://doi.org/10.4172/2168-958X.1000e111.

[32] Heidari, A. (2016). Synthesis and Study of 5-[(Phenylsulfonyl) Amino]-1, 3, 4-Thiadiazole-2-Sulfonamide as Potential AntiPertussis Drug Using Chromatography and Spectroscopy Techniques, Transl Med (Sunnyvale) 6: e138. https://doi.org/10.4172/2161-1025.1000e137.

[33] Heidari, A. (2016). Nitrogen, Oxygen, Phosphorus and Sulphur Heterocyclic Anti-Cancer Nano Drugs Separation in the Supercritical Fluid of Ozone $\left(\mathrm{O}_{3}\right)$ Using Soave-Redlich-Kwong (SRK) and Pang-Robinson (PR) Equations, Electronic J Biol 12: 4.

[34] Heidari, A. (2016). an Analytical and Computational Infrared Spectroscopic Review of Vibrational Modes in Nucleic Acids, Austin J Anal Pharm Chem. 3(1): 1058.

[35] Heidari, A., Brown, C. (2016). Phase, Composition and Morphology Study and Analysis of Os-Pd/HfC Nanocomposites, Nano Res Appl. 2: 1 .

[36] Heidari, A., Brown, C. (2016). Vibrational Spectroscopic Study of Intensities and Shifts of Symmetric Vibration Modes of Ozone Diluted by Cumene, International Journal of Advanced Chemistry, 4 (1) 5-9. https://doi.org/10.14419/ijac.v4i1.6080.

[37] Heidari, A. (2016). Study of the Role of Anti-Cancer Molecules with Different Sizes for Decreasing Corresponding Bulk Tumor Multiple Organs or Tissues, Arch Can Res. 4: 2. https://doi.org/10.21767/2254-6081.100083.

[38] Heidari, A. (2016). Genomics and Proteomics Studies of Zolpidem, Necopidem, Alpidem, Saripidem, Miroprofen, Zolimidine, Olprinone and Abafungin as Anti-Tumor, Peptide Antibiotics, Antiviral and Central Nervous System (CNS) Drugs, J Data Mining Genomics \& Proteomics 7: e125. https://doi.org/10.4172/2153$0602.1000 \mathrm{e} 125$.

[39] Heidari, A. (2016). Pharmacogenomics and Pharmacoproteomics Studies of Phosphodiesterase-5 (PDE5) Inhibitors and Paclitaxel Albumin-Stabilized Nanoparticles as Sandwiched Anti-Cancer Nano Drugs between Two DNA/RNA Molecules of Human Cancer Cells, J Pharmacogenomics Pharmacoproteomics 7: e153. https://doi.org/10.4172/2153-0645.1000e153.

[40] Heidari, A. (2016). Biotranslational Medical and Biospectroscopic Studies of Cadmium Oxide (CdO) Nanoparticles-DNA/RNA Straight and Cycle Chain Complexes as Potent Anti-Viral, AntiTumor and Anti-Microbial Drugs: A Clinical Approach, Transl Biomed. 7: 2. https://doi.org/10.21767/2172-0479.100076.

[41] Heidari, A. (2016). A Comparative Study on Simultaneous Determination and Separation of Adsorbed Cadmium Oxide (CdO) Nanoparticles on DNA/RNA of Human Cancer Cells Using Biospectroscopic Techniques and Dielectrophoresis (DEP) Method, Arch Can Res. 4: 2. https://doi.org/10.21767/2254-6081.100086.

[42] Heidari, A. (2016). Cheminformatics and System Chemistry of Cisplatin, Carboplatin, Nedaplatin, Oxaliplatin, Heptaplatin and Lobaplatin as Anti-Cancer Nano Drugs: A Combined Computational and Experimental Study, $\mathbf{J}$ Inform Data Min 1: 3. https://doi.org/10.21767/2472-1956.100015.

[43] Heidari, A. (2016). Linear and Non-Linear Quantitative StructureAnti-Cancer-Activity Relationship (QSACAR) Study of Hydrous Ruthenium (IV) Oxide $\left(\mathrm{RuO}_{2}\right)$ Nanoparticles as Non-Nucleoside Reverse Transcriptase Inhibitors (NNRTIs) and Anti-Cancer Nano Drugs, J Integr Oncol 5: e110.
[44] Heidari, A. (2016). Synthesis, Characterization and Biospectroscopic Studies of Cadmium Oxide (CdO) Nanoparticles-Nucleic Acids Complexes Absence of Soluble Polymer as a Protective Agent Using Nucleic Acids Condensation and Solution Reduction Method, J Nanosci Curr Res 1: e101.

[45] Heidari, A. (2016). Coplanarity and Collinearity of 4'-Dinonyl2,2'-Bithiazole in One Domain of Bleomycin and Pingyangmycin to be Responsible for Binding of Cadmium Oxide (CdO) Nanoparticles to DNA/RNA Bidentate Ligands as Anti-Tumor Nano Drug, Int J Drug Dev \& Res 8: 007-008.

[46] Heidari, A. (2016). A Pharmacovigilance Study on Linear and Non-Linear Quantitative Structure (Chromatographic) Retention Relationships (QSRR) Models for the Prediction of Retention Time of Anti-Cancer Nano Drugs under Synchrotron Radiations, J Pharmacovigil 4: e161. https://doi.org/10.4172/2329. $6887.1000 \mathrm{e} 161$.

[47] Heidari, A. (2016). Nanotechnology in Preparation of Semipermeable Polymers, J Adv Chem Eng 6: 157. https://doi.org/10.4172/2090-4568.1000e108.

[48] Heidari, A. (2016). A Gastrointestinal Study on Linear and NonLinear Quantitative Structure (Chromatographic) Retention Relationships (QSRR) Models for Analysis 5-Aminosalicylates Nano Particles as Digestive System Nano Drugs under Synchrotron Radiations, J Gastrointest Dig Syst 6: e119. https://doi.org/10.4172/2161-069X.1000e119.

[49] Heidari, A. (2016). DNA/RNA Fragmentation and Cytolysis in Human Cancer Cells Treated with Diphthamide Nano Particles Derivatives, Biomedical Data Mining 5: e102. https://doi.org/10.4172/2090-4924.1000e102.

[50] Heidari, A. (2016). A Successful Strategy for the Prediction of Solubility in the Construction of Quantitative Structure-Activity Relationship (QSAR) and Quantitative Structure-Property Relationship (QSPR) under Synchrotron Radiations Using Genetic Function Approximation (GFA) Algorithm, J Mol Biol Biotechnol 1: 1.

[51] Heidari, A. (2016). Computational Study on Molecular Structures of $\mathrm{C}_{20}, \mathrm{C}_{60}, \mathrm{C}_{240}, \mathrm{C}_{540}, \mathrm{C}_{960}, \mathrm{C}_{2160}$ and $\mathrm{C}_{3840}$ Fullerene Nano Molecules under Synchrotron Radiations Using Fuzzy Logic, J Material Sci Eng 5: 282. https://doi.org/10.4172/2169-0022.1000282.

[52] Heidari, A. (2016). Graph Theoretical Analysis of Zigzag Polyhexamethylene Biguanide, Polyhexamethylene Adipamide, Polyhexamethylene Biguanide Gauze and Polyhexamethylene Biguanide Hydrochloride (PHMB) Boron Nitride Nanotubes (BNNTs), Amorphous Boron Nitride Nanotubes (a-BNNTs) and Hexagonal Boron Nitride Nanotubes (h-BNNTs), J Appl Computat Math 5: e143. https://doi.org/10.4172/2168-9679.1000e143.

[53] Heidari, A. (2016). The Impact of High Resolution Imaging on Diagnosis, Int J Clin Med Imaging 3: 1000e101.

[54] Heidari, A. (2016). A Comparative Study of Conformational Behavior of Isotretinoin (13-Cis Retinoic Acid) and Tretinoin (AllTrans Retinoic Acid (ATRA)) Nano Particles as Anti-Cancer Nano Drugs under Synchrotron Radiations Using Hartree-Fock (HF) and Density Functional Theory (DFT) Methods, Insights in Biomed 1: 2.

[55] Heidari, A. (2016). Advances in Logic, Operations and Computational Mathematics, J Appl Computat Math 5: 5. https://doi.org/10.4172/2168-9679.1000e144.

[56] Heidari, A. (2016). Mathematical Equations in Predicting Physical Behavior, J Appl Computat Math 5: 5. https://doi.org/10.4172/2168-9679.1000e145.

[57] Heidari, A. (2016). Chemotherapy a Last Resort for Cancer Treatment, Chemo Open Access 5: 4. https://doi.org/10.4172/21677700.1000e 130 .

[58] Heidari, A. (2016). Separation and Pre-Concentration of Metal Cations-DNA/RNA Chelates Using Molecular Beam Mass Spectrometry with Tunable Vacuum Ultraviolet (VUV) Synchrotron Radiation and Various Analytical Methods, Mass Spectrom Purif Tech 2: e101. https://doi.org/10.4172/2469-9861.1000e101.

[59] Heidari, A. (2016). Yoctosecond Quantitative Structure-Activity Relationship (QSAR) and Quantitative Structure-Property Relationship (QSPR) under Synchrotron Radiations Studies for Prediction of Solubility of Anti-Cancer Nano Drugs in Aqueous Solutions Using Genetic Function Approximation (GFA) Algorithm, Insight Pharm Res. 1: 1

[60] Heidari, A. (2016). Cancer Risk Prediction and Assessment in $\mathrm{Hu}-$ man Cells under Synchrotron Radiations Using Quantitative Structure Activity Relationship (QSAR) and Quantitative Structure Properties Relationship (QSPR) Studies, Int J Clin Med Imaging 3: 516. https://doi.org/10.4172/2376-0249.1000516.

[61] Heidari, A. (2016). A Novel Approach to Biology, Electronic J Biol 12: 4 . 
[62] Heidari, A. (2016). Innovative Biomedical Equipment's for Diagnosis and Treatment, J Bioengineer \& Biomedical Sci 6: 2 https://doi.org/10.4172/2155-9538.1000e124.

[63] Heidari, A. (2016). Integrating Precision Cancer Medicine into Healthcare, Medicare Reimbursement Changes and the Practice of Oncology: Trends in Oncology Medicine and Practices, J Oncol Med \& Pract 1: 2

[64] Heidari, A. (2016). Promoting Convergence in Biomedical and Biomaterials Sciences and Silk Proteins for Biomedical and Biomaterials Applications: An Introduction to Materials in Medicine and Bioengineering Perspectives, J Bioengineer \& Biomedical Sci 6: 3. https://doi.org/10.4172/2155-9538.1000e126.

[65] Heidari, A. (2017). X-Ray Fluorescence and X-Ray Diffraction Analysis on Discrete Element Modeling of Nano Powder Metallurgy Processes in Optimal Container Design, J Powder Metall Min 6: 1.

[66] Heidari, A. (2017). Biomolecular Spectroscopy and Dynamics of Nano-Sized Molecules and Clusters as Cross-Linking-Induced Anti-Cancer and Immune-Oncology Nano Drugs Delivery in DNA/RNA of Human Cancer Cells' Membranes under Synchrotron Radiations: A Payload-Based Perspective, Arch Chem Res. 1: 2. https://doi.org/10.21767/2572-4657.100011.

[67] Heidari, A. (2017). Deficiencies in Repair of Double-Standard DNA/RNA-Binding Molecules Identified in Many Types of Solid and Liquid Tumors Oncology in Human Body for Advancing Cancer Immunotherapy Using Computer Simulations and Data Analysis, J Appl Bioinforma Comput Biol, 6: 1 . https://doi.org/10.4172/2329-9533.1000e104.

[68] Heidari, A. (2017). Electronic Coupling among the Five Nanomolecules Shuts Down Quantum Tunneling in the Presence and Absence of an Applied Magnetic Field for Indication of the Dimer or other Provide Different Influences on the Magnetic Behavior of Single Molecular Magnets (SMMs) as Qubits for Quantum Computing, Glob J Res Rev. 4: 2. https://doi.org/10.21767/23938854.100019 .

[69] Heidari, A. (2017). Polymorphism in Nano-Sized Graphene Ligand-Induced Transformation of $\mathrm{Au}_{38}-\mathrm{xAg}_{\mathrm{x}} / \mathrm{xCu_{ \textrm {x } }}(\mathrm{SPh}-\mathrm{tBu})_{24}$ to $\mathrm{Au}_{36}-\mathrm{XAg}_{\mathrm{x}} / \mathrm{xCu_{ \textrm {x } }}(\mathrm{SPh}-\mathrm{tBu})_{24}(\mathrm{x}=1-12)$ Nanomolecules for Synthesis of $\mathrm{Au}_{144}-\mathrm{xAg}_{\mathrm{x}} / \mathrm{xCu}_{\mathrm{x}}\left[(\mathrm{SR})_{60},\left(\mathrm{SC}_{4}\right)_{60},\left(\mathrm{SC}_{6}\right)_{60},\left(\mathrm{SC}_{12}\right)_{60},(\mathrm{PET})_{60}\right.$, $(\mathrm{p}-\mathrm{MBA})_{60},(\mathrm{~F})_{60},(\mathrm{Cl})_{60},(\mathrm{Br})_{60},(\mathrm{I})_{60},(\mathrm{At})_{60},(\mathrm{Uus})_{60}$ and $\left.\left(\mathrm{SC}_{6} \mathrm{H}_{13}\right)_{60}\right]$ Nano Clusters as Anti-Cancer Nano Drugs, J Nanomater Mol Nanotechnol, 6: 3. https://doi.org/10.4172/2324-8777.1000109e.

[70] Heidari, A. (2017). Biomedical Resource Oncology and Data Mining to Enable Resource Discovery in Medical, Medicinal, Clinical, Pharmaceutical, Chemical and Translational Research and Their Applications in Cancer Research, Int J Biomed Data Min 6: e103. https://doi.org/10.4172/2090-4924.1000e103.

[71] Heidari, A. (2017). Study of Synthesis, Pharmacokinetics, Pharmacodynamics, Dosing, Stability, Safety and Efficacy of Olympiadane Nanomolecules as Agent forCancer Enzymotherapy, Immunotherapy, Chemotherapy, Radiotherapy, Hormone Therapy and Targeted Therapy under Synchrotorn Radiation, J Dev Drugs 6: e154. https://doi.org/10.4172/2329-6631.1000e154.

[72] Heidari, A. (2017). A Novel Approach to Future Horizon of Top Seven Biomedical Research Topics to Watch in 2017: Alzheimer's, Ebola, Hypersomnia, Human Immunodeficiency Virus (HIV), Tuberculosis (TB), Microbiome/Antibiotic Resistance and Endovascular Stroke, J Bioengineer \& Biomedical Sci 7: e127. https://doi.org/10.4172/2155-9538.1000e127.

[73] Heidari, A. (2017). Opinion on Computational Fluid Dynamics (CFD) Technique, Fluid Mech Open Acc 4: 157 https://doi.org/10.4172/2476-2296.1000157.

[74] Heidari, A. (2017). Concurrent Diagnosis of Oncology Influence Outcomes in Emergency General Surgery for Colorectal Cancer and Multiple Sclerosis (MS) Treatment Using Magnetic Resonance Imaging (MRI) and $\mathrm{Au}_{329}(\mathrm{SR})_{84}, \quad \mathrm{Au}_{329-\mathrm{x}} \mathrm{Ag}_{\mathrm{x}}(\mathrm{SR})_{84}$, $\mathrm{Au}_{144}(\mathrm{SR})_{60}, \quad \mathrm{Au}_{68}(\mathrm{SR})_{36}, \mathrm{Au}_{30}(\mathrm{SR})_{18}, \quad \mathrm{Au}_{102}(\mathrm{SPh})_{44}, \mathrm{Au}_{38}(\mathrm{SPh})_{24}$, $\mathrm{Au}_{38}\left(\mathrm{SC}_{2} \mathrm{H}_{4} \mathrm{Ph}\right)_{24}, \quad \mathrm{Au}_{21} \mathrm{~S}(\mathrm{SAdm})_{15}, \quad \mathrm{Au}_{36}(\mathrm{pMBA})_{24} \quad$ and $\mathrm{Au}_{25}(\mathrm{pMBA})_{18}$ Nano Clusters, J Surgery Emerg Med 1: 21.

[75] Heidari, A. (2017). Developmental Cell Biology in Adult Stem Cells Death and Autophagy to Trigger a Preventive Allergic Reaction to Common Airborne Allergens under Synchrotron Radiation Using Nanotechnology for Therapeutic Goals in Particular Allergy Shots (Immunotherapy), Cell Biol (Henderson, NV) 6: 1

[76] Heidari, A. (2017). Changing Metal Powder Characteristics for Elimination of the Heavy Metals Toxicity and Diseases in Disruption of Extracellular Matrix (ECM) Proteins Adjustment in Cancer Metastases Induced by Osteosarcoma, Chondrosarcoma, Carcinoid, Carcinoma, Ewing's Sarcoma, Fibrosarcoma and Secondary Hema- topoietic Solid or Soft Tissue Tumors, J Powder Metall Min 6: 170. https://doi.org/10.4172/2168-9806.1000170.

[77] Heidari, A. (2017). Nanomedicine-Based Combination AntiCancer Therapy between Nucleic Acids and Anti-Cancer Nano Drugs in Covalent Nano Drugs Delivery Systems for Selective Imaging and Treatment of Human Brain Tumors Using Hyaluronic Acid, Alguronic Acid and Sodium Hyaluronate as Anti-Cancer Nano Drugs and Nucleic Acids Delivery under Synchrotron Radiation, Am J Drug Deliv 5: 2. https://doi.org/10.21767/2321547X.1000016

[78] Heidari, A. (2017). Clinical Trials of Dendritic Cell Therapies for Cancer Exposing Vulnerabilities in Human Cancer Cells' Metabolism and Metabolomics: New Discoveries, Unique Features Inform New Therapeutic Opportunities, Biotech's Bumpy Road to the Market and Elucidating the Biochemical Programs that Support Cancer Initiation and Progression, J Biol Med Science 1: e103.

[79] Heidari, A. (2017). The Design Graphene-Based Nanosheets as a New Nanomaterial in Anti-Cancer Therapy and Delivery of Chemotherapeutics and Biological Nano Drugs for Liposomal Anti-Cancer Nano Drugs and Gene Delivery, Br Biomed Bull 5: 305.

[80] Heidari, A. (2017). Integrative Approach to Biological Networks for Emerging Roles of Proteomics, Genomics and Transcriptomics in the Discovery and Validation of Human Colorectal Cancer Biomarkers from DNA/RNA Sequencing Data under Synchrotron Radiation, Transcriptomics 5: e117. https://doi.org/10.4172/2329. 8936.1000e117.

[81] Heidari, A. (2017). Elimination of the Heavy Metals Toxicity and Diseases in Disruption of Extracellular Matrix (ECM) Proteins and Cell Adhesion Intelligent Nanomolecules Adjustment in Cancer Metastases Using Metalloenzymes and under Synchrotron Radiation, Lett Health Biol Sci 2 (2): 1-4. https://doi.org/10.15436/24756245.17.019.

[82] Heidari, A. (2017). Treatment of Breast Cancer Brain Metastases through a Targeted Nanomolecule Drug Delivery System Based on Dopamine Functionalized Multi-Wall Carbon Nanotubes (MWCNTs) Coated with Nano Graphene Oxide (GO) and Protonated Polyaniline (PANI) in Situ During the Polymerization of Aniline Autogenic Nanoparticles for the Delivery of Anti-Cancer Nano Drugs under Synchrotron Radiation, Br J Res, 4(3): 16. https://doi.org/10.21767/2394-3718.100016.

[83] Heidari, A. (2017). Sedative, Analgesic and Ultrasound-Mediated Gastrointestinal Nano Drugs Delivery for Gastrointestinal Endoscopic Procedure, Nano Drug-Induced Gastrointestinal Disorders and Nano Drug Treatment of Gastric Acidity, Res Rep Gastroenterol, $1: 1$.

[84] Heidari, A. (2017). Synthesis, Pharmacokinetics, Pharmacodynamics, Dosing, Stability, Safety and Efficacy of Orphan Nano Drugs to Treat High Cholesterol and Related Conditions and to Prevent Cardiovascular Disease under Synchrotron Radiation, J Pharm Sci Emerg Drugs 5: 1. https://doi.org/10.4172/23809477.1000e104.

[85] Heidari, A. (2017). Non-Linear Compact Proton Synchrotrons to Improve Human Cancer Cells and Tissues Treatments and Diagnostics through Particle Therapy Accelerators with Monochromatic Microbeams, J Cell Biol Mol Sci 2(1): 1-5.

[86] Heidari, A. (2017). Design of Targeted Metal Chelation Therapeutics Nanocapsules as Colloidal Carriers and Blood-Brain Barrier (BBB) Translocation to Targeted Deliver Anti-Cancer Nano Drugs into the Human Brain to Treat Alzheimer's Disease under Synchrotron Radiation, J Nanotechnol Material Sci 4(2): 1-5.

[87] Gobato, R., Heidari, A. (2017). Calculations Using Quantum Chemistry for Inorganic Molecule Simulation $\mathrm{BeLi}_{2} \mathrm{SeSi}$, American Journal of Quantum Chemistry and Molecular Spectroscopy, Vol. 2, No. 3, Pages 37-46.

[88] Heidari, (2017). A. Different High-Resolution Simulations of Medical, Medicinal, Clinical, Pharmaceutical and Therapeutics Oncology of Human Lung Cancer Translational Anti-Cancer Nano Drugs Delivery Treatment Process under Synchrotron and X-Ray Radiations, J Med Oncol. Vol. 1 No. 1: 1.

[89] Heidari, A. (2017). A Modern Ethnomedicinal Technique for Transformation, Prevention and Treatment of Human Malignant Gliomas Tumors into Human Benign Gliomas Tumors under Synchrotron Radiation, Am J Ethnomed, Vol. 4 No. 1: 10. https://doi.org/10.21767/2348-9502.100010.

[90] Heidari, A. (2014). An Investigation of the Role of DNA as Molecular Computers: A Computational Study on the Hamiltonian Path Problem, International Journal of Scientific \& Engineering Research, Vol. 5, Issue 1, Pages 1884-1889.

[91] Heidari, A. (2017). Active Targeted Nanoparticles for Anti-Cancer Nano Drugs Delivery across the Blood-Brain Barrier for Human 
Brain Cancer Treatment, Multiple Sclerosis (MS) and Alzheimer's Diseases Using Chemical Modifications of Anti-Cancer Nano Drugs or Drug-Nanoparticles through Zika Virus (ZIKV) Nanocarriers under Synchrotron Radiation, J Med Chem Toxicol, 2(3): 1-5. https://doi.org/10.15436/2575-808X.17.1594.

[92] Heidari, A. (2017). Investigation of Medical, Medicinal, Clinical and Pharmaceutical Applications of Estradiol, Mestranol (Norlutin), Norethindrone (NET), Norethisterone Acetate (NETA), Norethisterone Enanthate (NETE) and Testosterone Nanoparticles as Biological Imaging, Cell Labeling, Anti-Microbial Agents and Anti-Cancer Nano Drugs in Nanomedicines Based Drug Delivery Systems for Anti-Cancer Targeting and Treatment, Parana Journal of Science and Education (PJSE)-V.3, n.4, (10-19) October 12.

[93] Heidari, A. (2017). A Comparative Computational and Experimental Study on Different Vibrational Biospectroscopy Methods, Techniques and Applications for Human Cancer Cells in Tumor Tissues Simulation, Modeling, Research, Diagnosis and Treatment, Open J Anal Bioanal Chem 1(1): 014-020.

[94] Heidari, A. (2017). Combination of DNA/RNA Ligands and Linear/Non-Linear Visible-Synchrotron Radiation-Driven N-Doped Ordered Mesoporous Cadmium Oxide (CdO) Nanoparticles Photocatalysts Channels Resulted in an Interesting Synergistic Effect Enhancing Catalytic Anti-Cancer Activity, Enz Eng 6: 1.

[95] Heidari, A. (2017). Modern Approaches in Designing Ferritin, Ferritin Light Chain, Transferrin, Beta-2 Transferrin and Bacterioferritin-Based Anti-Cancer Nano Drugs Encapsulating Nanosphere as DNA-Binding Proteins from Starved Cells (DPS), Mod Appro Drug Des. 1(1). MADD.000504.

[96] Heidari, A. (2017). Potency of Human Interferon $\beta-1 \mathrm{a}$ and Human Interferon $\beta-1 b$ in Enzymotherapy, Immunotherapy, Chemotherapy, Radiotherapy, Hormone Therapy and Targeted Therapy of Encephalomyelitis Disseminate/Multiple Sclerosis (MS) and Hepatitis A, B, C, D, E, F and G Virus Enter and Targets Liver Cells, J Pro-

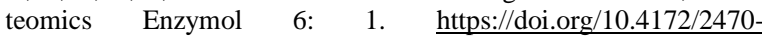
1289.1000e109.

[97] Heidari, A. (2017). Transport Therapeutic Active Targeting of Human Brain Tumors Enable Anti-Cancer Nanodrugs Delivery across the Blood-Brain Barrier (BBB) to Treat Brain Diseases Using Nanoparticles and Nanocarriers under Synchrotron Radiation, J Pharm Pharmaceutics 4(2): 1-5.

[98] Heidari, A., Brown, C. (2017). Combinatorial Therapeutic Approaches to DNA/RNA and Benzylpenicillin (Penicillin G), Fluoxetine Hydrochloride (Prozac and Sarafem), Propofol (Diprivan), Acetylsalicylic Acid (ASA) (Aspirin), Naproxen Sodium (Aleve and Naprosyn) and Dextromethamphetamine Nanocapsules with Surface Conjugated DNA/RNA to Targeted Nano Drugs for Enhanced Anti-Cancer Efficacy and Targeted Cancer Therapy Using Nano Drugs Delivery Systems, Ann Adv Chem. 1(2): 061-069.

[99] Heidari, A. (2016). Vibrational Spectroscopy of Nucleic Acids, Wahid Ali Khan (Editor), Basic Biochemistry, Austin Publishing Group (APG)/Austin Publications LLC, ISBN: 978-0-9971499-20, Pages 1-18, Jersey City, New Jersey, USA.

[100] Heidari, A. (2017). High-Resolution Simulations of Human Brain Cancer Translational Nano Drugs Delivery Treatment Process under Synchrotron Radiation, J Transl Res 1(1): 1-3.

[101] Bastogne, T. (2017). Quality-by-design of nanopharmaceuticals - a state of the art, Nanomedicine: Nanotechnology, Biology and Medicine, ISSN https://doi.org/10.1016/j.nano.2017.05.014.

[102] Vanić, Ž. Škalko-Basnet, N. (2013). Nanopharmaceuticals for improved topical vaginal therapy: Can they deliver?, European Journal of Pharmaceutical Sciences, Volume 50, Issue 1, Pages 2941, ISSN 0928-0987, https://doi.org/10.1016/j.ejps.2013.04.035

[103] Islan, G. A., Durán, M., Cacicedo, M. L., Nakazato, G., Kobayashi, R. K. T., Martinez, D. S. T., Castro, G. R., Durán, N. (2017). Nanopharmaceuticals as a solution to neglected diseases: Is it possible?, Acta Tropica, Volume 170, Pages 16-42, ISSN 0001-706X, https://doi.org/10.1016/j.actatropica.2017.02.019.

[104] Bawarski, W. E., Chidlowsky, E., Bharali, D. J., Mousa, S. A. (2008). Emerging nanopharmaceuticals, Nanomedicine: Nanotechnology, Biology and Medicine, Volume 4, Issue 4, Pages 273-282, ISSN 1549-9634, https://doi.org/10.1016/j.nano.2008.06.002.

[105] Eaton, M. A. W. (2011). How do we develop nanopharmaceuticals under open innovation?, Nanomedicine: Nanotechnology, Biology and Medicine, Volume 7, Issue 4, Pages 371-375, ISSN 1549-9634, https://doi.org/10.1016/j.nano.2011.05.015.

[106] Hadinoto, K., Yang, Y. (2014). Continuous and sustainable granulation of nanopharmaceuticals by spray coagulation encapsulation in alginate, International Journal of Pharmaceutics, Volume
473, Issue 1, Pages 644-652, ISSN 0378-5173, https://doi.org/10.1016/j.ijpharm.2014.07.042.

[107] Svenson, S., Wolfgang, M., Hwang, J., Ryan, J., Eliasof, S (2011). Preclinical to clinical development of the novel camptothecin nanopharmaceutical CRLX101, Journal of Controlled Release, Volume 153, Issue 1, Pages 49-55, ISSN 0168-3659, https://doi.org/10.1016/j.jconrel.2011.03.007.

[108] Sosnik, A. (2013). Reversal of multidrug resistance by the inhibition of ATP-binding cassette pumps employing Generally Recognized As Safe (GRAS) nanopharmaceuticals: A review, Advanced Drug Delivery Reviews, Volume 65, Issue 13, Pages 1828-1851, ISSN 0169-409X, https://doi.org/10.1016/j.addr.2013.09.002.

[109] Filipović-Grčić, J., Mrhar, A., Junginger, H. (2013). Thematic Issue on Emerging nanopharmaceuticals for non-parenteral application routes, European Journal of Pharmaceutical Sciences, Volume 50, Issue 1, Page 1, ISSN 0928-0987, https://doi.org/10.1016/j.ejps.2013.05.025.

[110] Yu, H., Hadinoto, K. (2015). Mitigating the adverse effect of spray drying on the supersaturation generation capability of amorphous nanopharmaceutical powders, Powder Technology, Volume 277, Pages 97-104, ISSN 0032-5910, https://doi.org/10.1016/j.powtec.2015.02.059.

[111] Moghimi, S. M., Farhangrazi, Z. S. (2013). Nanomedicine and the complement paradigm, Nanomedicine: Nanotechnology, Biology and Medicine, Volume 9, Issue 4, Pages 458-460, ISSN 15499634, https://doi.org/10.1016/j.nano.2013.02.011.

[112] Eliasof, S., Ng, P. S., Soo, P. L., Podobinski, J., Case, R. I., Shum, P., Martinez, J. G., Kabir, S. R., Lazarus, D., Svenson, S. (2010). 425 Significantly enhanced therapeutic profile of docetaxel in novel nanopharmaceutical CRLX288, European Journal of Cancer Supplements, Volume 8, Issue 7, Page 135, ISSN 1359-6349, https://doi.org/10.1016/S1359-6349(10)72132-7.

[113] Domingo, C., Saurina, J. (2012). An overview of the analytical characterization of nanostructured drug delivery systems: Towards green and sustainable pharmaceuticals: A review, Analytica Chimica Acta, Volume 744, Pages 8-22, ISSN 0003-2670, https://doi.org/10.1016/j.aca.2012.07.010

[114] Samadder, A., Abraham, S. K., Khuda-Bukhsh, A. R. (2016) Nanopharmaceutical approach using pelargonidin towards enhancement of efficacy for prevention of alloxan-induced DNA damage in L6 cells via activation of PARP and p53, Environmental Toxicology and Pharmacology, Volume 43, Pages 27-37, ISSN 1382-6689, https://doi.org/10.1016/j.etap.2016.02.010.

[115] Yen, Y., Synold, T., Weiss, G. J., Schluep, T., Ryan, J. (2010). 423 Phase 1 dose escalation, safety and pharmacokinetic study of IT-101 (CRLX101), a novel nanopharmaceutical containing camptothecin, in advanced solid tumor cancer patients, European Journa of Cancer Supplements, Volume 8, Issue 7, Pages 134-135, ISSN 1359-6349, https://doi.org/10.1016/S1359-6349(10)72130-3.

[116] Azmi, I. D. M., Wibroe, P. P., Wu, L. P., Kazem, A. I., Amenitsch, H., Moghimi, S. M., Yaghmur, A. (2016). A structurally diverse library of safe-by-design citrem-phospholipid lamellar and non-lamellar liquid crystalline nano-assemblies, Journal of Controlled Release, Volume 239, Pages 1-9, ISSN 0168-3659, https://doi.org/10.1016/j.jconrel.2016.08.011.

[117] Li, J., Wang, Y., Liang, R., an, X., Wang, K., Shen, G., Tu, Y., Zhu, J., Tao, J. (2015). Recent advances in targeted nanoparticles drug delivery to melanoma, Nanomedicine: Nanotechnology, Biology and Medicine, Volume 11, Issue 3, Pages 769-794, ISSN 15499634, https://doi.org/10.1016/j.nano.2014.11.006.

[118] Liu, J., Zhao, Y., Guo, Q., Wang, Z., Wang, H., Yang, Y., Huang, Y. (2012). TAT-modified nanosilver for combating multidrug-resistant cancer, Biomaterials, Volume 33, Issue 26, Pages 6155-6161 ISSN

0142-9612 https://doi.org/10.1016/j.biomaterials.2012.05.035.

[119] Gabellieri, C., Frima, H. (2011). Nanomedicine in the European Commission policy for nanotechnology, Nanomedicine: Nanotechnology, Biology and Medicine, Volume 7, Issue 5, Pages 519-520, ISSN 1549-9634, https://doi.org/10.1016/j.nano.2011.07.003.

[120] Frederickson, R. M., Moghimi, S. M., Wagner, E., YlaHerttuala, S. (2016). Call for papers: Nanoparticle Development and Applications in Cellular and Molecular Therapies, Molecular Therapy, Volume 24, Issue 8, Pages 1334-1335, ISSN 1525-0016, https://doi.org/10.1038/mt.2016.164.

[121] Namdari, M., Eatemadi, A., Soleimaninejad, M., Hammed, A. T., (2017). A brief review on the application of nanoparticle enclosed herbal medicine for the treatment of infective endocarditis, Biomedicine \& Pharmacotherapy, Volume 87, Pages 321-331, ISSN 0753-3322, https://doi.org/10.1016/j.biopha.2016.12.099. 
[122] Kiew, T. Y., Cheow, W. S., Hadinoto, K. (2015). Preserving the supersaturation generation capability of amorphous drugpolysaccharide nanoparticle complex after freeze-drying, International Journal of Pharmaceutics, Volume 484, Issue 1, Pages 115 123 , ISSN https://doi.org/10.1016/j.ijpharm.2015.02.057.

0378-5173,

[123] Moghimi, S. M., Wibroe, P. P., Helvig, S. Y., Farhangrazi, Z. S., Hunter, A. C. (2012). Genomic perspectives in inter-individual adverse responses following nanomedicine administration: The way forward, Advanced Drug Delivery Reviews, Volume 64, Issue 13, Pages 1385-1393, ISSN 0169-409X https://doi.org/10.1016/j.addr.2012.05.010.

[124] Gil, P. R., Hühn, D., Del Mercato, L. L., Sasse, D., Parak, W. J. (2010). Nanopharmacy: Inorganic nanoscale devices as vectors and active compounds, Pharmacological Research, Volume 62, Issue 2, Pages 115-125, ISSN 1043-6618, https://doi.org/10.1016/j.phrs.2010.01.009.

[125] Rzigalinski, B. A., Strobl, J. S. (2009). Cadmium-containing nanoparticles: Perspectives on pharmacology and toxicology of quantum dots, Toxicology and Applied Pharmacology, Volume 238, Issue 3, Pages 280-288, ISSN 0041-008X, https://doi.org/10.1016/j.taap.2009.04.010.

[126] Fako, V. E., Furgeson, D. Y. (2009). Zebrafish as a correlative and predictive model for assessing biomaterial nanotoxicity, Advanced Drug Delivery Reviews, Volume 61, Issue 6, Pages 478486, ISSN 0169-409X, https://doi.org/10.1016/j.addr.2009.03.008.

[127] Sainz, V., Conniot, J., Matos, A. I., Peres, C., Zupanǒiǒ, E., Moura, L., Silva, L. C., Florindo, H. F., Gaspar, R. S. (2015). Regulatory aspects on nanomedicines, Biochemical and Biophysical Research Communications, Volume 468, Issue 3, Pages 504-510, ISSN 0006-291X, https://doi.org/10.1016/j.bbrc.2015.08.023.

[128] Duncan, R., Vicent, M. J., (2010). Do HPMA copolymer conjugates have a future as clinically useful nanomedicines? A critical overview of current status and future opportunities, Advanced Drug Delivery Reviews, Volume 62, Issue 2, Pages 272-282, ISSN 0169409X, https://doi.org/10.1016/j.addr.2009.12.005.

[129] Zhou, X., Che, L., Wei, Y., Dou, Y., Chen, S., He, H., Gong, H., Li, X., Zhang, J. (2014). Facile route to versatile nanoplatforms for drug delivery by one-pot self-assembly, Acta Biomaterialia, Volume 10, Issue 6, Pages 2630-2642, ISSN 1742-7061, https://doi.org/10.1016/j.actbio.2014.01.024.

[130] Wibroe, P. P., Ahmadvand, D., Oghabian, M. A., Yaghmur, A., Moghimi, S. M. (2016). An integrated assessment of morphology, size, and complement activation of the PEGylated liposomal doxorubicin products Doxil®, Caelyx $®$, DOXOrubicin, and SinaDoxosome, Journal of Controlled Release, Volume 221, Pages 1-8, ISSN 0168-3659, https://doi.org/10.1016/j.jconrel.2015.11.021.

[131] Nguyen, M. H., Yu, H., Dong, B., Hadinoto, K. (2016). A supersaturating delivery system of silibinin exhibiting high payload achieved by amorphous nano-complexation with chitosan, European Journal of Pharmaceutical Sciences, Volume 89, Pages 163-171, ISSN 0928-0987, https://doi.org/10.1016/j.ejps.2016.04.036.

[132] Special Issue Title Page, Biotechnology Advances, Volume 32, Issue 4, 2014, Page iii, ISSN 0734-9750, https://doi.org/10.1016/S0734-9750(14)00084-6.

[133] Beija, M., Salvayre, R., Viguerie, N. L., Marty, J. D. (2012) Colloidal systems for drug delivery: from design to therapy, Trends in Biotechnology, Volume 30, Issue 9, Pages 485-496, ISSN 0167. 7799, https://doi.org/10.1016/j.tibtech.2012.04.008

[134] Vaishali, A., Varma, K. M., Bhupathi, P. A., Bharath, T. S. Ramesh, M. V., Varma, P. V. K. (2017). In vitro evaluation of antimicrobial efficacy of $2 \%$ chlorhexidine loaded electrospun nanofibers, Journal of Pierre Fauchard Academy (India Section), ISSN 0970-2199, https://doi.org/10.1016/j.jpfa.2017.01.006.

[135] Bawa, R. (2009). NanoBiotech 2008: Exploring global advances in nanomedicine, Nanomedicine: Nanotechnology, Biology and Medicine, Volume 5, Issue 1, Pages 5-7, ISSN 1549-9634, https://doi.org/10.1016/j.nano.2009.01.004

[136] Marianecci, C., Petralito, S., Rinaldi, F., Hanieh, P. N., Carafa, M. (2016). Some recent advances on liposomal and niosomal vesicular carriers, Journal of Drug Delivery Science and Technology, Volume 32, Pages 256-269, ISSN 1773-2247, https://doi.org/10.1016/j.jddst.2015.10.008

[137] Patil, S., Chaudhari, K., Kamble, R. (2017). Electrospray technique for cocrystallization of phytomolecules, Journal of King Saud University - $\quad$ Science, ISSN 1018-3647, https://doi.org/10.1016/j.jksus.2017.04.001.

[138] Fonseca, N. A., Gregório, A. C., Valério-Fernandes, Â., Simões, S., Moreira, J. N. (2014). Bridging cancer biology and the patients' needs with nanotechnology-based approaches, Cancer
Treatment Reviews, Volume 40, Issue 5, Pages 626-635, ISSN 0305-7372, https://doi.org/10.1016/j.ctrv.2014.02.002.

[139] Bedi, D., Musacchio, T., Fagbohun, O. A., Gillespie, J. W., Deinnocentes, P., Bird, R. C., Bookbinder, L., Torchilin, V. P., Petrenko, V. A. (2011). Delivery of siRNA into breast cancer cells via phage fusion protein-targeted liposomes, Nanomedicine: Nanotechnology, Biology and Medicine, Volume 7, Issue 3, Pages 315323, ISSN 1549-9634, https://doi.org/10.1016/j.nano.2010.10.004.

[140] Canal, F., Sanchis, J., Vicent, M. J. (2011). Polymer-drug conjugates as nano-sized medicines, Current Opinion in Biotechnology, Volume 22, Issue 6, Pages 894-900, ISSN 0958-1669, http://dx.doi.org/10.1016/j.copbio.2011.06.003.

[141] Hügel, H. M., Jackson, N. (2014). Danshen diversity defeating dementia, Bioorganic \& Medicinal Chemistry Letters, Volume 24, Issue 3, Pages 708-716, ISSN 0960-894X, http://dx.doi.org/10.1016/j.bmcl.2013.12.042.

[142] Special Issue title page, European Journal of Pharmaceutics and Biopharmaceutics, Volume 79, Issue 1, Page v, ISSN 0939-6411, http://dx.doi.org/10.1016/S0939-6411(11)00237-2.

[143] Donaldson, L. (2012). Designer nanoparticles to treat blood cancer, Materials Today, Volume 15, Issue 7, Page 298, ISSN 1369-7021, http://dx.doi.org/10.1016/S1369-7021(12)70128-1.

[144] Graphical Abstracts, Journal of Fluorine Chemistry, Volume 198, 2017, Pages v-viii, ISSN 0022-1139, http://dx.doi.org/10.1016/S0022-1139(17)30214-2.

[145] Bose, R. J. C., Lee, S. H., Park, H. (2016). Biofunctionalized nanoparticles: an emerging drug delivery platform for various disease treatments, Drug Discovery Today, Volume 21, Issue 8, Pages 1303-1312 ISSN 1359-6446, http://dx.doi.org/10.1016/j.drudis.2016.06.005.

[146] Hall, A., Lächelt, U., Bartek, J., Wagner, E., Moghimi, S. M. (2017). Polyplex Evolution: Understanding Biology, Optimizing Performance, Molecular Therapy, Volume 25, Issue 7, Pages 14761490 ISSN http://dx.doi.org/10.1016/j.ymthe.2017.01.024.

[147] Storm, G. (2012). Preface, European Journal of Pharmaceutical Sciences, Volume 45, Issue 4, Page 387, ISSN 0928-0987, http://dx.doi.org/10.1016/j.ejps.2011.11.001.

[148] Table of Contents, Acta Pharmaceutica Sinica B, Volume 7, Issue 3, 2017, Pages iii-vii, ISSN 2211-3835, http://dx.doi.org/10.1016/S2211-3835(17)30142-9.

[149] Du Toit, L. C., Pillay, V., Choonara, Y. E. (2010). Nanomicrobicides: Challenges in drug delivery, patient ethics and intellectual property in the war against HIV/AIDS, Advanced Drug Delivery Reviews, Volume 62, Issue 4, Pages 532-546, ISSN 0169409X, http://dx.doi.org/10.1016/j.addr.2009.11.022.

[150] Kumar, B., Angulo, Y., Smita, K., Cumbal, L., Debut, A. (2016). Capuli cherry-mediated green synthesis of silver nanoparticles under white solar and blue LED light, Particuology, Volume 24, Pages 123-128, ISSN 1674-2001, http://dx.doi.org/10.1016/j.partic.2015.05.005.

[151] Rajabi, M., Sudha, T., Darwish, N. H. E., Davis, P. J., Mousa, S. A. (2016). Synthesis of MR-49, a deiodinated analog of tetraiodothyroacetic acid (tetrac), as a novel pro-angiogenesis modulator, Bioorganic \& Medicinal Chemistry Letters, Volume 26, Issue 16, Pages 4112-4116, ISSN 0960-894X, http://dx.doi.org/10.1016/j.bmcl.2016.06.064.

[152] Andersen, A. J., Wibroe, P. P., Moghimi, S. M. (2012). Perspectives on carbon nanotube-mediated adverse immune effects, Advanced Drug Delivery Reviews, Volume 64, Issue 15, Pages 1700-1705, ISSN 0169-409X http://dx.doi.org/10.1016/j.addr.2012.05.005.

[153] Subject Index Volume 153, Journal of Controlled Release, Volume 153, Issue 3, 2011, Pages e8-e9, ISSN 0168-3659, http://dx.doi.org/10.1016/S0168-3659(11)00517-7.

[154] Kabanov, A., Bronich, T. (2011). Eighth International Nanomedicine and Drug Delivery Symposium (NanoDDS'10), Journal of Controlled Release, Volume 153, Issue 1, Page 1, ISSN 0168-3659, http://dx.doi.org/10.1016/j.jconrel.2011.06.002.

[155] Nagy, Z. K., Balogh, A., Démuth, B., Pataki, H., Vigh, T., Szabó, B., Molnár, K., Schmidt, B. T., Horák, P., Marosi, G., Verreck, G., Assche, I. V., Brewster, M. E. (2015). High speed electrospinning for scaled-up production of amorphous solid dispersion of itraconazole, International Journal of Pharmaceutics, Volume 480 , Issue 1, Pages 137-142, ISSN 0378-5173, http://dx.doi.org/10.1016/j.ijpharm.2015.01.025.

[156] Nickols-Richardson, S. M. (2007). Nanotechnology: Implications for Food and Nutrition Professionals, Journal of the American Dietetic Association, Volume 107, Issue 9, Pages 1494-1497, ISSN 0002-8223, http://dx.doi.org/10.1016/j.jada.2007.06.016. 
[157] Gaspar, R., Duncan, R. (2009). Polymeric carriers: Preclinical safety and the regulatory implications for design and development of polymer therapeutics, Advanced Drug Delivery Reviews, Volume 61, Issue 13, Pages 1220-1231, ISSN 0169-409X, http://dx.doi.org/10.1016/j.addr.2009.06.003.

[158] Graphical Abstracts Contents Listing, Journal of Controlled Release, Volume 153, Issue 1, 2011, Pages e1-e4, ISSN 0168-3659, http://dx.doi.org/10.1016/S0168-3659(11)00428-7.

[159] Bourlinos, A. B., Georgakilas, V., Bakandritsos, A., Kouloumpis, A., Gournis, D., Zboril, R. (2012). Aqueous-dispersible fullerol-carbon nanotube hybrids, Materials Letters, Volume 82, Pages 48-50, ISSN 0167-577X, http://dx.doi.org/10.1016/j.matlet.2012.05.026.

[160] Recommended Articles, Journal of Acupuncture and Meridian Studies, Volume 9, Issue 6, 2016, Pages 345-348, ISSN 2005-2901, http://dx.doi.org/10.1016/j.jams.2016.12.001.

[161] Svenson, S. (2012). Clinical translation of nanomedicines, Current Opinion in Solid State and Materials Science, Volume 16, Issue 6, Pages 287-294, ISSN 1359-0286, http://dx.doi.org/10.1016/j.cossms.2012.10.001.

[162] Sitterberg, J., Özcetin, A., Ehrhardt, C., Bakowsky, U. (2010) Utilising atomic force microscopy for the characterisation of nanoscale drug delivery systems, European Journal of Pharmaceutics and Biopharmaceutics, Volume 74, Issue 1, Pages 2-13, ISSN 0939-6411, http://dx.doi.org/10.1016/j.ejpb.2009.09.005.

[163] Telford, M. (2005). Cancer centers founded, Materials Today, Volume 8, Issue 12, Page 19, ISSN 1369-7021, http://dx.doi.org/10.1016/S1369-7021(05)71277-3.

[164] Alibolandi, M., Sadeghi, F., Abnous, K., Atyabi, F., Ramezani, M., Hadizadeh, F. (2015). The chemotherapeutic potential of doxorubicin-loaded PEG-b-PLGA nanopolymersomes in mouse breast cancer model, European Journal of Pharmaceutics and Biopharmaceutics, Volume 94, Pages 521-531, ISSN 0939-6411, http://dx.doi.org/10.1016/j.ejpb.2015.07.005.

[165] Bridoux, A., Cui, H., Dyskin, E., Yalcin, M., Mousa, S. A. (2009). Semisynthesis and pharmacological activities of Tetrac analogs: Angiogenesis modulators, Bioorganic \& Medicinal Chemistry Letters, Volume 19, Issue 12, Pages 3259-3263, ISSN 0960-894X, http://dx.doi.org/10.1016/j.bmcl.2009.04.094

[166] Stuurman, F. E., Voest, E. E., Awada, A., Schellens, J. H. M., Witteveen, P. O., Bergeland, T., Hals, P. A., Hendlisz, A. (2010). 426 Phase I study of oral CP-4126, a gemcitabine analog, in patients with advanced solid tumours, European Journal of Cancer Supplements, Volume 8, Issue 7, Page 135, ISSN 1359-6349, http://dx.doi.org/10.1016/S1359-6349(10)72133-9.

[167] Kondo, E. (2010). 424 Development of novel cancer cellselective cell-penetrating peptides for the advanced peptide-based drug delivery system, European Journal of Cancer Supplements, Volume 8, Issue 7, Page 135, ISSN 1359-6349, http://dx.doi.org/10.1016/S1359-6349(10)72131-5.

[168] Recommended Articles, Journal of Acupuncture and Meridian Studies, Volume 9, Issue 5, 2016, Pages 281-284, ISSN 2005-2901, http://dx.doi.org/10.1016/j.jams.2016.10.002.

[169] Jindal, A. B., Bachhav, S. S., Devarajan, P. V. (2017). Hybrid nano drug delivery system (IHN-DDS) of antiretroviral drug for simultaneous targeting to multiple viral reservoirs: An proof of concept, International Journal of Pharmaceutics, Volume 521, Issue 1, Pages 196-203, ISSN 0378-5173, http://dx.doi.org/10.1016/j.ijpharm.2017.02.024.

[170] Rapoport, N. (2007). Physical stimuli-responsive polymeric micelles for anti-cancer drug delivery, Progress in Polymer Science, Volume 32, Issue 8, Pages 962-990, ISSN 0079-6700, http://dx.doi.org/10.1016/j.progpolymsci.2007.05.009.

[171] Fernández, L. Á. (2011). Muyldermans, S. Recent developments in engineering and delivery of protein and antibody therapeutics, Current Opinion in Biotechnology, Volume 22, Issue 6, Pages 839-842, ISSN

0958-1669, http://dx.doi.org/10.1016/j.copbio.2011.08.001.

[172] Pippa, N., Dokoumetzidis, A., Demetzos, C., Macheras, P. (2013). On the ubiquitous presence of fractals and fractal concepts in pharmaceutical sciences: A review, International Journal of Pharmaceutics, Volume 456, Issue 2, Pages 340-352, ISSN 03785173, http://dx.doi.org/10.1016/j.ijpharm.2013.08.087.

[173] Verreault, M., Strutt, D., Masin, D., Anantha, M., Waterhouse, D., Yapp, D. T., Bally, M. B. (2012). Irinophore C ${ }^{\mathrm{TM}}$, a lipid-based nanoparticulate formulation of irinotecan, is more effective than free irinotecan when used to treat an orthotopic glioblastoma model, Journal of Controlled Release, Volume 158, Issue 1, Pages 34 43, ISSN 0168-3659, http://dx.doi.org/10.1016/j.jconrel.2011.09.095.
[174] Hassanzadeh, P., Atyabi, F., Dinarvand, R. (2017). Application of modelling and nanotechnology-based approaches: The emergence of breakthroughs in theranostics of central nervous system disorders, Life Sciences, Volume 182, Pages 93-103, ISSN 00243205, http://dx.doi.org/10.1016/j.lfs.2017.06.001

[175] Sivanesan, S., Tan, A., Jeyaraj, R., Lam, J., Gole, M., Hardan, A., Ashkan, K., Rajadas, J. (2017). Pharmaceuticals and Stem Cells in Autism Spectrum Disorders: Wishful Thinking?, World Neurosurgery, Volume 98, Pages 659-672, ISSN 1878-8750, http://dx.doi.org/10.1016/j.wneu.2016.09.100.

[176] Phillips, R., Makeen, H., Periasamy, N., Loadman, P., Smye, S., Sleeman, B., Jones, P., Evans, C., Twelves, C. (2010). 427 The development and evaluation of an experimental model for assessing convective fluid flow through multicell layers, European Journal of Cancer Supplements, Volume 8, Issue 7, Pages 135-136, ISSN 1359-6349, http://dx.doi.org/10.1016/S1359-6349(10)72134-0.

[177] Varan, G., Varan, C., Erdoğar, N., Hıncal, A. A., Bilensoy, E. (2017). Amphiphilic cyclodextrin nanoparticles, International Journal of Pharmaceutics, ISSN 0378-5173, http://dx.doi.org/10.1016/j.ijpharm.2017.06.010.

[178] [Moghimi, S. M., Farhangrazi, Z. S. (2014). Just so stories: The random acts of anti-cancer nanomedicine performance, Nanomedicine: Nanotechnology, Biology and Medicine, Volume 10, Issue 8 , Pages 1661-1666, ISSN $1549-9634$ http://dx.doi.org/10.1016/j.nano.2014.04.011

[179] Soria, J.C., Gomez-Roca, C.A., Ware, J.A., Adjei, A.A., Brachmann, R.K., Groen, H.J.M. (2010). 421 A Phase Ib study to evaluate the pan-PI3K inhibitor GDC-0941 with paclitaxel and carboplatin with and without bevacizumab in non-small cell lung cancer patients, European Journal of Cancer Supplements, Volume 8, Issue 7, Page 134, ISSN 1359-6349, http://dx.doi.org/10.1016/S1359-6349(10)72128-5.

[180] McMurray, J., Klostergaard, J., Auzenne, E.J., Liao, W.S.L., Lu, Z., Mandal, P.K., Ramesh, R., Shanker, M., Scott, A.W. (2010). 422 Targeting the SH2 domain of Stat 3 with phosphopeptide mimetic prodrugs leads to tumor growth inhibition and downregulation of phosphoTyr705 Stat3 and angiogenic pathways, European Journal of Cancer Supplements, Volume 8, Issue 7, Page 134, ISSN 1359-6349, http://dx.doi.org/10.1016/S13596349(10)72129-7.

[181] Sans-Serramitjana, E., Fusté, E., Martínez-Garriga, B., Merlos, A., Pastor, M., Pedraz, J.L., Esquisabel, A., Bachiller, D., Vinuesa, T., Viñas, M. (2016). Killing effect of nanoencapsulated colistin sulfate on from cystic fibrosis patients, Journal of Cystic Fibrosis, Volume 15, Issue 5, Pages 611-618, ISSN 1569-1993, http://dx.doi.org/10.1016/j.jcf.2015.12.005.

[182] Rigo, L. A., Carvalho-Wodarz, C. S., Pohlmann, A. R., Guterres, S. S., Schneider-Daum, N., Lehr, C. M., Beck, R. C. R. (2017). Nanoencapsulation of a glucocorticoid improves barrier function and anti-inflammatory effect on monolayers of pulmonary epithelial cell lines, European Journal of Pharmaceutics and Biopharmaceutics, Volume 119, Pages 1-10, ISSN 0939-6411, http://dx.doi.org/10.1016/j.ejpb.2017.05.006.

[183] Alibolandi, M., Taghdisi, S. M., Ramezani, P., Shamili, F. H., Farzad, S. A., Abnous, K., Ramezani, M. (2017). Smart AS1411aptamer conjugated pegylated PAMAM dendrimer for the superior delivery of camptothecin to colon adenocarcinoma and, International Journal of Pharmaceutics, Volume 519, Issue 1, Pages 352 364, ISSN 0378-5173, http://dx.doi.org/10.1016/j.ijpharm.2017.01.044.

[184] Bridoux, A., Cui, H., Dyskin, E., Schmitzer, A. R., Yalcin, M., Mousa, S. A. (2010). Semisynthesis and pharmacological activities of thyroxine analogs: Development of new angiogenesis modulators, Bioorganic \& Medicinal Chemistry Letters, Volume 20, Issue 11, Pages 3394-3398, ISSN 0960-894X, http://dx.doi.org/10.1016/j.bmcl.2010.04.011.

[185] Tutaj, K., Szlazak, R., Szalapata, K., Starzyk, J., Luchowski, R., Grudzinski, W., Osinska-Jaroszuk, M., Jarosz-Wilkolazka, A., Szuster-Ciesielska, A., Gruszecki, W. I. (2016). Amphotericin Bsilver hybrid nanoparticles: synthesis, properties and antifungal activity, Nanomedicine: Nanotechnology, Biology and Medicine, Volume 12, Issue 4, Pages 1095-1103, ISSN 1549-9634, http://dx.doi.org/10.1016/j.nano.2015.12.378

[186] Kuppusamy, P., Yusoff, M. M., Maniam, G. P., Govindan, N. (2013). A case study - Regulation and functional mechanisms of cancer cells and control its activity using plants and their derivatives, Journal of Pharmacy Research, Volume 6, Issue 8, Pages 884 892, ISSN 0974-6943, http://dx.doi.org/10.1016/j.jopr.2013.08.002.

[187] Tomalia, D. A. (2006). International report on nanomedicine in the U.S.A., Nanomedicine: Nanotechnology, Biology and Medi- 
cine, Volume 2, Issue 4, Page 299, ISSN 1549-9634, http://dx.doi.org/10.1016/j.nano.2006.10.098.

[188] Menjoge, A. R., Kannan, R. M., Tomalia, D. A. (2010). Dendrimer-based drug and imaging conjugates: design considerations for nanomedical applications, Drug Discovery Today, Volume 15, Issue 5, Pages 171-185, and ISSN 1359-6446, http://dx.doi.org/10.1016/j.drudis.2010.01.009.

[189] Vega-Villa, K. R., Takemoto, J. K., Yáñez, J. A., Remsberg, C. M., Forrest, M. L., Davies, N. M. (2008). Clinical toxicities of nanocarrier systems, Advanced Drug Delivery Reviews, Volume 60, Issue 8, Pages 929-938, ISSN 0169-409X, http://dx.doi.org/10.1016/j.addr.2007.11.007.

[190] Gaur, S., Wang, Y., Kretzner, L., Chen, L., Yen, T., Wu, X., Yuan, Y. C., Davis, M., Yen, Y. (2014). Pharmacodynamic and pharmacogenomic study of the nanoparticle conjugate of camptothecin CRLX101 for the treatment of cancer, Nanomedicine: Nanotechnology, Biology and Medicine, Volume 10, Issue 7, Pages 1477-1486, $\quad$ ISSN $1549-9634$ http://dx.doi.org/10.1016/j.nano.2014.04.003.

[191] Tietze, R., Zaloga, J., Unterweger, H., Lyer, S., Friedrich, R. P., Janko, C., Pöttler, M., Dürr, S., Alexiou, C. (2015). Magnetic nanoparticle-based drug delivery for cancer therapy, Biochemical and Biophysical Research Communications, Volume 468, Issue 3, Pages 463-470, ISSN 0006-291X, http://dx.doi.org/10.1016/j.bbrc.2015.08.022.

[192] Schwengber, A., Prado, H. J., Zilli, D. A., Bonelli, P. R., Cukierman, A. L. (2015). Carbon nanotubes buckypapers for potential transdermal drug delivery, Materials Science and Engineering: C, Volume 57, Pages 7-13, ISSN 0928-4931, http://dx.doi.org/10.1016/j.msec.2015.07.030.

[193] Adhikari, P., Pal, P., Das, A. K., Ray, S., Bhattacharjee, A., Mazumder, B. (2017). NANO LIPID-DRUG CONJUGATE: AN INTEGRATED REVIEW, International Journal of Pharmaceutics, ISSN 0378-5173, http://dx.doi.org/10.1016/j.ijpharm.2017.07.039.

[194] Szebeni, J., Storm, G. (2015). Complement activation as a bioequivalence issue relevant to the development of generic liposomes and other nanoparticulate drugs, Biochemical and Biophysical Research Communications, Volume 468, Issue 3, Pages 490-497, ISSN 0006-291X, http://dx.doi.org/10.1016/j.bbrc.2015.06.177.

[195] Chen, K., Guan, J. (2011). A bibliometric investigation of research performance in emerging nanobiopharmaceuticals, Journal of Informetrics, Volume 5, Issue 2, Pages 233-247, ISSN 17511577, http://dx.doi.org/10.1016/j.joi.2010.10.007.

[196] Requejo-Aguilar, R., Alastrue-Agudo, A., Cases-Villar, M., Lopez-Mocholi, E., England, R., Vicent, M. J., Moreno-Manzano, V. (2017). Combined polymer-curcumin conjugate and ependymal progenitor/stem cell treatment enhances spinal cord injury functional recovery, Biomaterials, Volume 113, Pages 18-30, ISSN 0142-9612, http://dx.doi.org/10.1016/j.biomaterials.2016.10.032.

[197] Golyshkin, D., Kobyliak, N., Virchenko, O., Falalyeyeva, T., Beregova, T., Ostapchenko, L., Caprnda, M., Skladany, L., Opatrilova, R., Rodrigo, L., Kruzliak, P., Shcherbokov, A., Spivak, M. (2016). Nanocrystalline cerium dioxide efficacy for prophylaxis of erosive and ulcerative lesions in the gastric mucosa of rats induced by stress, Biomedicine \& Pharmacotherapy, Volume 84, Pages 1383-1392, $\quad$ ISSN 0753-3322, http://dx.doi.org/10.1016/j.biopha.2016.10.060.

[198] Szulc, A., Pulaski, L., Appelhans, D., Voit, B., KlajnertMaculewicz, B. (2016). Sugar-modified poly(propylene imine) dendrimers as drug delivery agents for cytarabine to overcome drug resistance, International Journal of Pharmaceutics, Volume 513, Issue 1, Pages 572-583, ISSN 0378-5173, http://dx.doi.org/10.1016/j.ijpharm.2016.09.063.

[199] Haddad, P. S., Martins, T. M., D'Souza-Li, L., Li, L. M., Metze, K., Adam, R. L., Knobel, M., Zanchet, D. (2008). Structural and morphological investigation of magnetic nanoparticles based on iron oxides for biomedical applications, Materials Science and Engineering: C, Volume 28, Issue 4, Pages 489-494, ISSN 0928-4931, http://dx.doi.org/10.1016/j.msec.2007.04.014.

[200] Mignani, S., El Kazzouli, S., Bousmina, M., Majoral, J. P. (2013). Dendrimer space concept for innovative nanomedicine: A futuristic vision for medicinal chemistry, Progress in Polymer Science, Volume 38, Issue 7, Pages 993-1008, ISSN 0079-6700, http://dx.doi.org/10.1016/j.progpolymsci.2013.03.003.

[201] Eaton, M. A. W., Levy, L., Fontaine, O. M. A. (2015). Delivering nanomedicines to patients: A practical guide, Nanomedicine: Nanotechnology, Biology and Medicine, Volume 11, Issue 4, Pages 983-992, ISSN http://dx.doi.org/10.1016/j.nano.2015.02.004.
[202] Lollo, G., Hervella, P., Calvo, P., Avilés, P., Guillén, M. J., Garcia-Fuentes, M., Alonso, M. J., Torres, D. (2015). Enhanced therapeutic efficacy of plitidepsin-loaded nanocapsules decorated with a new poly-aminoacid-PEG derivative, International Journal of Pharmaceutics, Volume 483, Issue 1, Pages 212-219, and ISSN 0378-5173, http://dx.doi.org/10.1016/j.ijpharm.2015.02.028.

[203] Thompson, N., Ahn, M., Chessari, G., Hearn, K., Johnson, C. N., Lewis, J., Ward, G., Williams, P., Woolford, A. (2012). 85 Characterization of a Potent XIAP and CIAP1 Dual Antagonist in Models of Melanoma and Leukemia, European Journal of Cancer, Volume $\quad 48, \quad$ Page 27, ISSN 0959-8049, http://dx.doi.org/10.1016/S0959-8049(12)71883-X.

[204] Graphical Abstracts, Journal of Fluorine Chemistry, Volume 174, 2015, Pages vii-xii, ISSN 0022-1139, http://dx.doi.org/10.1016/S0022-1139(15)00114-1.

[205] Muntimadugu, E., Kommineni, N., Khan, W. (2017). Exploring the Potential of Nanotherapeutics in Targeting Tumor Microenvironment for Cancer Therapy, Pharmacological Research, ISSN 1043-6618, and http://dx.doi.org/10.1016/j.phrs.2017.05.010.

[206] Foldvari, M., Bagonluri, M. (2008). Carbon nanotubes as functional excipients for nanomedicines: II. Drug delivery and biocompatibility issues, Nanomedicine: Nanotechnology, Biology and Medicine, Volume 4, Issue 3, Pages 183-200, ISSN 1549-9634, http://dx.doi.org/10.1016/j.nano.2008.04.003.

[207] Graphical Abstracts, Journal of Fluorine Chemistry, Volume 171, 2015, Pages vii-xiii, ISSN 0022-1139, http://dx.doi.org/10.1016/S0022-1139(15)00032-9.

[208] Riley, J.S., Johnston, P.G., Longley, D.B. (2012). 83 Investigation of Post-translational Modifications of c-FLIP, European Journal of Cancer, Volume 48, Page 27, ISSN 0959-8049, http://dx.doi.org/10.1016/S0959-8049(12)71881-6.

[209] Fernandes, E., Ferreira, J. A., Andreia, P., Luís, L., Barroso, S., Sarmento, B., Santos, L. L. (2015). New trends in guided nanotherapies for digestive cancers: A systematic review, Journal of Controlled Release, Volume 209, Pages 288-307, ISSN 0168-3659, http://dx.doi.org/10.1016/j.jconrel.2015.05.003.

[210] Mehra, N. K., Palakurthi, S. (2016). Interactions between carbon nanotubes and bioactives: a drug delivery perspective, Drug Discovery Today, Volume 21, Issue 4, Pages 585-597, ISSN 13596446, http://dx.doi.org/10.1016/j.drudis.2015.11.011.

[211] Mignani, S., Huber, S., Tomás, H., Rodrigues, J., Majoral, J. P. (2016). Why and how have drug discovery strategies in pharma changed? What are the new mindsets?, Drug Discovery Today, Volume 21, Issue 2, Pages 239-249, ISSN 1359-6446, http://dx.doi.org/10.1016/j.drudis.2015.09.007.

[212] Naderkhani, E., Erber, A., Škalko-Basnet, N., Flaten, G. E. (2014). Improved Permeability of Acyclovir: Optimization of Mucoadhesive Liposomes Using the Phospholipid Vesicle-Based Permeation Assay, Journal of Pharmaceutical Sciences, Volume 103, Issue 2, Pages 661-668, ISSN 0022-3549, and http://dx.doi.org/10.1002/jps.23845.

[213] Newton, D. (2013). Literature listing, World Patent Information, Volume 35, Issue 4, Pages 352-357, ISSN 0172-2190, http://dx.doi.org/10.1016/j.wpi.2013.06.006.

[214] Aoki, I., Yoneyama, M., Hirose, J., Minemoto, Y., Koyama, T., Kokuryo, D., Bakalova, R., Murayama, S., Saga, T., Aoshima, S., Ishizaka, Y., Kono, K. (2015). Thermoactivatable polymer-grafted liposomes for low-invasive image-guided chemotherapy, Translational Research, Volume 166, Issue 6, Pages 660-673.e1, ISSN 1931-5244, http://dx.doi.org/10.1016/j.trs1.2015.07.009.

[215] Ita, K.B. (2014). Transdermal drug delivery: progress and challenges, Journal of Drug Delivery Science and Technology, Volume 24, Issue 3, Pages 245-250, ISSN 1773-2247, http://dx.doi.org/10.1016/S1773-2247(14)50041-X.

[216] Liu, J. R., Chen, G. F., Shih, H. N., Kuo, P. C. (2008). Enhanced antioxidant bioactivity of (Danshen) products prepared using nanotechnology, Phytomedicine, Volume 15, Issue 1, Pages 2330, ISSN 0944-7113, http://dx.doi.org/10.1016/j.phymed.2007.11.012.

[217] Mallapragada, S. K., Brenza, T. M., McMillan, J. M., Narasimhan, B., Sakaguchi, D. S., Sharma, A. D., Zbarska, S., Gendelman, H. E. (2015). Enabling nanomaterial, nanofabrication and cellular technologies for nanoneuromedicines, Nanomedicine: Nanotechnology, Biology and Medicine, Volume 11, Issue 3, Pages 715-729, ISSN 1549-9634, http://dx.doi.org/10.1016/j.nano.2014.12.013.

[218] Peres, C., Matos, A. I., Conniot, J., Sainz, V., Zupančič, E., Silva, J. M., Graça, L., Gaspar, R. S., Préat, V., Florindo, H. F. (2017). Poly(lactic acid)-based particulate systems are promising tools for immune modulation, Acta Biomaterialia, Volume 48, Pag- 
$41-57$

ISSN

$1742-7061$

http://dx.doi.org/10.1016/j.actbio.2016.11.012.

[219] Ferreira, A. J., Cemlyn-Jones, J., Cordeiro, C. R. (2013). Nanoparticles, nanotechnology and pulmonary nanotoxicology, Revista Portuguesa de Pneumologia (English Edition), Volume 19, Issue 1, Pages 28-37, ISSN 2173-5115, http://dx.doi.org/10.1016/i.rppnen.2013.01.004

[220] Ferreira, A. J., Cemlyn-Jones, J., Cordeiro, C. R. (2013). Nanoparticles, nanotechnology and pulmonary nanotoxicology, Revista Portuguesa de Pneumologia, Volume 19, Issue 1, Pages 28-37, ISSN 0873-2159, http://dx.doi.org/10.1016/j.rppneu.2012.09.003.

[221] Salerno, A., Pascual, C. D. (2015). Bio-based polymers, supercritical fluids and tissue engineering, Process Biochemistry, Volume 50, Issue 5, Pages 826-838, ISSN 1359-5113, http://dx.doi.org/10.1016/j.procbio.2015.02.009.

[222] Tyler, B., Gullotti, D., Mangraviti, A., Utsuki, T., Brem, H. (2016). Polylactic acid (PLA) controlled delivery carriers for biomedical applications, Advanced Drug Delivery Reviews, Volume 107, Pages 163-175, ISSN 0169-409X, http://dx.doi.org/10.1016/j.addr.2016.06.018.

[223] Iannazzo, D., Pistone, A., Galvagno, S., Ferro, S., Luca, L. D., Monforte, A. M., Ros, T. D., Hadad, C., Prato, M., Pannecouque, C. (2015). Synthesis and anti-HIV activity of carboxylated and drug-conjugated multi-walled carbon nanotubes, Carbon, Volume 82, Pages 548-561, ISSN 0008-6223, http://dx.doi.org/10.1016/j.carbon.2014.11.007.

[224] Jemec, A., Djinović, P., Tišler, T., Pintar, A. (2012). Effects of four $\mathrm{CeO}$ nanocrystalline catalysts on early-life stages of zebrafish and crustacean, Journal of Hazardous Materials, Volume 219, Pages 213-220, ISSN 0304-3894, http://dx.doi.org/10.1016/j.jhazmat.2012.03.080.

[225] Chen, H.L., Tai, W.T., Shiau, C.W., Liu, C.Y., Lin, C.S., Cheng, A.L., Chen, P.J., Chen, K.F. (2012). 82 Sorafenib and Its Derivative SC-59 Induces Autophagy in Hepatocellular Carcinoma Through SHP-1 Dependent Inhibition of STAT3, European Journal of Cancer, Volume 48, Pages 26-27, ISSN 0959-8049, http://dx.doi.org/10.1016/S0959-8049(12)71880-4.

[226] Lütscher, N., Hönes, S., Grubert, M., Scheulen, M.E., Hilger, R.A. (2012). 86 Antitumoral Activity of a New Class of Triazenes, European Journal of Cancer, Volume 48, Pages 27-28, ISSN 09598049, http://dx.doi.org/10.1016/S0959-8049(12)71884-1.

[227] Park, C. W., Li, X., Vogt, F. G., Hayes, D., Zwischenberger, J. B., Park, E. S., Mansour, H. M. (2013). Advanced spray-dried design, physicochemical characterization, and aerosol dispersion performance of vancomycin and clarithromycin multifunctional controlled release particles for targeted respiratory delivery as dry powder inhalation aerosols, International Journal of Pharmaceutics, Volume 455, Issue 1, Pages 374-392, ISSN 0378-5173, http://dx.doi.org/10.1016/j.ijpharm.2013.06.047.

[228] Huang, H., Yuan, Q., Shah, J.S., Misra, R.D.K. (2011). A new family of folate-decorated and carbon nanotube-mediated drug delivery system: Synthesis and drug delivery response, Advanced Drug Delivery Reviews, Volume 63, Issue 14, Pages 1332-1339, ISSN 0169-409X, http://dx.doi.org/10.1016/j.addr.2011.04.001.

[229] Depan D., Shah, J., Misra, R.D.K. (2011). Controlled release of drug from folate-decorated and graphene mediated drug delivery system: Synthesis, loading efficiency, and drug release response, Materials Science and Engineering: C, Volume 31, Issue 7, Pages $1305-1312$

ISSN 0928-4931, http://dx.doi.org/10.1016/j.msec.2011.04.010.

[230] Guo, S., Huang, L. (2014). Nanoparticles containing insoluble drug for cancer therapy, Biotechnology Advances, Volume 32, Issue 4, Pages 778-788, ISSN 0734-9750, http://dx.doi.org/10.1016/j.biotechadv.2013.10.002.

[231] Duncan, R. (2011). Polymer therapeutics as nanomedicines: new perspectives, Current Opinion in Biotechnology, Volume 22, Issue 4, Pages 492-501, ISSN 0958-1669, http://dx.doi.org/10.1016/j.copbio.2011.05.507.

[232] Sidik, N. A. C., Yazid, M. N. A. W. M., Samion, S., Musa, M N., Mamat, R. (2016). Latest development on computational approaches for nanofluid flow modeling: Navier-Stokes based multiphase models, International Communications in Heat and Mass Transfer, Volume 74, Pages 114-124, ISSN 0735-1933, http://dx.doi.org/10.1016/j.icheatmasstransfer.2016.03.007.

[233] Yuan, Q., Hein, S., Misra, R. D. K. (2010). New generation of chitosan-encapsulated $\mathrm{ZnO}$ quantum dots loaded with drug: Synthesis, characterization and in vitro drug delivery response, Acta Biomaterialia, Volume 6, Issue 7, Pages 2732-2739, ISSN 1742 7061, http://dx.doi.org/10.1016/j.actbio.2010.01.025
[234] He, W., Liu, Y., Wamer, W. G., Yin, J. J. (2014). Electron spin resonance spectroscopy for the study of nanomaterial-mediated generation of reactive Oxygen species, Journal of Food and Drug Analysis, Volume 22, Issue 1, Pages 49-63, ISSN 1021-9498, http://dx.doi.org/10.1016/j.jfda.2014.01.004.

[235] An, J., Gou, Y., Yang, C., Hu, F., Wang, C. (2013). Synthesis of a biocompatible gelatin functionalized graphene nanosheets and its application for drug delivery, Materials Science and Engineering: C, Volume 33, Issue 5, Pages 2827-2837, ISSN 0928-4931, and http://dx.doi.org/10.1016/j.msec.2013.03.008.

[236] Meenach, S. A., Anderson, K. W., Hilt, J. Z., McGarry, R. C., Mansour, H. M. (2013). Characterization and aerosol dispersion performance of advanced spray-dried chemotherapeutic PEGylated phospholipid particles for dry powder inhalation delivery in lung cancer, European Journal of Pharmaceutical Sciences, Volume 49, Issue 4, Pages 699-711, ISSN 0928-0987, http://dx.doi.org/10.1016/j.ejps.2013.05.012.

[237] England, R. M., Masiá, E., Giménez, V., Lucas, R., Vicent, M. J. (2012). Polyacetal-stilbene conjugates — the first examples of polymer therapeutics for the inhibition of HIF-1 in the treatment of solid tumours, Journal of Controlled Release, Volume 164, Issue 3 , Pages 314-322, ISSN 0168-3659, and http://dx.doi.org/10.1016/i.jconrel.2012.08.017.

[238] Pippa, N., Merkouraki, M., Pispas, S., Demetzos, C. (2013) DPPC:MPOx chimeric advanced Drug Delivery nano Systems (chiaDDnSs): Physicochemical and structural characterization, stability and drug release studies, International Journal of Pharmaceutics, Volume 450, Issue 1, Pages 1-10, ISSN 0378-5173, http://dx.doi.org/10.1016/j.ijpharm.2013.03.052.

[239] Boisseau, P., Loubaton, B. (2011). Nanomedicine, nanotechnology in medicine, Comptes Rendus Physique, Volume 12, Issue 7, Pages 620-636, ISSN 1631-0705, http://dx.doi.org/10.1016/j.crhy.2011.06.001.

[240] Petrichenko, O., Rucins, M., Vezane, A., Timofejeva, I., Sobolev, A., Cekavicus, B., Pajuste, K., Plotniece, M., Gosteva, M., Kozlovska, T., Plotniece, A. (2015). Studies of the physicochemical and structural properties of self-assembling cationic pyridine derivatives as gene delivery agents, Chemistry and Physics of Lipids, Volume 191, Pages 25-37, ISSN 0009-3084, http://dx.doi.org/10.1016/j.chemphyslip.2015.08.005.

[241] Rodríguez-Gascón, A., Del Pozo-Rodríguez, A., Isla, A., Solinís, M. A. (2015). Vaginal gene therapy, Advanced Drug Delivery Reviews, Volume 92, Pages 71-83, ISSN 0169-409X, http://dx.doi.org/10.1016/j.addr.2015.07.002.

[242] Frima, H. J., Gabellieri, C., Nilsson, M. I. (2012). Drug delivery research in the European Union's Seventh Framework Programme for Research, Journal of Controlled Release, Volume 161, Issue 2, Pages 409-415, ISSN 0168-3659, http://dx.doi.org/10.1016/j.jconrel.2012.01.044.

[243] Yallapu, M. M., Chauhan, N., Othman, S. F., KhalilzadSharghi, V., Ebeling, M. C., Khan, S., Jaggi, M., Chauhan, S. C. (2015). Implications of protein corona on physico-chemical and biological properties of magnetic nanoparticles, Biomaterials, Volume 46, Pages 1-12, ISSN 0142-9612, http://dx.doi.org/10.1016/j.biomaterials.2014.12.045.

[244] Duan, J., Mansour, H. M., Zhang, Y., Deng, X., Chen, Y., Wang, J., Pan, Y., Zhao, J. (2012). Reversion of multidrug resistance by co-encapsulation of doxorubicin and curcumin in chitosan/poly(butyl cyanoacrylate) nanoparticles, International Journal of Pharmaceutics, Volume 426, Issue 1, Pages 193-201, ISSN 0378-5173, http://dx.doi.org/10.1016/j.ijpharm.2012.01.020.

[245] Perez, R. A., Kim, H. W. (2015). Core-shell designed scaffolds for drug delivery and tissue engineering, Acta Biomaterialia, Volume 21, Pages 2-19, ISSN 1742-7061, http://dx.doi.org/10.1016/j.actbio.2015.03.013.

[246] Costantino, L., Boraschi, D. (2012). Is there a clinical future for polymeric nanoparticles as brain-targeting drug delivery agents?, Drug Discovery Today, Volume 17, Issue 7, Pages 367-378, ISSN 1359-6446, http://dx.doi.org/10.1016/j.drudis.2011.10.028.

[247] Wei, C., Lyubchenko, Y. L., Ghandehari, H., Hanes, J., Stebe, K. J., Mao, H. Q., Haynie, D. T., Tomalia, D. A., Foldvari, M., Monteiro-Riviere, N., Simeonova, P., Nie, S., Mori, H., Gilbert, S. P., Needham, D. (2006). New technology and clinical applications of nanomedicine: Highlights of the second annual meeting of the American Academy of Nanomedicine (Part I), Nanomedicine: Nanotechnology, Biology and Medicine, Volume 2, Issue 4, Pages 253-263, ISSN $1549-9634$ http://dx.doi.org/10.1016/j.nano.2006.11.001

[248] Murday, J. S., Siegel, R. W., Stein, J., Wright, J. F. (2009). Translational nanomedicine: status assessment and opportunities, 
Nanomedicine: Nanotechnology, Biology and Medicine, Volume 5, Issue 3, Pages 251-273, ISSN 1549-9634, http://dx.doi.org/10.1016/j.nano.2009.06.001.

[249] Dixit, N., Vaibhav, K., Pandey, R. S., Jain, U. K., Katare, O. P., Katyal, A., Madan, J. (2015). Improved cisplatin delivery in cervical cancer cells by utilizing folate-grafted non-aggregated gelatin nanoparticles, Biomedicine \& Pharmacotherapy, Volume 69, Pages 1-10, and ISSN 0753-3322, http://dx.doi.org/10.1016/j.biopha.2014.10.016.

[250] Nair, H. B., Sung, B., Yadav, V. R., Kannappan, R., Chaturvedi, M. M., Aggarwal, B. B. (2010). Delivery of antiinflammatory nutraceuticals by nanoparticles for the prevention and treatment of cancer, Biochemical Pharmacology, Volume 80, Issue 12, Pages 1833-1843, ISSN

0006-2952 http://dx.doi.org/10.1016/j.bcp.2010.07.021.

[251] Bawa, R., Bawa, S.R., Maebius, S. B., Flynn, T., Wei, C. (2005). Protecting new ideas and inventions in nanomedicine with patents, Nanomedicine: Nanotechnology, Biology and Medicine, Volume 1, Issue 2, Pages 150-158, ISSN 1549-9634, http://dx.doi.org/10.1016/j.nano.2005.03.009.

[252] Farkhani, S. M., Valizadeh, A., Karami, H., Mohammadi, S. Sohrabi, N., Badrzadeh, F. (2014). Cell penetrating peptides: Efficient vectors for delivery of nanoparticles, nanocarriers, therapeutic and diagnostic molecules, Peptides, Volume 57, Pages 78-94, ISSN 0196-9781, http://dx.doi.org/10.1016/j.peptides.2014.04.015.

[253] Graphical Abstracts, Journal of Fluorine Chemistry, Volume 168, 2014, Pages v-xv, ISSN 0022-1139, http://dx.doi.org/10.1016/S0022-1139(14)00353-4.

[254] Lal, R., Arnsdorf, M. F. (2010). Multidimensional atomic force microscopy for drug discovery: A versatile tool for defining targets, designing therapeutics and monitoring their efficacy, Life Sciences, Volume 86, Issue 15, Pages 545-562, ISSN 0024-3205, http://dx.doi.org/10.1016/j.lfs.2009.02.030.

[255] Hacklin, F., Marxt, C., Fahrni, F. (2009). Coevolutionary cycles of convergence: An extrapolation from the ICT industry, Technological Forecasting and Social Change, Volume 76, Issue 6, Pages 723-736, ISSN $0040-1625$, http://dx.doi.org/10.1016/j.techfore.2009.03.003.

[256] Gabizon, A. A., Patil, Y., La-Beck, N. M. (2016). New insights and evolving role of pegylated liposomal doxorubicin in cancer therapy, Drug Resistance Updates, Volume 29, Pages 90-106, ISSN 1368-7646, http://dx.doi.org/10.1016/j.drup.2016.10.003.

[257] Zhang, J., Ma, P. X. (2013). Cyclodextrin-based supramolecular systems for drug delivery: Recent progress and future perspective, Advanced Drug Delivery Reviews, Volume 65, Issue 9, Pages 1215-1233, ISSN 0169-409X, http://dx.doi.org/10.1016/j.addr.2013.05.001.

[258] Vanić, Ž. Škalko-Basnet, N. (2014). Mucosal nanosystems for improved topical drug delivery: vaginal route of administration, Journal of Drug Delivery Science and Technology, Volume 24, Issue 5, Pages 435-444, ISSN 1773-2247, http://dx.doi.org/10.1016/S1773-2247(14)50085-8.

[259] Ellis-Behnke, R. (2007). Nano Neurology and the Four P's of Central Nervous System Regeneration: Preserve, Permit, Promote, Plasticity, Medical Clinics of North America, Volume 91, Issue 5, Pages 937-962, ISSN 0025-7125, http://dx.doi.org/10.1016/j.mcna.2007.04.005.

[260] Srivalli, K. M. R., Mishra, B. (2016). Drug nanocrystals: A way toward scale-up, Saudi Pharmaceutical Journal, Volume 24, Issue 4, Pages 386-404, ISSN 1319-0164, http://dx.doi.org/10.1016/j.jsps.2014.04.007.

[261] Collnot, E. M., Ali, H., Lehr, C. M. (2012). Nano- and microparticulate drug carriers for targeting of the inflamed intestinal mucosa, Journal of Controlled Release, Volume 161, Issue 2, Pages 235-246, ISSN 0168-3659, http://dx.doi.org/10.1016/i.jconrel.2012.01.028.

[262] Rychak, J. J., Lindner, J. R., Ley, K., Klibanov, A. L. (2006). Deformable gas-filled microbubbles targeted to P-selectin, Journal of Controlled Release, Volume 114, Issue 3, Pages 288-299, ISSN 0168-3659, and http://dx.doi.org/10.1016/j.jconrel.2006.06.008

[263] Watala, C., Karolczak, K., Kassassir, H., Talar, M. Przygodzki, T., Maczynska, K., Labieniec-Watala, M. (2016). How do the full-generation poly (amido) amine (PAMAM) dendrimers activate blood platelets? Activation of circulating platelets and formation of fibrinogen aggregates in the presence of polycations, International Journal of Pharmaceutics, Volume 503, Issue 1, Pages 247-261, ISSN http://dx.doi.org/10.1016/j.ijpharm.2015.08.073.

[264] Palombo, M.S., Singh, Y., Sinko, P.J. (2009). Prodrug and conjugate drug delivery strategies for improving HIV/AIDS therapy,
Journal of Drug Delivery Science and Technology, Volume 19, Issue 1, Pages 3-14, ISSN 1773-2247, http://dx.doi.org/10.1016/S1773-2247(09)50001-9.

[265] Table of Contents, Nanomedicine: Nanotechnology, Biology and Medicine, Volume 7, Issue 4, 2011, Pages A4-A5, ISSN 1549 9634, http://dx.doi.org/10.1016/S1549-9634(11)00192-4.

[266] Kuzmov, A., Minko, T. (2015). Nanotechnology approaches for inhalation treatment of lung diseases, Journal of Controlled Release, Volume 219, Pages 500-518, and ISSN 0168-3659, http://dx.doi.org/10.1016/j.jconrel.2015.07.024.

[267] Diebold, Y., Calonge, M. (2010). Applications of nanoparticles in ophthalmology, Progress in Retinal and Eye Research, Volume 29, Issue 6, Pages 596-609, ISSN 1350-9462, http://dx.doi.org/10.1016/j.preteyeres.2010.08.002.

[268] Bal, R., Türk, G., Tuzcu, M., Yilmaz, O., Ozercan, I., Kuloglu, T., Gür, S., Nedzvetsky, V. S., Tykhomyrov, A. A., Andrievsky, G. V., Baydas, G., Naziroglu, M. (2011). Protective effects of nanostructures of hydrated $\mathrm{C}$ fullerene on reproductive function in streptozotocin-diabetic male rats, Toxicology, Volume 282, Issue 3, Pages 69-81, ISSN r 0300-483X http://dx.doi.org/10.1016/j.tox.2010.12.003

[269] Bharali, D. J., Mousa, S. A. (2010). Emerging nanomedicines for early cancer detection and improved treatment: Current perspective and future promise, Pharmacology \& Therapeutics, Volume 128, Issue 2, Pages 324-335, ISSN 0163-7258, http://dx.doi.org/10.1016/j.pharmthera.2010.07.007.

[270] Ray, S., Chandra, H., Srivastava, S. (2010). Nanotechniques in proteomics: Status, promises and challenges, Biosensors and Bioelectronics, Volume 25, Issue 11, Pages 2389-2401, ISSN 09565663, http://dx.doi.org/10.1016/j.bios.2010.04.010.

[271] Mishra, B., Patel, B. B., Tiwari, S. (2010). Colloidal nanocarriers: a review on formulation technology, types and applications toward targeted drug delivery, Nanomedicine: Nanotechnology, Biology and Medicine, Volume 6, Issue 1, Pages 9-24, ISSN 15499634, http://dx.doi.org/10.1016/j.nano.2009.04.008.

[272] [Contents, Nanomedicine: Nanotechnology, Biology and Medicine, Volume 4, Issue 4, 2008, Pages A3-A4, ISSN 1549-9634, http://dx.doi.org/10.1016/S1549-9634(08)00178-0.

[273] Torchilin, V. (2009). Multifunctional and stimuli-sensitive pharmaceutical nanocarriers, European Journal of Pharmaceutics and Biopharmaceutics, Volume 71, Issue 3, Pages 431-444, ISSN 0939-6411, http://dx.doi.org/10.1016/j.ejpb.2008.09.026.

[274] Cupaioli, F. A., Zucca, F. A., Boraschi, D., Zecca, L. (2014) Engineered nanoparticles. How brain friendly is this new guest? Progress in Neurobiology, Volume 119, Pages 20-38, ISSN 03010082, http://dx.doi.org/10.1016/j.pneurobio.2014.05.002.

[275] Sosnik, A., Carcaboso, A. M. (2014). Nanomedicines in the future of pediatric therapy, Advanced Drug Delivery Reviews, Volume 73, Pages 140-161, ISSN 0169-409X, http://dx.doi.org/10.1016/j.addr.2014.05.004.

[276] Table of Contents, Nanomedicine: Nanotechnology, Biology and Medicine, Volume 10, Issue 1, 2014, Pages A4-A7, ISSN 1549-9634, http://dx.doi.org/10.1016/S1549-9634(13)00599-6.

[277] Guan, J., Zhao, Q. (2013). The impact of university-industry collaboration networks on innovation in nanobiopharmaceuticals, Technological Forecasting and Social Change, Volume 80, Issue 7 Pages 1271-1286, ISSN 0040-1625, http://dx.doi.org/10.1016/j.techfore.2012.11.013.

[278] Toit, L. C. D., Govender, T., Carmichael, T., Kumar, P., Choonara, Y. E., Pillay, V. (2013). Design of an Anti-Inflammatory Composite Nanosystem and Evaluation of Its Potential for Ocular Drug Delivery, Journal of Pharmaceutical Sciences, Volume 102, Issue 8, Pages 2780-2805, ISSN 0022-3549, http://dx.doi.org/10.1002/jps.23650.

[279] Emerging Fields, Free Radical Biology and Medicine, Volume 43, 2007, Pages S67-S74, ISSN 0891-5849, http://dx.doi.org/10.1016/j.freeradbiomed.2007.10.018.

[280] Zhang, X. Q., Xu, X., Bertrand, N., Pridgen, E., Swami, A. Farokhzad, O. C. (2012). Interactions of nanomaterials and biological systems: Implications to personalized nanomedicine, Advanced Drug Delivery Reviews, Volume 64, Issue 13, Pages 1363-1384, ISSN 0169-409X, http://dx.doi.org/10.1016/j.addr.2012.08.005.

[281] Muthaiyan, A., Limayem, A., Ricke, S. C. (2011). Antimicrobial strategies for limiting bacterial contaminants in fuel bioethano fermentations, Progress in Energy and Combustion Science, Volume 37, Issue 3, Pages 351-370, ISSN 0360-1285, http://dx.doi.org/10.1016/j.pecs.2010.06.005.

[282] Scientific Programme - Details, European Journal of Cancer Supplements, Volume 8, Issue 7, 2010, Pages xxiv-lxvi, ISSN 1359-6349, http://dx.doi.org/10.1016/S1359-6349(10)71697-9. 
[283] Subject Index, European Journal of Cancer Supplements, Volume 8, Issue 7, 2010, Pages 233-243, ISSN 1359-6349, http://dx.doi.org/10.1016/S1359-6349(10)72373-9.

[284] Duncan, R. (2009). Development of HPMA copolymeranticancer conjugates: Clinical experience and lessons learnt, Advanced Drug Delivery Reviews, Volume 61, Issue 13, Pages 11311148, and ISSN $0169-409$ X http://dx.doi.org/10.1016/j.addr.2009.05.007.

[285] Palao-Suay, R., Gómez-Mascaraque, L.G., Aguilar, M.R., Vázquez-Lasa, B., Román, J. S. (2016). Self-assembling polymer systems for advanced treatment of cancer and inflammation, Progress in Polymer Science, Volume 53, Pages 207-248, ISSN 00796700, and http://dx.doi.org/10.1016/j.progpolymsci.2015.07.005.

[286] Morrow, K. J., Bawa, R., Wei, C. (2007). Recent Advances in Basic and Clinical Nanomedicine, Medical Clinics of North America, Volume 91, Issue 5, Pages 805-843, ISSN 0025-7125, http://dx.doi.org/10.1016/j.mcna.2007.05.009.

[287] Tissue/Cell Targets and Reactions, Free Radical Biology and Medicine, Volume 41, 2006, Pages S144-S154, ISSN 0891-5849, http://dx.doi.org/10.1016/j.freeradbiomed.2006.10.015.

[288] Inflammation, Free Radical Biology and Medicine, Volume 41 2006, Pages S68-S78, ISSN 0891-5849, http://dx.doi.org/10.1016/i.freeradbiomed.2006.10.008.

[289] Punetha, V. D., Rana, S., Yoo, H. J., Chaurasia, A., McLeskey, J. T., Ramasamy, M. S., Sahoo, N. G., Cho, J. W. (2017). Functionalization of carbon nanomaterials for advanced polymer nanocomposites: A comparison study between CNT and graphene, Progress in Polymer Science, Volume 67, Pages 1-47, ISSN 0079-6700, http://dx.doi.org/10.1016/j.progpolymsci.2016.12.010.

[290] Antioxidants, Nutrition \& Health, Free Radical Biology and Medicine, Volume 41, 2006, Pages S18-S31, ISSN 0891-5849, http://dx.doi.org/10.1016/j.freeradbiomed.2006.10.002.

[291] Scientific Programme - Proffered Papers, European Journal of Cancer, Volume 49, 2013, Pages S97-S153, ISSN 0959-8049, http://dx.doi.org/10.1016/S0959-8049(13)70060-1.

[292] Subject Index, European Journal of Cancer, Volume 49, 2013, Pages S975-S1028, ISSN 0959-8049, http://dx.doi.org/10.1016/S0959-8049(13)70067-4.

[293] Goldschmidt Abstracts $2010-\mathrm{H}$, Geochimica et Cosmochimica Acta, Volume 74, Issue 12, 2010, Pages A369-A440, ISSN 0016-7037, http://dx.doi.org/10.1016/j.gca.2010.04.033.

[294] Manickam, S. (2017). Editorial Note, Ultrasonics Sonochemistry, Volume 35, Pages 529-530, ISSN 1350-4177, http://dx.doi.org/10.1016/j.ultsonch.2016.06.028.

[295] Osorio, J. G., Muzzio, F. J. (2015). Evaluation of resonant acoustic mixing performance, Powder Technology, Volume 278, Pages 46-56, ISSN 0032-5910, http://dx.doi.org/10.1016/j.powtec.2015.02.033.

[296] Karami, Z., Hamidi, M. (2016). Cubosomes: remarkable drug delivery potential, Drug Discovery Today, Volume 21, Issue 5 , Pages 789-801, ISSN 1359-6446, http://dx.doi.org/10.1016/j.drudis.2016.01.004.

[297] Park, J., Nam, H., Ahn, S. Y., Pak, Y. K., Pak, J. J. (2013). A reservoir-type oxygen sensor with $2 \times 3$ array for measuring cellular respiration levels, Sensors and Actuators B: Chemical, Volume 176, Pages 913-920, ISSN 0925-4005, http://dx.doi.org/10.1016/j.snb.2012.09.037.

[298] Heidari, A. (2017). Investigation of Anti-Cancer Nano Drugs' Effects' Trend on Human Pancreas Cancer Cells and Tissues Prevention, Diagnosis and Treatment Process under Synchrotron and $\mathrm{X}$-Ray Radiations with the Passage of Time Using Mathematica, Current Trends Anal Bioanal Chem, 1 (1): 36-41.

[299] Heidari, A. (2017). Pros and Cons Controversy on Molecular Imaging and Dynamics of Double-Standard DNA/RNA of Human Preserving Stem Cells-Binding Nano Molecules with Androgens/Anabolic Steroids (AAS) or Testosterone Derivatives through Tracking of Helium-4 Nucleus (Alpha Particle) Using Synchrotron Radiation, Arch Biotechnol Biomed. 1 (1): 067-0100.

[300] Heidari, A. (2017). Visualizing Metabolic Changes in Probing Human Cancer Cells and Tissues Metabolism Using Vivo ${ }^{1} \mathrm{H}$ or Proton NMR, ${ }^{13} \mathrm{C}$ NMR, ${ }^{15} \mathrm{~N}$ NMR and ${ }^{31} \mathrm{P}$ NMR Spectroscopy and Self-Organizing Maps under Synchrotron Radiation, SOJ Mater Sci Eng 5 (2): 1-6.

[301] Heidari, (2017). A. Cavity Ring-Down Spectroscopy (CRDS), Circular Dichroism Spectroscopy, Cold Vapour Atomic Fluorescence Spectroscopy and Correlation Spectroscopy Comparative Study on Malignant and Benign Human Cancer Cells and Tissues with the Passage of Time under Synchrotron Radiation, Enliven Challenges Cancer Detect Ther 4 (2): e001.
[302] Heidari, A. (2017). Laser Spectroscopy, Laser-Induced Breakdown Spectroscopy and Laser-Induced Plasma Spectroscopy Comparative Study on Malignant and Benign Human Cancer Cells and Tissues with the Passage of Time under Synchrotron Radiation, Int J Hepatol Gastroenterol, 3 (4): 079-084.

[303] Heidari, A. (2017). Time-Resolved Spectroscopy and TimeStretch Spectroscopy Comparative Study on Malignant and Benign Human Cancer Cells and Tissues with the Passage of Time under Synchrotron Radiation, Enliven: Pharmacovigilance and Drug Safety 4 (2): e001.

[304] Heidari, A. (2017). Overview of the Role of Vitamins in Reducing Negative Effect of Decapeptyl (Triptorelin Acetate or Pamoate Salts) on Prostate Cancer Cells and Tissues in Prostate Cancer Treatment Process through Transformation of Malignant Prostate Tumors into Benign Prostate Tumors under Synchrotron Radiation, Open J Anal Bioanal Chem 1 (1): 021-026.

[305] Heidari, A. (2017). Electron Phenomenological Spectroscopy, Electron Paramagnetic Resonance (EPR) Spectroscopy and Electron Spin Resonance (ESR) Spectroscopy Comparative Study on Malignant and Benign Human Cancer Cells and Tissues with the Passage of Time under Synchrotron Radiation, Austin J Anal Pharm Chem. 4 (3): 1091.

[306] Heidari, A. (2017). Therapeutic Nanomedicine Different HighResolution Experimental Images and Computational Simulations for Human Brain Cancer Cells and Tissues Using Nanocarriers Deliver DNA/RNA to Brain Tumors under Synchrotron Radiation with the Passage of Time Using Mathematica and MATLAB, Madridge J Nano Tech. Sci. 2 (2): 77-83.

[307] Heidari, A. (2017). A Consensus and Prospective Study on Restoring Cadmium Oxide (CdO) Nanoparticles Sensitivity in Recurrent Ovarian Cancer by Extending the Cadmium Oxide (CdO) $\mathrm{Na}$ noparticles-Free Interval Using Synchrotron Radiation Therapy as Antibody-Drug Conjugate for the Treatment of Limited-Stage Small Cell Diverse Epithelial Cancers, Cancer Clin Res Rep, 1: 2 , e001.

[308] Heidari, A. (2017). A Novel and Modern Experimental Imaging and Spectroscopy Comparative Study on Malignant and Benign Human Cancer Cells and Tissues with the Passage of Time under White Synchrotron Radiation, Cancer Sci Res Open Access 4 (2) $1-8$.

[309] Heidari, A. (2017). Different High-Resolution Simulations of Medical, Medicinal, Clinical, Pharmaceutical and Therapeutics Oncology of Human Breast Cancer Translational Nano Drugs Delivery Treatment Process under Synchrotron and X-Ray Radiations, J Oral Cancer Res 1 (1): 12-17.

[310] Heidari, A. (2017). Vibrational Decihertz (dHz), Centihertz $(\mathrm{cHz})$, Millihertz $(\mathrm{mHz})$, Microhertz $(\mu \mathrm{Hz})$, Nanohertz $(\mathrm{nHz})$, Picohertz $(\mathrm{pHz})$, Femtohertz $(\mathrm{fHz})$, Attohertz $(\mathrm{aHz})$, Zeptohertz $(\mathrm{zHz})$ and Yoctohertz $(\mathrm{yHz})$ Imaging and Spectroscopy Comparative Study on Malignant and Benign Human Cancer Cells and Tissues under Synchrotron Radiation, International Journal of Biomedicine, 7 (4), 335-340. https://doi.org/10.21103/Article7(4)_IA1.

[311] Heidari, A. (2017). Force Spectroscopy and Fluorescence Spectroscopy Comparative Study on Malignant and Benign Human Cancer Cells and Tissues with the Passage of Time under Synchrotron Radiation, EC Cancer, 2 (5), 239-246.

[312] Heidari, A. (2017). Photoacoustic Spectroscopy, Photoemission Spectroscopy and Photothermal Spectroscopy Comparative Study on Malignant and Benign Human Cancer Cells and Tissues with the Passage of Time under Synchrotron Radiation, BAOJ Cancer Res Ther, 3: 3, 045-052.

[313] Heidari, A. (2017). J-Spectroscopy, Exchange Spectroscopy (EXSY), Nucle 7 ar Overhauser Effect Spectroscopy (NOESY) and Total Correlation Spectroscopy (TOCSY) Comparative Study on Malignant and Benign Human Cancer Cells and Tissues under Synchrotron Radiation, EMS Eng Sci J, 1 (2): 006-013.

[314] Heidari, A. (2017). Neutron Spin Echo Spectroscopy and Spin Noise Spectroscopy Comparative Study on Malignant and Benign Human Cancer Cells and Tissues with the Passage of Time under Synchrotron Radiation, Int J Biopharm Sci, 1: 103-107.

[315] Heidari, A. (2017). Vibrational Decahertz (daHz), Hectohertz $(\mathrm{hHz})$, Kilohertz (kHz), Megahertz (MHz), Gigahertz (GHz), Terahertz $(\mathrm{THz})$, Petahertz $(\mathrm{PHz})$, Exahertz $(\mathrm{EHz})$, Zettahertz $(\mathrm{ZHz})$ and Yottahertz (YHz) Imaging and Spectroscopy Comparative Study on Malignant and Benign Human Cancer Cells and Tissues under Synchrotron Radiation, Madridge J Anal Sci Instrum, 2 (1): 41-46.

[316] Heidari, A. (2018). Two-Dimensional Infrared Correlation Spectroscopy, Linear Two-Dimensional Infrared Spectroscopy and Non-Linear Two-Dimensional Infrared Spectroscopy Comparative 
Study on Malignant and Benign Human Cancer Cells and Tissues under Synchrotron Radiation with the Passage of Time, J Mater Sci Nanotechnol 6 (1): 101.

[317] Heidari, A. (2018). Infrared Photo Dissociation Spectroscopy and Infrared Correlation Table Spectroscopy Comparative Study on Malignant and Benign Human Cancer Cells and Tissues under Synchrotron Radiation with the Passage of Time, Austin Pharmacol Pharm, 3 (1): 1011.

[318] Heidari, A. (2018). Fourier Transform Infrared (FTIR) Spectroscopy, Near-Infrared Spectroscopy (NIRS) and Mid-Infrared Spectroscopy (MIRS) Comparative Study on Malignant and Benign Human Cancer Cells and Tissues under Synchrotron Radiation with the Passage of Time, Int J Nanotechnol Nanomed, 3 (1).

[319] Heidari, A. (2017). Novel and Transcendental Prevention, Diagnosis and Treatment Strategies for Investigation of Interaction among Human Blood Cancer Cells, Tissues, Tumors and Metastases with Synchrotron Radiation under Anti-Cancer Nano Drugs Delivery Efficacy Using MATLAB Modeling and Simulation, Madridge J Nov Drug Res, 1 (1): 18-24.

[320] Heidari, A. (2018). Comparative Study on Malignant and Benign Human Cancer Cells and Tissues with the Passage of Time under Synchrotron Radiation, Open Access J Trans Med Res, 2 (1) 00026. https://doi.org/10.15406/oajtmr.2018.02.00026

[321] Gobato, M. R. R., Gobato, R., Heidari, A. (2018). Planting of Jaboticaba Trees for Landscape Repair of Degraded Area, Landscape Architecture and Regional Planning, Vol. 3, No. 1, 2018, Pages 1-9.

[322] Heidari, A. (2018). Fluorescence Spectroscopy, Phosphorescence Spectroscopy and Luminescence Spectroscopy Comparative Study on Malignant and Benign Human Cancer Cells and Tissues under Synchrotron Radiation with the Passage of Time, SM J Clin. Med. Imaging, 4 (1): 1018

[323] Heidari, A. (2018). Nuclear Inelastic Scattering Spectroscopy (NISS) and Nuclear Inelastic Absorption Spectroscopy (NIAS) Comparative Study on Malignant and Benign Human Cancer Cells and Tissues under Synchrotron Radiation, Int J Pharm Sci, 2 (1): 114.

[324] Heidari, A. (2018). X-Ray Diffraction (XRD), Powder X-Ray Diffraction (PXRD) and Energy-Dispersive X-Ray Diffraction (EDXRD) Comparative Study on Malignant and Benign Human Cancer Cells and Tissues under Synchrotron Radiation, J Oncol Res; two (1): 1-14.

[325] Heidari, A. (2018). Correlation Two-Dimensional Nuclear Magnetic Reso $\neg$ nance (NMR) (2D-NMR) (COSY) Imaging and Spectrosco $\neg$ py Comparative Study on Malignant and Benign $\mathrm{Hu}$ man Cancer Cells and Tissues under Synchrotron Radiation, EMS Can Sci, 1-1-001.

[326] Heidari, A. (2018). Thermal Spectroscopy, Photothermal Spectroscopy, Thermal Microspectroscopy, Photothermal Microspectroscopy, Thermal Macrospectroscopy and Photothermal Macrospectroscopy Comparative Study on Malignant and Benign Human Cancer Cells and Tissues with the Passage of Time under Synchrotron Radiation, SM J Biometrics Biostat, 3 (1): 1024.

[327] Heidari, A. (2018). A Modern and Comprehensive Experimental Biospectroscopic Comparative Study on Human Common Cancers' Cells, Tissues and Tumors before and after Synchrotron Radiation Therapy, Open Acc J Oncol Med. 1 (1).

[328] Heidari, A. (2018). Heteronuclear Correlation Experiments such as Heteronuclear Single-Quantum Correlation Spectroscopy (HSQC), Heteronuclear Multiple-Quantum Correlation Spectroscopy (HMQC) and Heteronuclear Multiple-Bond Correlation Spectroscopy (HMBC) Comparative Study on Malignant and Benign Human Endocrinology and Thyroid Cancer Cells and Tissues under Synchrotron Radiation, J Endocrinol Thyroid Res, 3 (1): 555603.

[329] Heidari, A. (2018). Nuclear Resonance Vibrational Spectroscopy (NRVS), Nuclear Inelastic Scattering Spectroscopy (NISS), Nuclear Inelastic Absorption Spectroscopy (NIAS) and Nuclear Resonant Inelastic X-Ray Scattering Spectroscopy (NRIXSS) Comparative Study on Malignant and Benign Human Cancer Cells and Tissues under Synchrotron Radiation, Int J Bioorg Chem Mol Biol. 6 (1e): $1-5$.

[330] Heidari, A. (2018). A Novel and Modern Experimental Approach to Vibrational Circular Dichroism Spectroscopy and Video Spectroscopy Comparative Study on Malignant and Benign Human Cancer Cells and Tissues with the Passage of Time under White and Monochromatic Synchrotron Radiation, Glob J Endocrinol Metab. One (3). GJEM. 000514-000519.

[331] Heidari, A. (2018). Pros and Cons Controversy on Heteronuclear Correlation Experiments such as Heteronuclear SingleQuantum Correlation Spectroscopy (HSQC), Heteronuclear Multi-
ple-Quantum Correlation Spectroscopy (HMQC) and Heteronuclear Multiple-Bond Correlation Spectroscopy (HMBC) Comparative Study on Malignant and Benign Human Cancer Cells and Tissues under Synchrotron Radiation, EMS Pharma J. 1 (1): 002.

[332] Heidari, A. (2018). Saturated Spectroscopy and Unsaturated Spectroscopy Comparative Study on Malignant and Benign Human Cancer Cells and Tissues with the Passage of Time under Synchrotron Radiation, Imaging J Clin Medical Sci 5 (1): 001-007.

[333] Heidari, A. (2018). A Modern Comparative and Comprehensive Experimental Biospectroscopic Study on Different Types of Infrared Spectroscopy of Malignant and Benign Human Cancer Cells and Tissues with the Passage of Time under Synchrotron Radiation, J Analyt Molecul Tech. 3 (1): 8.

[334] Heidari, A. (2018). Investigation of Cancer Types Using Synchrotron Technology for Proton Beam Therapy: An Experimental Biospectroscopic Comparative Study, European Modern Studies Journal, Vol. 2, No. 1, 13-29, and 2018. With the Passage of Time under Synchrotron Radiation, Imaging J Clin Medical Sci. 5 (1): 001-007.

[335] Heidari, A. (2018). Small-Angle Neutron Scattering (SANS) and Wide-Angle X-Ray Diffraction (WAXD) Comparative Study on Malignant and Benign Human Cancer Cells and Tissues under Synchrotron Radiation, Int J Bioorg Chem Mol Biol. 6 (2e): 1-6.

[336] Heidari, A. (2018). Investigation of Bladder Cancer, Breast Cancer, Colorectal Cancer, Endometrial Cancer, Kidney Cancer, Leukemia, Liver, Lung Cancer, Melanoma, Non-Hodgkin Lymphoma, Pancreatic Cancer, Prostate Cancer, Thyroid Cancer and Non-Melanoma Skin Cancer Using Synchrotron Technology for Proton Beam Therapy: An Experimental Biospectroscopic Comparative Study, Ther Res Skin Dis 1 (1).

[337] Heidari, A. (2018). Attenuated Total Reflectance Fourier Transform Infrared (ATR-FTIR) Spectroscopy, Micro-Attenuated Total Reflectance Fourier Transform Infrared (Micro-ATR-FTIR) Spectroscopy and Macro-Attenuated Total Reflectance Fourier Transform Infrared (Macro-ATR-FTIR) Spectroscopy Comparative Study on Malignant and Benign Human Cancer Cells and Tissues under Synchrotron Radiation with the Passage of Time, International Journal of Chemistry Papers, 2 (1): 1-12.

[338] Heidari, A. (2018). Mössbauer Spectroscopy, Mössbauer Emission Spectroscopy and ${ }^{57} \mathrm{Fe}$ Mössbauer Spectroscopy Comparative Study on Malignant and Benign Human Cancer Cells and Tissues under Synchrotron Radiation, Acta Scientific Cancer Biology 2.3: 17-20.

[339] Heidari, A. (2018). Comparative Study on Malignant and Benign Human Cancer Cells and Tissues under Synchrotron Radiation with the Passage of Time, Organic \& Medicinal Chem IJ. Six (1): 555676.

[340] Heidari, A. (2018). Correlation Spectroscopy, Exclusive Correlation Spectroscopy and Total Correlation Spectroscopy Comparative Study on Malignant and Benign Human AIDS-Related Cancers Cells and Tissues with the Passage of Time under Synchrotron Radiation, Int J Bioanal Biomed. Two (1): 001-007.

[341] Heidari, A. (2018). Biomedical Instrumentation and Applications of Biospectroscopic Methods and Techniques in Malignant and Benign Human Cancer Cells and Tissues Studies under Synchrotron Radiation and Anti-Cancer Nano Drugs Delivery, Am J Nanotechnol Nanomed. One (1): 001-009.

[342] Heidari, A. (2018). Vivo ${ }^{1} \mathrm{H}$ or Proton NMR, ${ }^{13} \mathrm{C} \mathrm{NMR},{ }^{15} \mathrm{~N}$ NMR and ${ }^{31} \mathrm{P}$ NMR Spectroscopy Comparative Study on Malignant and Benign Human Cancer Cells and Tissues under Synchrotron Radiation, Ann Biomet Biostat. 1 (1): 1001.

[343] Heidari, A. (2018). Grazing-Incidence Small-Angle Neutron Scattering (GISANS) and Grazing-Incidence X-Ray Diffraction (GIXD) Comparative Study on Malignant and Benign Human Cancer Cells, Tissues and Tumors under Synchrotron Radiation, Ann Cardiovasc Surg. 1 (2): 1006.

[344] Heidari, A. (2018). Adsorption Isotherms and Kinetics of Multi-Walled Carbon Nanotubes (MWCNTs), Boron Nitride Nanotubes (BNNTs), Amorphous Boron Nitride Nanotubes (a-BNNTs) and Hexagonal Boron Nitride Nanotubes (h-BNNTs) for Eliminating Carcinoma, Sarcoma, Lymphoma, Leukemia, Germ Cell Tumor and Blastoma Cancer Cells and Tissues, Clin Med Rev Case Rep 5: 201.

[345] Heidari, A. (2018). Correlation Spectroscopy (COSY), Exclusive Correlation Spectroscopy (ECOSY), Total Correlation Spectroscopy (TOCSY), Incredible Natural-Abundance DoubleQuantum Transfer Experiment (INADEQUATE), Heteronuclear Single-Quantum Correlation Spectroscopy (HSQC), Heteronuclear Multiple-Bond Correlation Spectroscopy (HMBC), Nuclear Overhauser Effect Spectroscopy (NOESY) and Rotating Frame Nuclear 
Overhauser Effect Spectroscopy (ROESY) Comparative Study on Malignant and Benign Human Cancer Cells and Tissues under Synchrotron Radiation, Acta Scientific Pharmaceutical Sciences 2.5: 30-35.

[346] Heidari, A. (2018). Small-Angle X-Ray Scattering (SAXS), Ultra-Small Angle X-Ray Scattering (USAXS), Fluctuation XRay Scattering (FXS), Wide-Angle X-Ray Scattering (WAXS), Grazing-Incidence Small-Angle X-Ray Scattering (GISAXS), Grazing-Incidence Wide-Angle X-Ray Scattering (GIWAXS), Small-Angle Neutron Scattering (SANS), Grazing-Incidence Small-Angle Neutron Scattering (GISANS), X-Ray Diffraction (XRD), Powder X-Ray Diffraction (PXRD), Wide-Angle X-Ray Diffraction (WAXD), Grazing-Incidence X-Ray Diffraction (GIXD) and Energy-Dispersive X-Ray Diffraction (EDXRD) Comparative Study on Malignant and Benign Human Cancer Cells and Tissues under Synchrotron Radiation, Oncol Res Rev, Volume 1 (1): $1-10$.

[347] Heidari, A. (2018). Pump-Probe Spectroscopy and Transient Grating Spectroscopy Comparative Study on Malignant and Benign Human Cancer Cells and Tissues with the Passage of Time under Synchrotron Radiation, Adv Material Sci Engg, Volume 2, Issue 1, Pages 1-7.

[348] Heidari, A. (2018). Grazing-Incidence Small-Angle X-Ray Scattering (GISAXS) and Grazing-Incidence Wide-Angle X-Ray Scattering (GIWAXS) Comparative Study on Malignant and Benign Human Cancer Cells and Tissues under Synchrotron Radiation, Insights Pharmacol Pharm Sci 1 (1): 1-8.

[349] Heidari, A. (2018). Acoustic Spectroscopy, Acoustic Resonance Spectroscopy and Auger Spectroscopy Comparative Study on Anti-Cancer Nano Drugs Delivery in Malignant and Benign Human Cancer Cells and Tissues with the Passage of Time under Synchrotron Radiation, Nanosci Technol 5 (1): 1-9.

[350] Heidari, A. (2018). Niobium, Technetium, Ruthenium, Rhodium, Hafnium, Rhenium, Osmium and Iridium Ions Incorporation into the Nano Polymeric Matrix (NPM) by Immersion of the Nano Polymeric Modified Electrode (NPME) as Molecular Enzymes and Drug Targets for Human Cancer Cells, Tissues and Tumors Treatment under Synchrotron and Synchrocyclotron Radiations, Nanomed Nanotechnol, 3 (2): 000138

[351] Heidari, A. (2018). Homonuclear Correlation Experiments such as Homonuclear Single- Quantum Correlation Spectroscopy (HSQC), Homonuclear Multiple-Quantum Correlation Spectroscopy (HMQC) and Homonuclear Multiple-Bond Correlation Spectroscopy (HMBC) Comparative Study on Malignant and Benign Human Cancer Cells and Tissues under Synchrotron Radiation, Austin J Proteomics Bioinform \& Genomics. 5 (1): 1024

[352] Heidari, A. (2018). Atomic Force Microscopy Based Infrared (AFM-IR) Spectroscopy and Nuclear Resonance Vibrational Spectroscopy Comparative Study on Malignant and Benign Human Cancer Cells and Tissues under Synchrotron Radiation with the Passage of Time, J Appl Biotechnol Bioeng. Five (3): 142-148.

[353] Heidari, A. (2018). Time-Dependent Vibrational Spectral Analysis of Malignant and Benign Human Cancer Cells and Tissues under Synchrotron Radiation, J Cancer Oncol, 2 (2): 000124.

[354] Heidari, A. (2018). Palauamine and Olympiadane Nano Molecules Incorporation into the Nano Polymeric Matrix (NPM) by Immersion of the Nano Polymeric Modified Electrode (NPME) as Molecular Enzymes and Drug Targets for Human Cancer Cells, Tissues and Tumors Treatment under Synchrotron and Synchrocyclotron Radiations, Arc Org Inorg Chem Sci 3 (1).

[355] Gobato, R., Heidari, A. (2018). Infrared Spectrum and Sites of Action of Sanguinarine by Molecular Mechanics and ab initio Methods, International Journal of Atmospheric and Oceanic Sciences. Vol. 2, No. 1, pp. 1-9.

[356] Heidari, A. (2018). Angelic Acid, Diabolic Acids, Draculin and Miraculin Nano Molecules Incorporation into the Nano Polymeric Matrix (NPM) by Immersion of the Nano Polymeric Modified Electrode (NPME) as Molecular Enzymes and Drug Targets for Human Cancer Cells, Tissues and Tumors Treatment Under Synchrotron and Synchrocyclotron Radiations, Med \& Analy Chem Int J, 2 (1): 000111.

[357] Heidari, A. (2018). Gamma Linolenic Methyl Ester, 5Heptadeca-5,8,11-Trienyl 1,3,4- Oxadiazole-2-Thiol, Sulphoquinovosyl Diacyl Glycerol, Ruscogenin, Nocturnoside B, Protodioscine B, Parquisoside-B, Leiocarposide, Narangenin, 7-Methoxy Hespertin, Lupeol, Rosemariquinone, Rosmanol and Rosemadiol Nano Molecules Incorporation into the Nano Polymeric Matrix (NPM) by Immersion of the Nano Polymeric Modified Electrode (NPME) as Molecular Enzymes and Drug Targets for Human Cancer Cells, Tissues and Tumors Treatment under Synchrotron and
Synchrocyclotron Radiations, Int J Pharma Anal Acta, 2 (1): 007014.

[358] Heidari, A. (2018). Fourier Transform Infrared (FTIR) Spectroscopy, Attenuated Total Reflectance Fourier Transform Infrared (ATR-FTIR) Spectroscopy, Micro-Attenuated Total Reflectance Fourier Transform Infrared (Micro-ATR-FTIR) Spectroscopy, Macro- Attenuated Total Reflectance Fourier Transform Infrared (Macro-ATR-FTIR) Spectroscopy, Two-Dimensional Infrared Correlation Spectroscopy, Linear Two- Dimensional Infrared Spectroscopy, Non-Linear Two-Dimensional Infrared Spectroscopy, Atomic Force Microscopy Based Infrared (AFM-IR) Spectroscopy, Infrared Photodissociation Spectroscopy, Infrared Correlation Table Spectroscopy, Near-Infrared Spectroscopy (NIRS), Mid-Infrared Spectroscopy (MIRS), Nuclear Resonance Vibrational Spectroscopy, Thermal Infrared Spectroscopy and Photothermal Infrared Spectroscopy Comparative Study on Malignant and Benign Human Cancer Cells and Tissues under Synchrotron Radiation with the Passage of Time, Glob Imaging Insights, Volume 3 (2): 1-14. https://doi.org/10.15761/GII.1000153.

[359] Heidari, A. (2018). Heteronuclear Single-Quantum Correlation Spectroscopy (HSQC) and Heteronuclear Multiple-Bond Correlation Spectroscopy (HMBC) Comparative Study on Malignant and Benign Human Cancer Cells, Tissues and Tumors under Synchrotron and Synchrocyclotron Radiations, Chronicle of Medicine and Surgery 2.3: 144-156.

[360] Heidari, A. (2018). Tetrakis [3, 5-bis (Trifluoromethyl) Phenyl] Borate (BARF)- Enhanced Precatalyst Preparation Stabilization and Initiation (EPPSI) Nano Molecules, Medical Research and Clinical Case Reports 2.1: 113-126.

[361] Heidari, A. (2018). Sydnone, Münchnone, Montréalone, Mogone, Montelukast, Quebecol and Palau'amine-Enhanced Precatalyst Preparation Stabilization and Initiation (EPPSI) Nano Molecules, Sur Cas Stud Op Acc J. 1 (3).

[362] Heidari, A. (2018). Fornacite, Orotic Acid, Rhamnetin, Sodium Ethyl Xanthate (SEX) and Spermine (Spermidine or Polyamine) Nanomolecules Incorporation into the Nanopolymeric Matrix (NPM), International Journal of Biochemistry and Biomolecules, Vol. 4: Issue 1, Pages 1-19.

[363] Heidari, A., Gobato, R. (2018). Putrescine, Cadaverine, Spermine and Spermidine- Enhanced Precatalyst Preparation Stabilization and Initiation (EPPSI) Nano Molecules, Parana Journal of Science and Education (PJSE)-v.4, n.5, (1-14).

[364] Heidari, A. (2018). Cadaverine (1,5-Pentanediamine or Pentamethylenediamine), Diethyl Azodicarboxylate (DEAD or DEADCAT) and Putrescine (Tetramethylenediamine) Nano Molecules Incorporation into the Nano Polymeric Matrix (NPM) by Immersion of the Nano Polymeric Modified Electrode (NPME) as Molecular Enzymes and Drug Targets for Human Cancer Cells, Tissues and Tumors Treatment under Synchrotron and Synchrocyclotron Radiations, Hiv and Sexual Health Open Access Open Journal. One (1): 4-11.

[365] Heidari, A. (2018). Improving the Performance of NanoEndofullerenes in Polyaniline Nanostructure-Based Biosensors by Covering Californium Colloidal Nanoparticles with Multi-Walled Carbon Nanotubes, Journal of Advances in Nanomaterials, Vol. 3, No. 1, Pages 1-28. https://doi.org/10.22606/jan.2018.31001.

[366] Gobato, R., Heidari, A. (2018). Molecular Mechanics and Quantum Chemical Study on Sites of Action of Sanguinarine Using Vibrational Spectroscopy Based on Molecular Mechanics and Quantum Chemical Calculations, Malaysian Journal of Chemistry, Vol. 20 (1), 1-23.

[367] Heidari, A. (2018). Vibrational Biospectroscopic Studies on Anti-cancer Nanopharmaceuticals (Part I), Malaysian Journal of Chemistry, Vol. 20 (1), 33-73.

[368] Heidari, A. (2018). Vibrational Biospectroscopic Studies on Anti-cancer Nanopharmaceuticals (Part II), Malaysian Journal of Chemistry, Vol. 20 (1), 74-117.

[369] Heidari, A. (2018). Uranocene (U $\left.\left(\mathrm{C}_{8} \mathrm{H}_{8}\right)_{2}\right)$ and Bis(Cyclooctatetraene)Iron $\left(\mathrm{Fe}\left(\mathrm{C}_{8} \mathrm{H}_{8}\right)_{2} \quad\right.$ or $\left.\mathrm{Fe}(\mathrm{COT})_{2}\right)$-Enhanced Precatalyst Preparation Stabilization and Initiation (EPPSI) Nano Molecules, Chemistry Reports, Vol. 1, Iss. Two, Pages 1-16.

[370] Heidari, A. (2018). Biomedical Systematic and Emerging Technological Study on Human Malignant and Benign Cancer Cells and Tissues Biospectroscopic Analysis under Synchrotron Radiation, Glob Imaging Insights, and Volume 3 (3): 1-7.

[371] Heidari, A. (2018). Deep-Level Transient Spectroscopy and XRay Photoelectron Spectroscopy (XPS) Comparative Study on Malignant and Benign Human Cancer Cells and Tissues with the Passage of Time under Synchrotron Radiation. Res Dev Material Sci. 7 (2). RDMS.000659. 
[372] Heidari, A. (2018). A Clinical and Molecular Pathology Investigation of Correlation Spectroscopy (COSY), Exclusive Correlation Spectroscopy (ECOSY), Total Correlation Spectroscopy (TOCSY), Heteronuclear Single-Quantum Correlation Spectroscopy (HSQC) and Heteronuclear Multiple-Bond Correlation Spectroscopy (HMBC) Comparative Study on Malignant and Benign Human Cancer Cells, Tissues and Tumors under Synchrotron and Synchrocyclotron Radiations Using Cyclotron versus Synchrotron, Synchrocyclotron and the Large Hadron Collider (LHC) for Delivery of Proton and Helium Ion (Charged Particle) Beams for Oncology Radiotherapy, Euro. J. Adv. Engg. Tech. 5 (5): 414-426.

[373] Heidari, A. (2018). C70-Carboxyfullerenes Nano Molecules Incorporation into the Nano Polymeric Matrix (NPM) by Immersion of the Nano Polymeric Modified Electrode (NPME) as Molecular Enzymes and Drug Targets for Human Cancer Cells, Tissues and Tumors Treatment under Synchrotron and Synchrocyclotron Radiations, Glob Imaging Insights, Volume 3 (3): 1-7.

[374] Heidari, A. (2018). The Effect of Temperature on Cadmium Oxide $(\mathrm{CdO})$ Nanoparticles Produced by Synchrotron Radiation in the Human Cancer Cells, Tissues and Tumors, International Journal of Advanced Chemistry, 6 (2) 140-156.

[375] Heidari, A. (2018). Use of Molecular Enzymes in the Treatment of Chronic Disorders, Canc Oncol Open Access J. 1 (1): 12 15.

[376] Heidari, A. (2018). Nano Molecules Incorporation into the Nano Polymeric Matrix (NPM) by Immersion of the Nano Polymeric Modified Electrode (NPME) as Molecular Enzymes and Drug Targets for Human Cancer Cells, Tissues and Tumors Treatment under Synchrotron and Synchrocyclotron Radiations . J Oncol Res. 1 (1): 1-14.

[377] Heidari, A. (2018). Adamantane, Irene, Naftazone and Pyridine Enhanced Precatalyst Preparation Stabilization and Initiation (PEPPSI) Nano Molecules. Madridge J Nov Drug Res. 2 (1): 6167.

[378] Heidari, A., Gobato, R. (2018). A Novel Approach to Reduce Toxicities and to Improve Bioavailabilities of DNA/RNA of Hu- man Cancer Cells-Containing Cocaine (Coke), Lysergide (Lysergic Acid Diethyl Amide or LSD), $\Delta^{9}$-Tetrahydrocannabinol (THC) [(-)-trans- $\Delta^{9}$-Tetrahydrocannabinol], Theobromine (Xantheose), Caffeine, Aspartame (APM) (NutraSweet) and Zidovudine (ZDV) [Azidothymidine (AZT)] as Anti-Cancer Nano Drugs by Coassembly of Dual Anti-Cancer Nano Drugs to Inhibit DNA/RNA of Human Cancer Cells Drug Resistance, Parana Journal of Science and Education, v. 4, n. 5, pp. 1-14.

[379] Heidari, A., Gobato, R. (2018). Ultraviolet Photoelectron Spectroscopy (UPS) and Ultraviolet-Visible (UV-Vis) Spectroscopy Comparative Study on Malignant and Benign Human Cancer Cells and Tissues with the Passage of Time under Synchrotron Radiation, Parana Journal of Science and Education, v. 4, n. 6, pp. $1-14$. 


\section{Figures' Captions:}

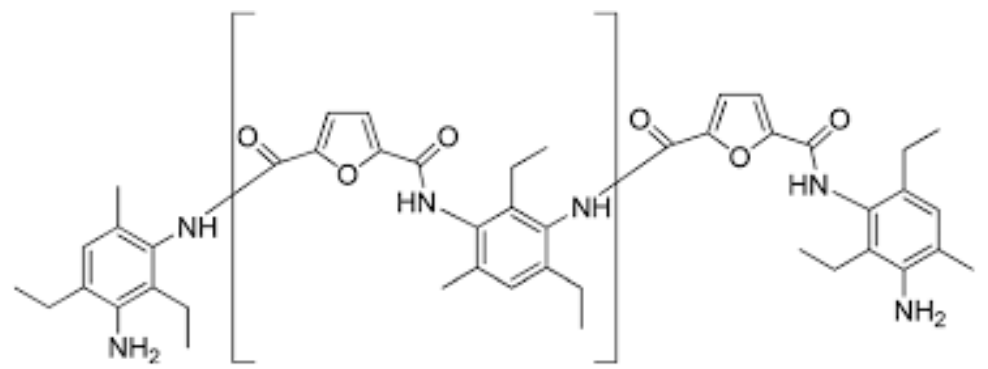

Fig. 1: Unsaturated polyamides nanoparticles chemical structure.

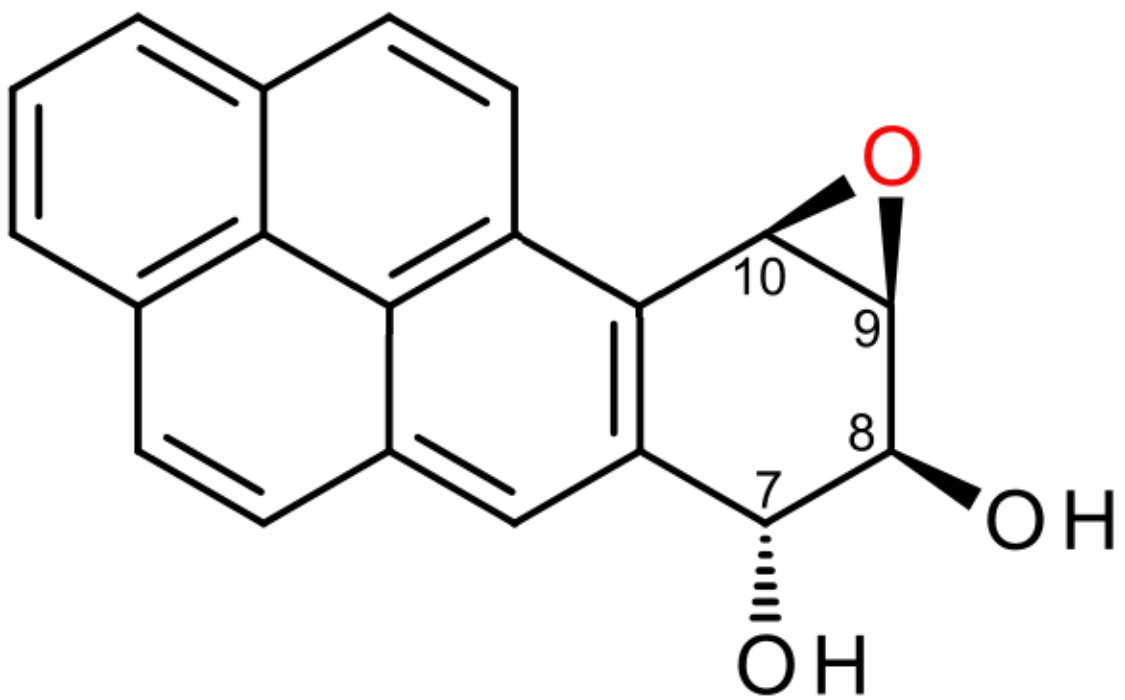

Fig. 2: Creation of cross link by hardener ((+)-Benzo(a)pyrene-7,8-dihydrodiol-9,10-epoxide).

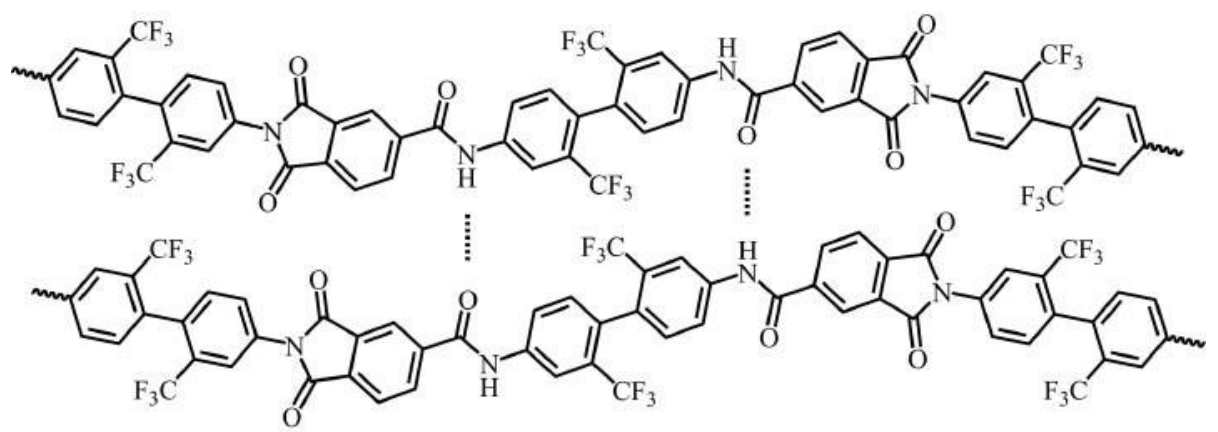

(a) 


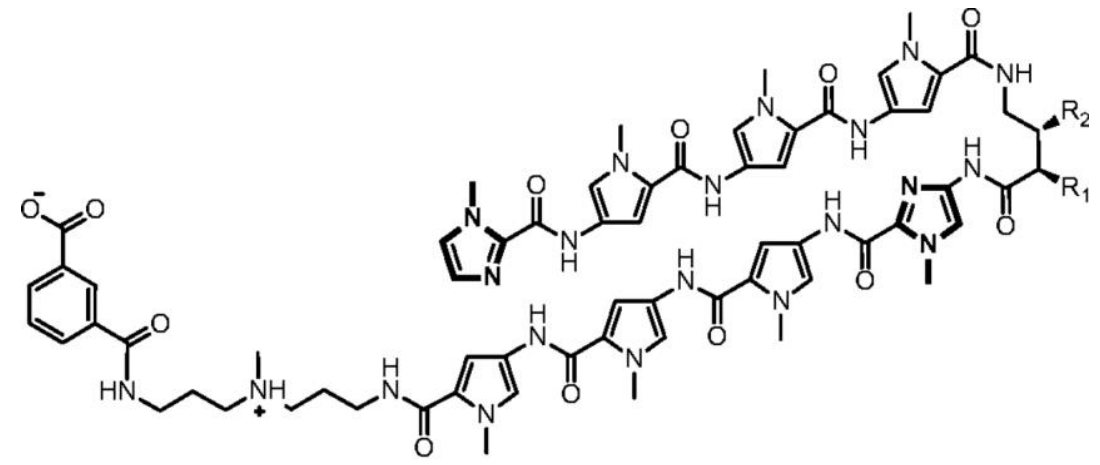

$\begin{array}{lll}1 R_{1}=N_{N_{3}}^{+} & R_{2}=H \\ 2 R_{1}=H & R_{2}=N_{H}\end{array}$

Fig. 3: (a) Liquid and (b) hardened polyamides nanoparticles.

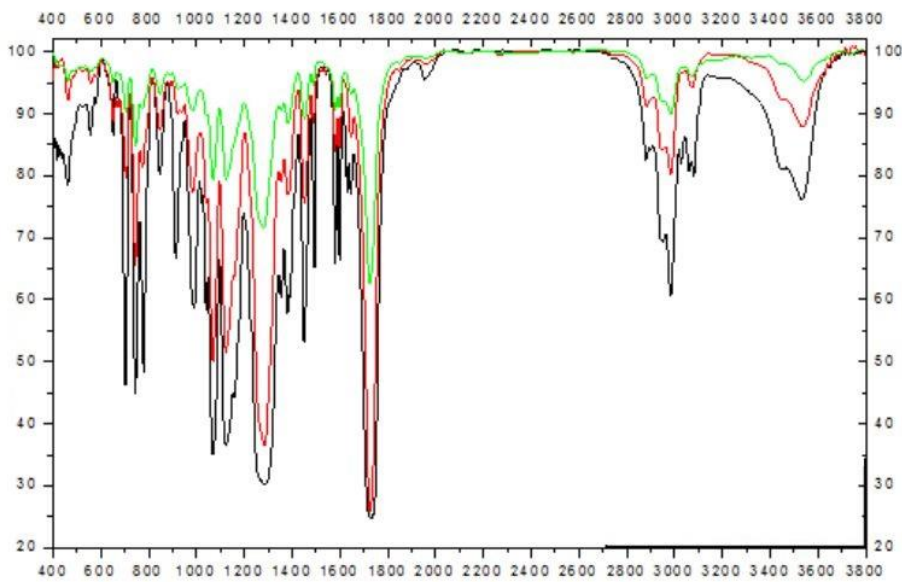

Fig. 4: ATR-FTIR spectra for three samples. Black is the sample without synchrotron radiation, red with 3 minutes and green with 6 minutes of synchrotron radiation. It should be noted that and $\mathrm{x}$-axis shows wavenumber $\left(\mathrm{cm}^{-1}\right)$ and $\mathrm{y}$-axis shows intensity, respectively.

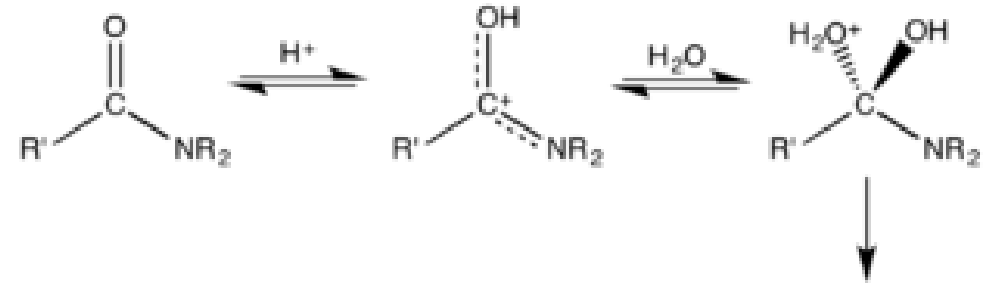<smiles>CCCCCCC(=O)O</smiles><smiles>[R]C(=O)O</smiles><smiles>[2H]C(O)(O)[18OH]</smiles>

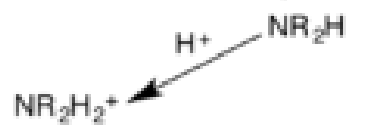

Fig. 5: Resonance created in chemical structure. 


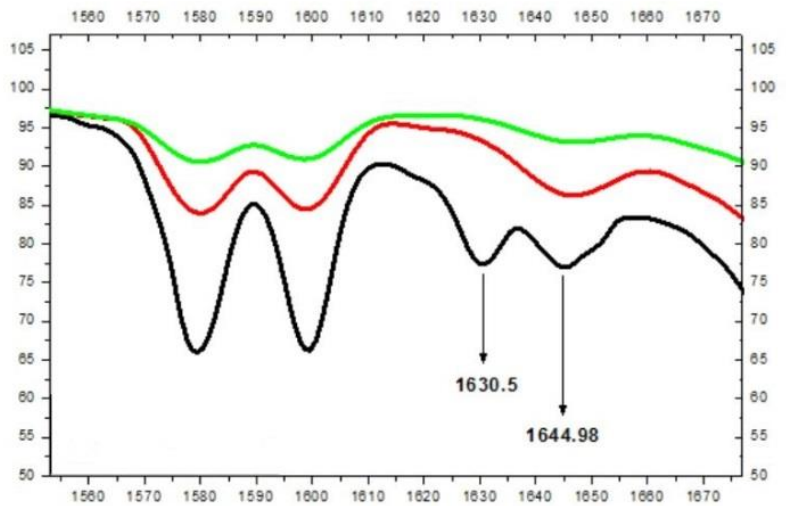

Fig. 6: Magnified range of $1540-1680\left(\mathrm{~cm}^{-1}\right)$ to show the changes happened in the structure of double bond. It should be noted that and $\mathrm{x}-\mathrm{axis}$ shows wavenumber $\left(\mathrm{cm}^{-1}\right)$ and $\mathrm{y}$-axis shows intensity, respectively.

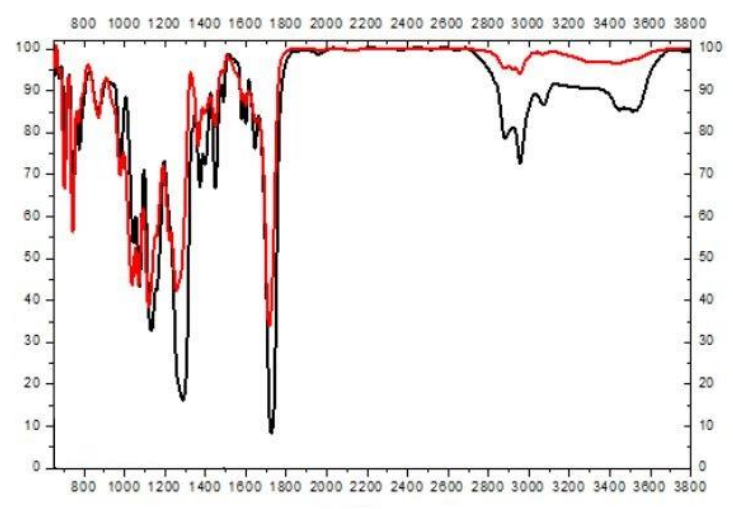

Fig. 7: ATR-FTIR spectrum for general unsaturated polyamides nanoparticles. $\mathrm{C}=\mathrm{C}$ bond is seen as a peak at $1644\left(\mathrm{~cm}^{-1}\right)$. It should be noted that and $\mathrm{x}-$ axis shows wavenumber $\left(\mathrm{cm}^{-1}\right)$ and $\mathrm{y}$-axis shows intensity, respectively.

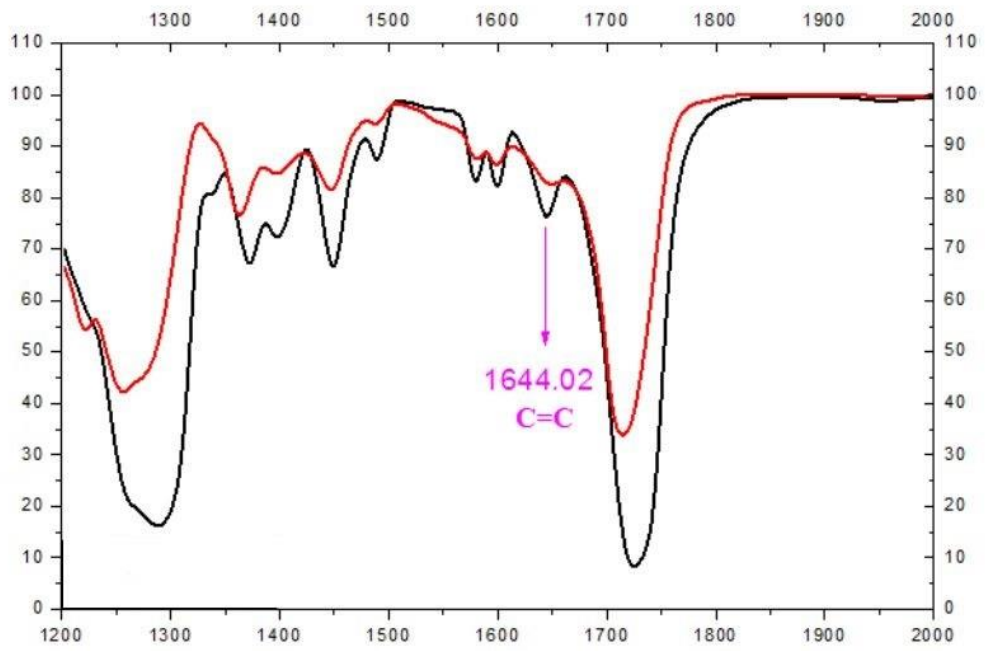

Fig. 8: Magnified range of $1200-2000\left(\mathrm{~cm}^{-1}\right)$ to show the reduction and shift of peak at 1644 and $1725\left(\mathrm{~cm}^{-1}\right)$. It should be noted that and $\mathrm{x}-\mathrm{axis}$ shows wavenumber $\left(\mathrm{cm}^{-1}\right)$ and $\mathrm{y}$-axis shows intensity, respectively. 


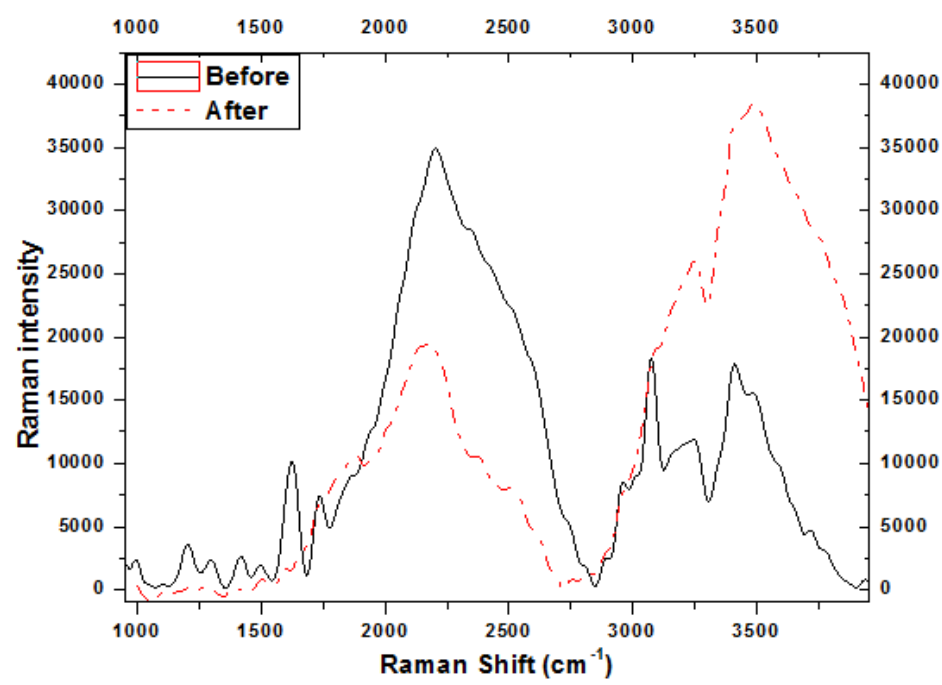

Fig. 9: Raman spectrum for polymer, dotted line is for after hardening and solid line is for before hardening. It should be noted that and $x-$ axis shows wavenumber $\left(\mathrm{cm}^{-1}\right)$ and $\mathrm{y}$-axis shows intensity, respectively.

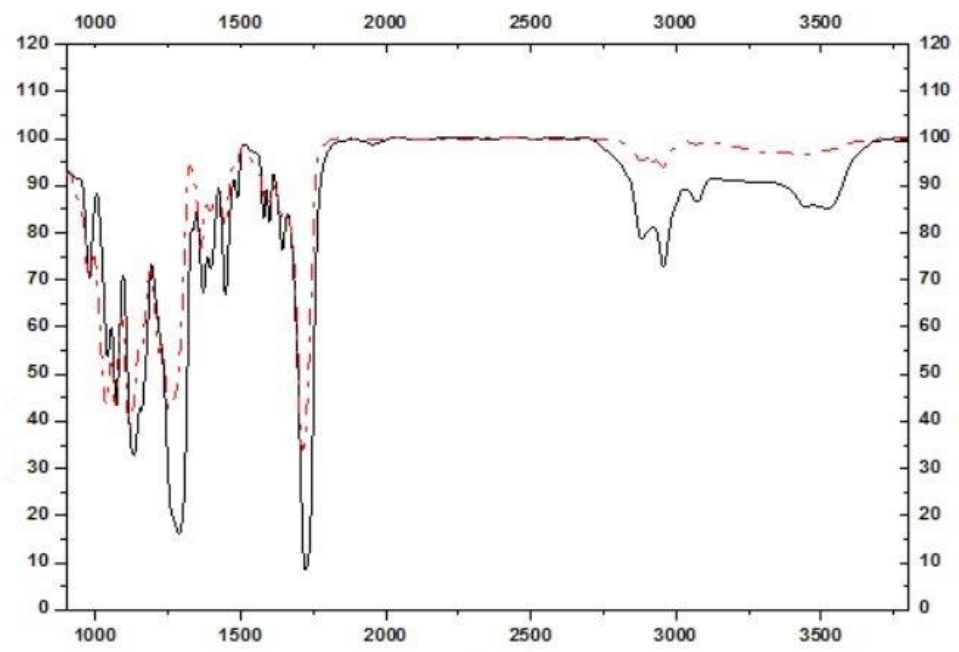

Fig. 10: ATR-FTIR spectrum, solid lines are related to liquid polymer and dotted lines are related to hardened polymer with synchrotron radiation. It should be noted that and $\mathrm{x}$-axis shows wavenumber $\left(\mathrm{cm}^{-1}\right)$ and $\mathrm{y}-$ axis shows intensity, respectively.

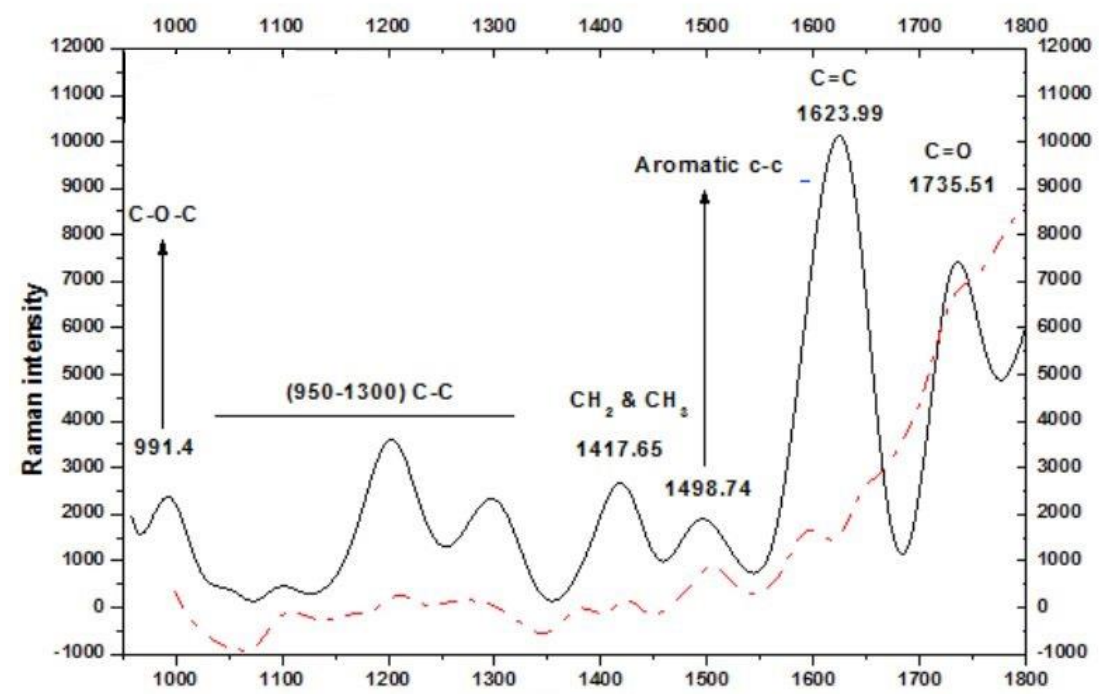


Fig. 11: Raman spectra before and after hardening are superimposed and peaks at 1623.99 and $1735.51\left(\mathrm{~cm}^{-1}\right)$ are related to $\mathrm{C}=\mathrm{C}$ and $\mathrm{C}=\mathrm{O}$, respectively. It should be noted that and $\mathrm{x}$-axis shows wavenumber $\left(\mathrm{cm}^{-1}\right)$ and $\mathrm{y}$-axis shows intensity, respectively.

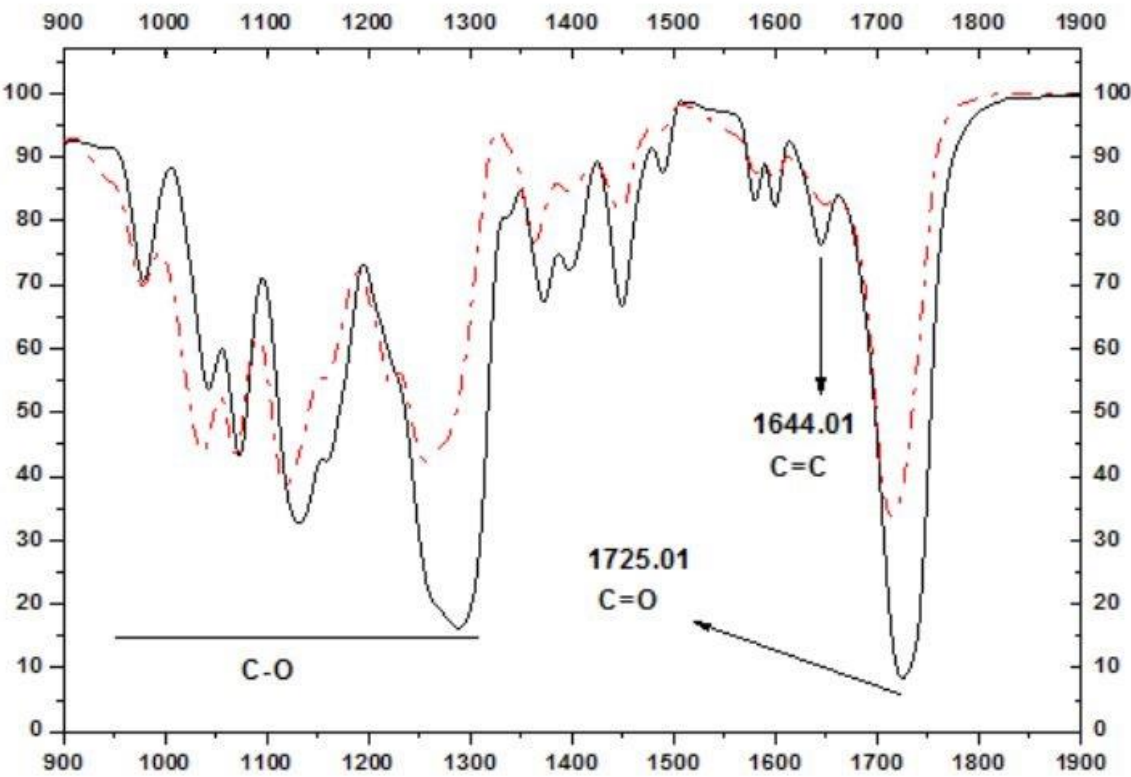

Fig. 12: ATR-FTIR spectra of liquid and solid phases of polyamides nanoparticles by solid and dashed lines, black and red, respectively, and important bonds are shown on the curve. It should be noted that and $\mathrm{x}$-axis shows wavenumber $\left(\mathrm{cm}^{-1}\right)$ and $\mathrm{y}-$ axis shows intensity, respectively. 


\section{Tables' Legends:}

Table. 1: Synchrotron radiation properties.

\begin{tabular}{|l|l|}
\hline Wavelength & $10.6 \mu \mathrm{m}$ fixed \\
\hline Output Power & $20 \mathrm{~W}$ \\
\hline Power Stability & $< \pm 3 \%$ \\
\hline Mode Quality & $>95 \% \quad \mathrm{TM}_{00} \quad \mathrm{M}^{2}<1.3$ \\
\hline Beam Size & $3.8 \pm 0.4 \mathrm{~mm}$ \\
\hline
\end{tabular}

Table. 2: Position of bonds and their intensities.

\begin{tabular}{|c|c|c|c|}
\hline $\begin{array}{c}\text { Functional } \\
\text { Group/vibratio } \\
\mathrm{n}\end{array}$ & $\begin{array}{c}\text { Region } \\
\mathrm{cm}^{-1}\end{array}$ & $\begin{array}{c}\text { Raman } \\
\text { intensity }\end{array}$ & $\begin{array}{c}\text { Infrared } \\
\text { intensity }\end{array}$ \\
\hline $\mathrm{C}=\mathrm{O}$ & $1680-1820$ & medium & Strong \\
\hline $\mathrm{C}=\mathrm{C}$ & $1500-1900$ & strong & Weak \\
\hline $\mathrm{C}-\mathrm{C}$ & $600-1300$ & medium & Medium \\
\hline $\mathrm{CH}_{3}$ & 1380 & medium & Strong \\
\hline $\mathrm{CH}_{3} \& \mathrm{CH}_{2}$ & $1400-1470$ & medium & Medium \\
\hline $\mathrm{C}-\mathrm{C}$ & $1580-1600$ & Strong & $\begin{array}{c}\text { Medium } \\
\text { Medium }\end{array}$ \\
\hline Aromatic & $1450-1500$ & medium & Medium \\
\hline
\end{tabular}

